\title{
Three essays on the economics of cocoa - The technical and environmental efficiency of Indonesian cocoa production
}

\author{
Dissertation \\ to obtain the $\mathrm{Ph}$. D. degree \\ in the International Ph. D. Program for Agricultural Sciences in Goettingen (IPAG) \\ at the Faculty of Agricultural Sciences, \\ Georg-August-University Göttingen, Germany
}

presented by

Andras Tothmihaly

born in Veszprem, Hungary

Göttingen, April 2017 
D7

1. Name of supervisor: Prof. Dr. Stephan von Cramon-Taubadel

2. Name of co-supervisors: Prof. Dr. Bernhard Brümmer, Dr. Vijesh Krishna

Date of dissertation: 12 July 2017 


\section{Summary}

In the new millennium, the soaring economic growth in Asia and Africa, the increase of world trade, and globalization have boosted the global demand for cocoa. However, world cocoa supply could barely keep up with demand. These processes triggered a high volatility in global cocoa prices. Volatility induces uncertainty among market participants, hence preventing the market from working properly. It also makes the millions of cocoa farmers in the developing world highly vulnerable to poverty.

Our first essay helps to inform development policies of the elements involved in the global cocoa bean market to understand the roots of the recent price volatility. A large volatility in the value of an agricultural commodity is linked to the inelasticity of its supply or demand. Therefore, we test the hypothesis that the price elasticities of the global cocoa supply and demand are low. We find that the global cocoa supply is extremely price-inelastic: the corresponding short- and long-run estimates are 0.07 and 0.57 . The price elasticity of the world cocoa demand also falls into the extremely inelastic range: the short- and long-run estimates are -0.06 and -0.34 . Based on these empirical results, we consider the prospects for cocoa price stabilization. The cocoa price volatility was treated with various unsuccessful methods in the past. A possible solution for reducing the price volatility would be the encouragement of crop diversification. This increases the price elasticity of cocoa supply by adjusting the effort and money allocation between the crops, thus decreasing price volatility.

Our second essay investigates how the cocoa sector can be made more productive to increase supply and farmer incomes. We concentrate on Indonesia, which gives 10 percent of the world cocoa production. According to our results, technical efficiency growth and the increased chemicals use supported by government subsidies were responsible for the majority of average productivity gains (75 percent) between 2001 and 2013. Furthermore, we find large distortions in the input allocations. Hence, policies that encourage the adjustment of the cocoa farms' input use would be highly beneficial. Moreover, because of the weather-induced volatility in cocoa production, policy makers should also promote investment in agricultural research and transfer of drought-resistant cocoa varieties to farmers. Additionally, the average efficiency of cocoa farmers is estimated to be around 50 percent. We find that farmers' educational attainment and their experience in cocoa farming are significant factors that can increase the efficiency levels. Our research also shows the insignificant effect of existing agricultural extension services, farmer associations, and rural credit programs on the technical 
efficiency of cocoa farming. Hence, public policy should focus on adjusting the public extension programs, fostering the mutual benefits in the farmer groups, and developing viable credit institutions.

In our third essay in Chapter 4, we look at the trade-off between smallholder cocoa intensification and the ecosystem in Indonesia and investigate the determinants of environmental efficiency in cocoa production. In our analysis, we apply a distance output function that includes cocoa production and the abundance of native rainforest plants as outputs. Our data set, based on a household and environment survey conducted in 2015, allows us to analyze 208 cocoa producers with both measured and self-reported data. We find that the intensification of cocoa farms results in higher ecosystem degradation. Additionally, the estimations show substantial average inefficiencies (50 percent). Increasing efficiency could lead to a win-win-win situation: more production coming from less hectares, with more native plants co-existing with cocoa on the remaining hectares. On average, the efficiency scores point to a possible production expansion of $367 \mathrm{~kg}$ of cocoa per farm and year, to a possible increase of 43680 rainforest plants per farm, or to a possible acreage reduction of 0.52 hectares per farm. Furthermore, we find that agricultural extension services have a substantial role in increasing efficiency. Finally, our results show that credit access does not have a significant effect on efficiency. Feasible agricultural credit services are viewed by numerous economists as a crucial prerequisite for improving efficiency, a critical part of encouraging development. We recommend linking credit to extension services as part of this effort. 


\section{Acknowledgement}

I am grateful to Professor Stephan von Cramon-Taubadel for his supervision. I would also like to thank Professor Verina Ingram, Professor Bernhard Brümmer, Dr. Sebastian Lakner, Ayako Ebata, and Malte Ehrich for their comments, as well as Dr. Vijesh Krishna for being the third member of the examination committee.

This project would have been impossible without the funding from the German Research Foundation and the Fiat Panis Foundation. I am also thankful to Professor Stephan Klasen, Dr. Aiyen Tjoa, Dr. Yulianti Kalaba, the University of Tadulako (UNTAD), the Indonesian Ministry of Research (RISTEK), Dr. Yann Clough, Anne Mareike Holtkamp, Rivayani Darmawan, Katharina van Treeck, the enumerators, drivers, village heads, and farmers for their contributions to data collection.

Furthermore, many thanks to Antje Wagener and GlobalFood: Professor Matin Qaim, Dr. Melanie Grosse, Katrin Pape, colleagues and HiWis for their support. Finally, I would never have been able to finish this $\mathrm{PhD}$ dissertation without the help from my wife, parents, and friends. 


\section{Table of contents}

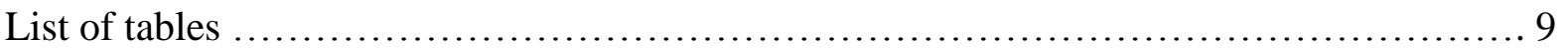

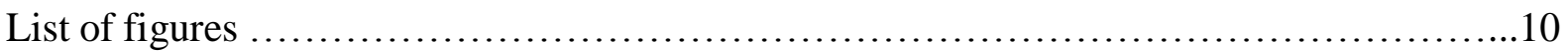

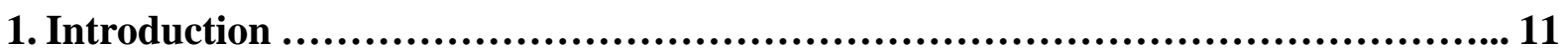

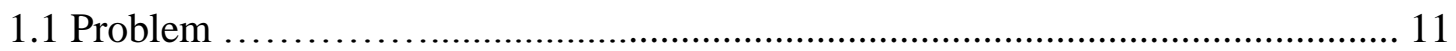

1.2 Topic 1: Price elasticity in the cocoa market .................................. 12

1.3 Topic 2: The productivity and efficiency of cocoa farms ....................... 13

1.4 Topic 3: The environmental efficiency of cocoa farms ........................ 14

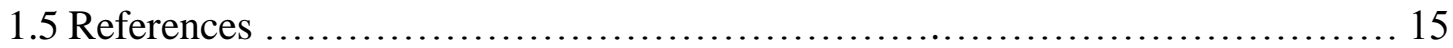

2. How low is the price elasticity in the global cocoa market? ............................. 18

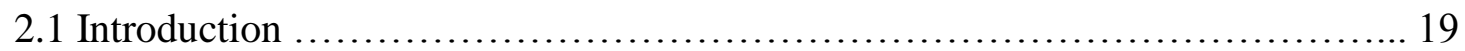

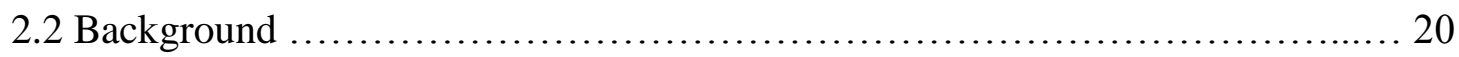

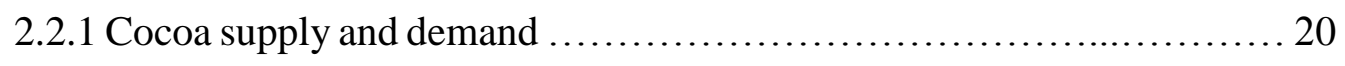

2.2.2 World cocoa price ...................................................... 21

2.3 Methodology and literature review .............................................. 23

2.3.1 Commodity market models ............................................ 23

2.3.2 Estimation issues and tests .................................................. 24

2.4 Empirical specification ....................................................... 26

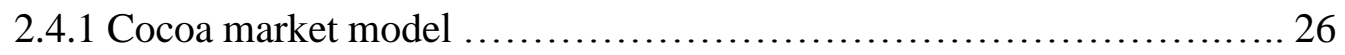

2.4.2 Data description ..................................................... 27

2.5 Results and discussion ..................................................... 30

2.5.1 Estimator selection ................................................ 30

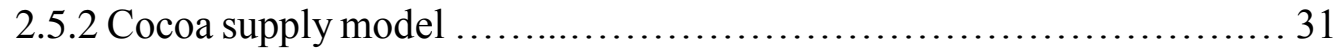

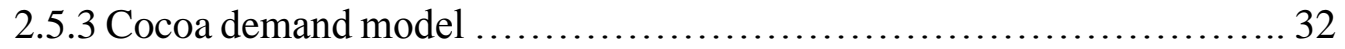

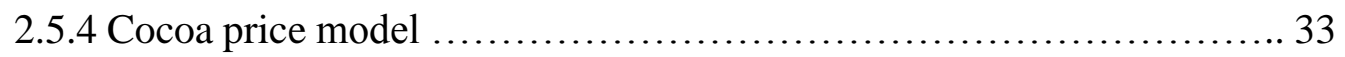

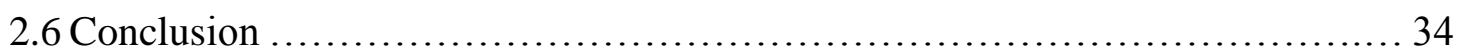

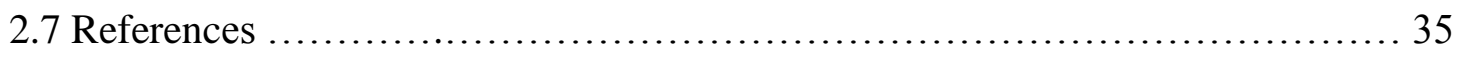

3. How can the productivity of Indonesian cocoa farms be increased? ................... 38

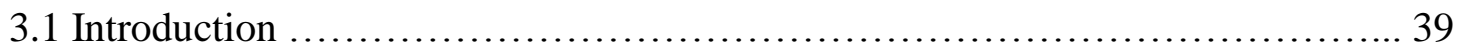

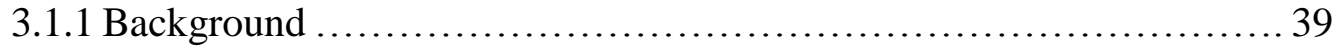

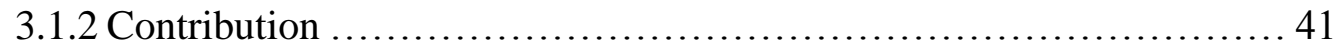

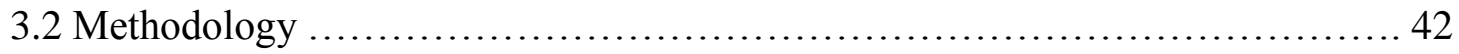




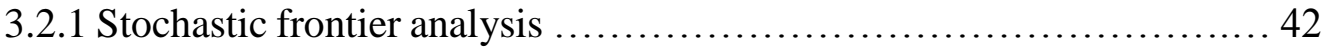

3.2.2 Estimation issues .............................................. 43

3.2.3 Total factor productivity change ............................. 45

3.3 Empirical specification ............................................ 45

3.3.1 Production frontier model $\ldots \ldots \ldots \ldots \ldots \ldots \ldots \ldots \ldots \ldots \ldots \ldots \ldots \ldots . \ldots \ldots$

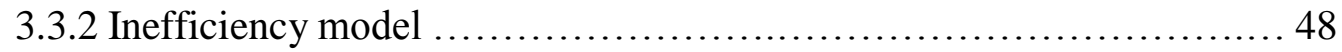

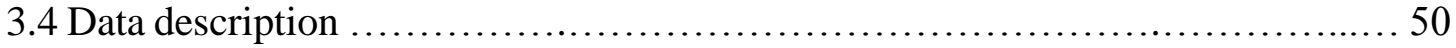

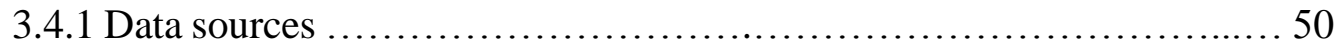

3.4.2 Descriptive statistics ............................................ 50

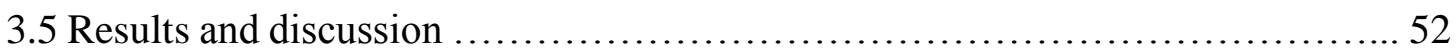

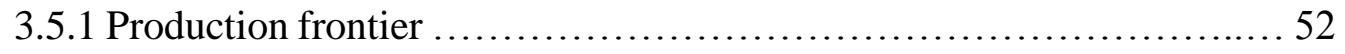

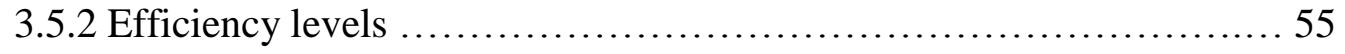

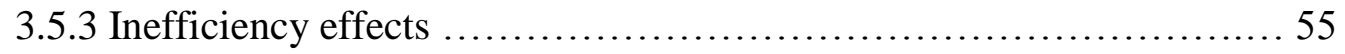

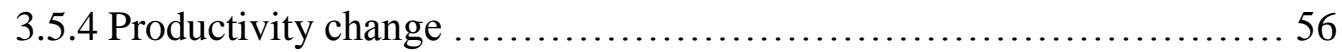

3.6. Conclusion ............................................................. 58

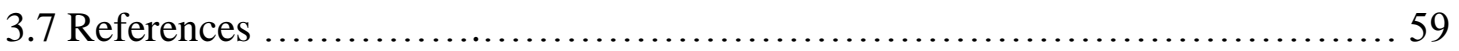

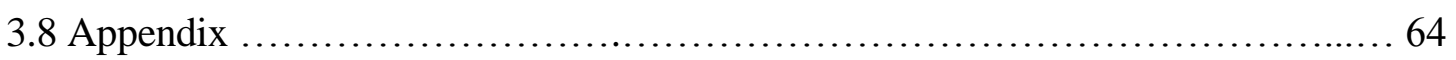

4. How can the environmental efficiency of Indonesian cocoa farms be increased? ...... 68

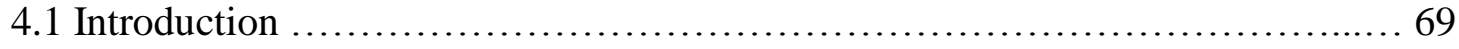

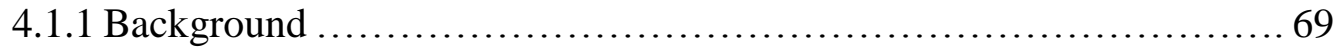

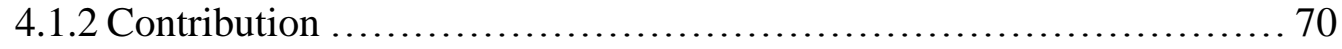

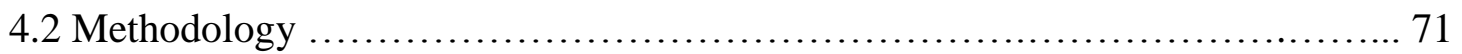

4.2.1 Multi-output frontier model .................................... 71

4.2.2 Estimation issues .............................................. 74

4.3 Empirical specification ............................................ 75

4.3.1 Production frontier model ...................................... 75

4.3.2 Inefficiency model ............................................. 77

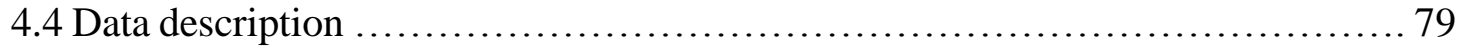

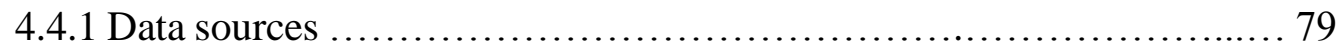

4.4.2 Descriptive statistics ..................................... 80

4.5 Results and discussion .............................................. 81

4.5.1 Production frontier ............................................ 81

4.5.2 Efficiency levels .......................................... 83

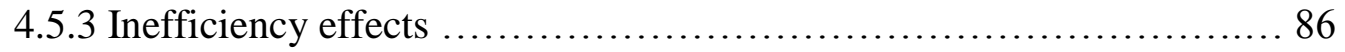


4.5.4 Shadow prices ............................................... 87

4.6 Conclusion ........................................................... 87

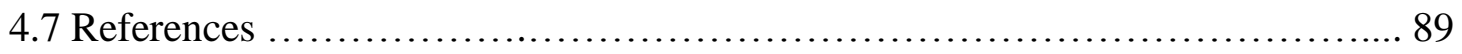

4.8 Appendix ...................................................... 94

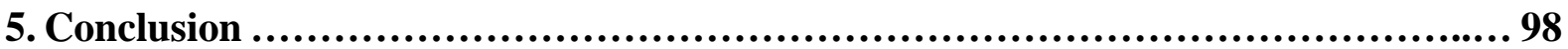

5.1 Main findings and policy implications ................................... 98

5.2 Limitations of the study and ideas for future research .......................... 99

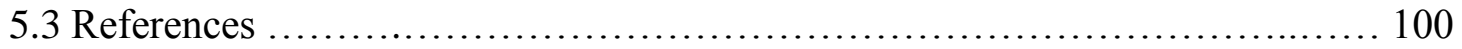

Appendix: Survey questionnaire ................................................... 101

Curriculum vitae ............................................................. 109 


\section{List of tables}

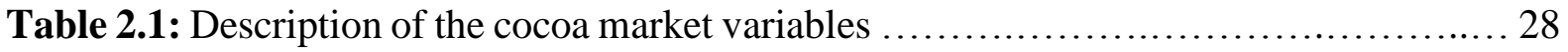

Table 2.2: Summary statistics of the cocoa market variables .......................... 28

Table 2.3: Unit root tests of the cocoa market variables .................................. 29

Table 2.4: Cointegration tests of the cocoa market model ............................ 30

Table 2.5: Instrumental variables tests of the cocoa market model ...................... 30

Table 2.6: Estimates of the cocoa supply equation ................................. 32

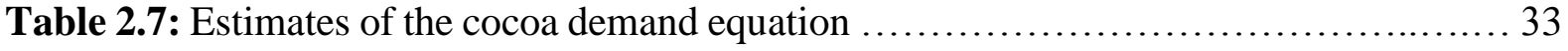

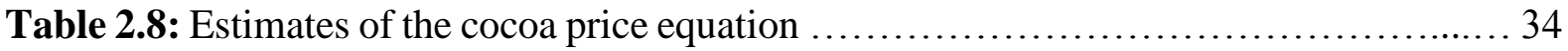

Table 3.1: Description of the cocoa farm variables ................................. 47

Table 3.2: Summary statistics of the cocoa farm variables ............................ 52

Table 3.3: Parameter estimates of the cocoa production frontier models .................. 54

Table 3.4: Descriptive statistics of the cocoa farm efficiency estimates (percentages) ........ 55

Table 3.5: Estimates and average marginal effects of the farm inefficiency models ............ 56

Table 3.6: Decomposition of total factor productivity change of cocoa farms (percentages) ... 58

Table 3.A1: Technical efficiencies in previous cocoa studies .......................... 64

Table 3.A2: Determinants of production and inefficiency in previous cocoa studies ....... 65

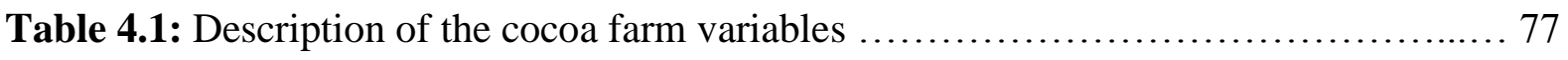

Table 4.2: Summary statistics of the cocoa farm variables $\ldots \ldots \ldots \ldots \ldots \ldots \ldots \ldots \ldots \ldots \ldots \ldots 1$

Table 4.3: Parameter estimates of the cocoa production frontier models $\ldots \ldots \ldots \ldots \ldots \ldots \ldots \ldots . \ldots 3$

Table 4.4: Descriptive statistics of the cocoa farm efficiency estimates (percentages) ....... 84

Table 4.5: Estimates and average marginal effects of the farm inefficiency models ........... 86

Table 4.6: The calculated shadow prices of the native rainforest plants in US cents ........... 87

Table 4.A1: Comparison of the self-reported and measured values of the dummy variables 97 


\section{List of figures}

Figure 2.1: World cocoa production, grindings, stocks-to-grindings, and import-to-grindings 21

Figure 2.2: The real and nominal world cocoa price in US dollar/ton (1963-2013) 22

Figure 3.A1: Distribution of efficiencies in the cocoa production models ................66 66

Figure 3.A2: Distribution of the $\mathrm{TEC}_{\mathrm{TC}}$ productivity change component in $2004 \ldots \ldots \ldots \ldots .67$

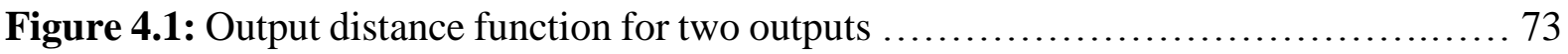

Figure 4.2: Scatter plot of the cocoa farm efficiencies and the number of native plants .... 85

Figure 4.A1: Histograms of the differences between self-reported and measured variables . 94

Figure 4.A2: Distribution of cocoa farm efficiencies in the models .................... 95

Figure 4.A3: Histogram of the differences between cocoa farm efficiencies ................ 96

Figure 4.A4: Histogram of the differences between the shadow prices of rainforest plants .. 96 


\section{Introduction}

\subsection{Problem}

The high economic and population growth in Africa and Asia, the increase of international trade, and globalization have largely boosted the global demand for cocoa (Squicciarini and Swinnen, 2016). However, cocoa growing countries can barely meet this expanding demand (ICCO, 2016). These enduring processes triggered a high volatility in world cocoa prices in this new century (Onumah et al., 2013). Volatility induces uncertainty among market participants, hence preventing the market from working properly (Piot-Lepetit and M'Barek, 2011). Extreme volatility of the world cocoa price also makes the millions of cocoa farmers in the developing world highly vulnerable to poverty (Fountain and Hütz-Adams, 2015). Our first essay in Chapter 2 helps to inform development policies of the elements involved in the global cocoa bean market to understand the roots of the recent price volatility. According to Piot-Lepetit and M'Barek (2011), the wide fluctuation in the price of an agricultural commodity is linked to the inelasticity of its supply and demand. Therefore, we test the hypothesis that the price elasticities of the global cocoa supply and demand are low.

After the Ivory Coast and Ghana, Indonesia is the third largest cocoa producing country with 10 percent of the global production (ICCO, 2016). Nearly 1.5 million Indonesian households depend on cocoa farming (ICCO, 2012). On the island of Sulawesi, which accounts for two thirds of Indonesia's cocoa production (Ministry of Agriculture, 2015), 60 percent of cocoa farmers were living below the World Bank poverty threshold of 1.90 US dollar per day in 2009 (van Edig et al., 2010). Farmer incomes can be improved and cocoa demand can be met by increasing the cultivated area, by increasing input use, or by increasing technical efficiency (Onumah et al., 2013). As a consequence of acreage expansion, cocoa plantations are increasingly intruding into the Indonesian rainforest, which is a world biodiversity hotspot hosting a large number of endemic species (REDD, 2012). Production levels can also be enhanced by input intensification. However, this pathway may also cause environmental deterioration and raise concerns about biodiversity conservation (Asare, 2005). The third method to increase production is to improve technical efficiency. For environmental sustainability, this is the most desirable option. Our second essay in Chapter 3 investigates to what extent and how cocoa cultivation can be made more productive considering technical efficiency. 
Our third essay in Chapter 4 analyses how the proposed measures affect the environment. For this purpose, the interdependence of economic performance and ecosystem disturbance and the magnitude of efficiency losses has to be determined. The economic literature promotes environmental efficiency to describe how the performance of environmental elements meet human demand (Huppes and Ishikawa, 2005). We study the environmental efficiency of cocoa production in Sulawesi, Indonesia. This region is an important example of environmental degradation due to economic development in terms of agricultural expansion and intensification. On this island, 80 percent of the rainforests were gone by 2010 causing sometimes irreversible losses of biodiversity (FAO, 2010).

Based on discussion above, this thesis deals with three research questions in the three essays that make up Chapters 2, 3 and 4:

1. how low is the price elasticity in the global cocoa market?

2. how can the productivity of Indonesian cocoa farms be increased?

3. how can the environmental efficiency of Indonesian cocoa farms be increased?

The next three sections of the introduction provide descriptions of the specific research contributions, methodologies, findings, and implications of these essays.

\subsection{Topic 1: Price elasticity in the cocoa market}

Regarding cocoa price elasticity, the papers from the last decades investigate only domestic cocoa markets over a period of 23-34 years (Hameed et al., 2009; Gilbert and Varangis, 2003; Uwakonye et al., 2004). The main contribution of our essay is twofold: we integrate a number of variables from a global cocoa data set that covers half a century (19632013) and carry out estimations with three different methods employing rigorous unit root, cointegration, and instrumental variable testing.

We describe the global cocoa market with three cointegration dynamic structural submodels (supply, demand, and price) in addition to the market equilibrium condition identity (Labys, 2006). It is assumed that four variables (cocoa price, supply, demand, and stocks) are determined jointly in the system. We estimate the model with the OLS, SUR, and 2SLS methods. Results compare favorably with theory: all significant variables carry the a priori expected signs. The world cocoa supply is extremely price-inelastic: the corresponding shortand long-run estimates are 0.07 and 0.57 . In addition, coffee appears to be a weak cocoa supply substitute. The price elasticity of the world cocoa demand also falls into the extremely inelastic 
range: the short- and long-run estimates are -0.06 and -0.34 . Finally, palm oil seems to be a weak cocoa demand substitute.

Based on these empirical results, we consider the prospects for cocoa price stabilization. The cocoa price volatility was treated with various unsuccessful methods in the past: planned economies, marketing boards, and explicit supply or price manipulations (Dand, 2011). These experiments caused inefficiencies, lead to market failures, and are unlikely to win wide support (Sarris and Hallam, 2006). In 1973, the International Cocoa Organization (ICCO) was set up to manipulate the global cocoa buffer stocks and production to stabilize world cocoa price in a zone. However, it has been ineffective in maintaining the stability of cocoa prices due to insufficient funding as well as the absence of the biggest cocoa consumer, the United States (Dand, 2011). According to Piot-Lepetit and M'Barek (2011), a possible solution for reducing the price volatility would be the encouragement of crop diversification. This increases the price elasticity of cocoa supply by adjusting the effort and money allocation between the crops, thus decreasing price volatility.

\subsection{Topic 2: The productivity and efficiency of cocoa farms}

Previous research on the efficiency of cocoa farming is only available with crosssectional data from African countries (Adedeji et al., 2011; Awotide et al., 2015; Ogundari and Odefadehan, 2007). We use household panel data from surveys conducted in Indonesia between 2001 and 2013. Our sample size of 1290 observations is larger than any previously used in the efficiency analysis of cocoa production. With the information gain of this data, we can characterize inefficiencies more realistically and we can also decompose productivity change.

Our study applies stochastic frontier analysis (Coelli et al., 2005) to investigate to what extent and how the Indonesian cocoa production can be made more productive and technically efficient. In multiple models, we explain cocoa bean output as a function of farm size, labor use, chemicals cost, and technological factors. These are augmented by inefficiency variables to express farmers' management capacities and their access to information and productive assets.

According to our results, the productivity of Indonesian cocoa farming increased by 75 percent between 2001 and 2013. Technical efficiency growth and the increased chemicals use supported by government subsidies were responsible for the majority of this gain. Furthermore, the calculations show large distortions in input allocation. Hence, policies that encourage the 
adjustment of the cocoa farms' input use would be highly beneficial. Moreover, the technical change component points to a weather-induced volatility in cocoa production. Thus, policy makers should also promote investment in agricultural research and transfer of droughtresistant cocoa varieties to farmers.

Additionally, the average efficiency of cocoa farmers is estimated to be around 50 percent. This result suggests that there is ample scope to expand Indonesian cocoa output without increasing input use. The significant factors that can increase efficiency levels are the smallholders' educational attainment and their experience in cocoa farming. Our research also shows the insignificant effect of existing agricultural extension services, farmer associations, and rural credit programs on the technical efficiency of cocoa farming. Hence, public policy should focus on adjusting the public extension programs, fostering the mutual benefits in the farmer groups, and developing viable credit institutions.

\subsection{Topic 3: The environmental efficiency of cocoa farms}

A number of studies (Ruf and Schroth, 2004; Schroth et al., 2004; Scherer-Lorenzen et al., 2005) address various issues related to the environmental effects of cocoa farming. However, these papers do not consider efficiency. We look at the trade-off between smallholder cocoa intensification and the ecosystem in Central Sulawesi, Indonesia and investigate the determinants of environmental efficiency in cocoa production. In our analysis, we apply a distance output function (Coelli et al., 2005) that includes cocoa production and the abundance of native rainforest plants as outputs. Our data set, based on a household and environment survey conducted in 2015, allows us to analyze 208 cocoa producers with both measured and self-reported data.

We find that there is a trade-off between cocoa yields and the abundance of native rainforest plants. According to this connection, the intensification of cocoa farms results in higher ecosystem degradation. By calculating the shadow prices (Fare et al., 2005) of these native plants, we estimate the monetary value of reductions in their abundance.

The estimations show substantial inefficiencies for the majority of cocoa farmers. The low average efficiency value of 50 percent indicates a less specialized and less competitive market with low pressure for cocoa producers. Increasing efficiency could lead to a win-winwin situation: more production coming from less hectares, with more native plants co-existing with cocoa on the remaining hectares. On average, the efficiency scores point to a possible 
production expansion of $367 \mathrm{~kg}$ of cocoa per farm and year, to a possible increase of 43680 rainforest plants per farm, or to a possible acreage reduction of 0.52 hectares per farm.

Looking at the inefficiency effects, we can see that agricultural extension services have a substantial role in increasing efficiency. We also observe that the model using self-reported variables overestimates the inefficiency effects, as well as the distance elasticities and efficiencies. Finally, we find that credit access does not have a significant effect on efficiency. This result is inconsistent with African studies which show positive linkages. Feasible agricultural credit services are viewed by numerous economists as a crucial prerequisite for improving efficiency, a critical part of encouraging development. We recommend linking credit to extension services as part of this effort.

The rest of this dissertation is structured as follows. The next tree chapters present the three essays outlined above. Furthermore, the fifth chapter summarizes the main findings and their policy implications and presents the limitations of our studies as well as possible avenues for future research.

\subsection{References}

Adedeji, I.A., Ajetomobi, J.O., Olapade-Ogunwole, F. (2011): Technical efficiency of cocoa production in Oyo State, Nigeria. Continental Journal of Agricultural Economics 5, $30-40$.

Asare, R. (2005): Cocoa agroforests in West Africa: a look at activities on preferred trees in the farming systems. Forestry and Landscape Working Paper No. 6, University of Copenhagen, Copenhagen.

Awotide D.O., Kehinde, A.L., Akorede, T.O. (2015): Metafrontier analysis of access to credit and technical efficiency among smallholder cocoa farmers in Southwest Nigeria. International Business Research 8, 132-144.

Coelli, T.J., Rao, D.S.P., O'Donnell, C.J., Battese, G.E. (2005): An Introduction to Efficiency and Productivity Analysis. Springer, New York.

Dand, R. (2011): The International Cocoa Trade. Sawston: Woodhead Publishing.

FAO (2010): Global Forest Resources Assessment. FAO, Rome.

Fare, R., Grosskopf, S., Noh, D., Weber, W. (2005): Characteristics of a polluting technology: theory and practice. Journal of Econometrics 126, 469-492.

Fountain, A.C., Hütz-Adams, F. (2015): Cocoa Barometer 2015. VOICE Network, The Netherlands. 
Gilbert, C., Varangis, P. (2003): Globalization and International Commodity Trade with Specific Reference to the West African Cocoa Producers. NBER Working Paper No. 9668.

Hameed, A.A.A., Applanaidu, S.D., Arshad, F.M., Shamsudin, M.N. (2009): An Econometric Model of the Malaysian Cocoa Market. Working Paper, Universiti Putra Malaysia.

Huppes, G.,Ishikawa, M. (2005): Eco-efficiency and its terminology. Journal of Industrial Ecology 9, 43-46.

ICCO (2012): The World Cocoa Economy: Past and Present. International Cocoa Organization, London.

ICCO (2016): Quarterly Bulletin of Cocoa Statistics. International Cocoa Organization, London.

Labys, W. (2006): Modeling and Forecasting Primary Commodity Prices. Burlington, VT: Ashgate.

Ministry of Agriculture (2015): Directorate General of Estate Crops. Ministry of Agriculture, Indonesia, Jakarta.

Ogundari, K., Odefadehan, O. (2007): Comparative analysis of resource-productivity and technical efficiency of cocoa producers: a study of farmers under training \& visit and farmer field school extension systems in Nigeria. Quarterly Journal of International Agriculture 46, 205-219.

Onumah, J.A., Onumah, E.E., Al-Hassan, R.M., Brümmer, B. (2013): Meta-frontier analysis of organic and conventional cocoa production in Ghana. Agricultural Economics Czech 59, 271-280.

Piot-Lepetit, I., M'Barek, R. (2011): Methods to Analyse Agricultural Commodity Price Volatility. New York, NY: Springer.

REDD (2012): Opportunity Costs of Major Land Uses in Central Sulawesi. UN Reducing Emissions from Deforestation and Forest Degradation, Geneva.

Ruf, F., Schroth, G. (2004): Chocolate forests and monocultures: a historical review of cocoa growing and its conflicting role in tropical deforestation and forest conservation. In: Schroth, G., Fonseca, G., Harvey, C., Gascon, C., Vasconcelos, H., Izac, A.-M. (Eds.), Agroforestry and Biodiversity Conservation in Tropical Landscapes. Island Press, Washington D.C., pp. 107-134.

Sarris, A., Hallam, D. (2006): Agricultural Commodity Markets and Trade: New Approaches to Analyzing Market Structure and Instability. Cheltenham: Edward Elgar Publishing and FAO. 
Scherer-Lorenzen, M., Korner, C., Schulze, E. (2005): The functional significance of forest diversity: the synthesis. In: Scherer-Lorenzen, M., Korner, C., Schulze, E. (Eds.), Forest Diversity and Functions: Temperate and Boreal Systems. Springer, Berlin, pp. 377-389.

Schroth, G., da Fonseca, G., Harvey, C., Gaston, C., Vasconcelos, H., Izac, A. (2004): Agroforestry and Biodiversity Conservation in Tropical Landscapes. Island Press, Washington D.C.

Squicciarini, M. P., Swinnen, J. (2016): The Economics of Chocolate. Oxford University Press, Oxford.

Uwakonye, M., Nazemzadeh, A., Osho, G.S., W.J. Etundi, W.J. (2004): Social welfare effect of Ghana cocoa price stabilization: time series projection and analysis. International Business \& Economics Research Journal 3, 45-54.

van Edig, X., Schwarze, S., Zeller, M. (2010): The robustness of indicator based poverty assessment tools in changing environments - empirical evidence from Indonesia. In: Tscharntke, T., Leuschner, C., Veldkamp, E., Faust, H., Guhardja, E., Bidin, A. (Eds.), Tropical Rainforests and Agroforests under Global Change: Ecological and Socioeconomic Valuations. Springer, Berlin, pp. 191-211. 


\title{
2. How low is the price elasticity in the global cocoa market?
}

\begin{abstract}
The high volatility of the world cocoa price makes the millions of cocoa farmers in the developing world highly vulnerable to poverty. A large volatility in the value of an agricultural commodity is linked to the inelasticity of its supply or demand. Therefore, we test the hypothesis that the price elasticities of the global cocoa supply and demand are low. We describe the global cocoa market with cointegration dynamic supply, demand and price submodels. Our OLS, 2SLS, and SUR estimates are based on annual global observations covering the years 1963 through 2013. We find that the global cocoa supply is extremely price-inelastic: the corresponding short- and long-run estimates are 0.07 and 0.57 . The price elasticity of cocoa demand also falls into the extremely inelastic range: the short- and long-run estimates are -0.06 and -0.34 . Based on these empirical results, we consider the prospects for cocoa price stabilization. The cocoa price volatility was treated with various unsuccessful methods in the past. A possible solution for reducing the price volatility would be the encouragement of crop diversification. This increases the price elasticity of cocoa supply by adjusting the effort and money allocation between the crops, thus decreasing price volatility.
\end{abstract}

Keywords: cocoa, supply, demand, price elasticity.

JEL codes: O13, Q11.

\footnotetext{
${ }^{1}$ I am the only author of this paper. I would like to thank Stephan von Cramon-Taubadel, Sebastian Lakner, and Ayako Ebata for their comments. Furthermore, this project would have been impossible without the funding from the German Research Foundation.
} 


\subsection{Introduction}

The soaring economic and population growth in Africa and Asia, the increase of global trade, and globalization have considerably boosted demand for cocoa beans (ICCO, 2012). However, cocoa growing countries can barely meet this expanding demand (ICCO, 2016). These sustained processes triggered extraordinary cocoa price volatility in this new century (Onumah et al., 2013). Price volatility induces uncertainty among cocoa market participants, hence preventing the market from working properly (Piot-Lepetit and M'Barek, 2011). Extreme volatility of the world cocoa price also makes the millions of cocoa farmers in the developing world highly vulnerable to poverty (Fountain and Hütz-Adams, 2015).

This study helps to inform development policies of the elements involved in the cocoa bean market to understand the roots of the recent price volatility. According to Piot-Lepetit and M'Barek (2011), a large volatility in the value of an agricultural commodity is connected to the inelasticity of its supply or demand. Therefore, we test the following two hypotheses. First, the global cocoa demand is extremely price-inelastic. Second, the price elasticity of global cocoa supply is extremely low. We model the global cocoa supply, demand, and price between 1963 and 2013 with cointegration dynamic simultaneous equations (Hsiao, 1997a and 1997b). Because OLS may not be an adequate estimation method, our model is also estimated with two other techniques: SUR (seemingly unrelated regressions) and 2SLS.

Regarding cocoa price elasticity, the papers from the last decades investigate only domestic cocoa markets over a period of 23-34 years. Shamsudin et al. (1993) and Hameed et al. (2009) analyze the Malaysian cocoa market. Furthermore, Gilbert and Varangis (2003) examine the cocoa markets in four West African countries. Moreover, Uwakonye et al. (2004) focus on Ghanaian cocoa. Our contribution to the literature, in the testing of the hypotheses above, is twofold. We integrate a number of variables from a global cocoa data set that covers half a century and carry out estimations with three different methods employing rigorous unit root, cointegration, and instrumental variable testing.

This paper is divided into six parts. We begin in part 2 with an overview of the global cocoa supply, demand, and price. Then in part 3, we review the methodologies of the previous cocoa market models and the estimation issues. Furthermore, the specification of our cocoa market model and our data sources are presented in part 4. Next, the different estimation results for the cocoa supply, demand, and price equations are reported in part 5. Last, we summarize our findings and draw a brief conclusion in part 6. 


\subsection{Background}

\subsubsection{Cocoa supply and demand}

Cocoa is primarily grown by smallholders in tropical areas. Usually, cocoa trees reach their productive age around three years after planting and their yields top out at around the seventh year, but decent cocoa yields can be harvested for additional 20 years (Dand, 2011). The presumed implication of the long cocoa cycle along with no close cocoa substitutes is extremely inelastic cocoa supply (Siswoputranto, 1995). Adverse weather and pests are also major factors influencing cocoa yields: it is estimated that diseases destroy about 30 percent of the global production every year (UNCTAD, 2006).

The three main cocoa-growing and exporting nations are the Ivory Coast, Ghana, and Indonesia. In 2013, their share of the global production were 38, 20, and 9 percent, while their share of global net exports were 37, 22, and 14 percent (ICCO, 2016). Figure 2.1 illustrates the development of the global cocoa supply over the last half a century. Cocoa production rose from 1.3 million tons to over 4 million tons in 2013, representing an average yearly growth rate of 2.60 percent. Moreover, with yearly growth rates between -10 and 13 percent, the global cocoa production fluctuated widely around the trend line due to climatic factors.

Because of the differences between the sources of cocoa production and the uses of cocoa, over two thirds of all cocoa production is traded internationally (Figure 2.1). Africa is by far the leading cocoa exporter. Furthermore, the largest regional cocoa bean trade is between Africa and the EU. Europe constitutes for more than half of all net cocoa imports (ICCO, 2016), but the United States is the main importing country with a 21 percent of the world cocoa imports.

Most of the cocoa grindings take place in cocoa importing nations near the main centers of cocoa consumption. Netherlands is the leading cocoa bean processor with a 13 percent share of the world grindings. However, origin cocoa grindings are also widespread: the Ivory Coast is the second largest cocoa processor (ICCO, 2016). Figures 2.1 also displays the global cocoa demand between 1963 and 2013. Demand, as measured by grindings, rose on average by 2.63 percent per year over the period from 1.2 million tons to 4.3 million tons. Furthermore, cocoa grindings showed a steadier trend than cocoa supply with yearly growth rates between -7 and 10 percent. Finally, we can also see from Figure 2.1 that the ratio of cocoa stocks-to-grindings peaked in 1990 and has been falling ever since. 
Figure 2.1: World cocoa production, grindings, stocks-to-grindings, and import-to-grindings (1963-2013).

Cocoa production, grindings

Cocoa stocks-to-use, import-to-use

(1000 metric tons)

(percent)

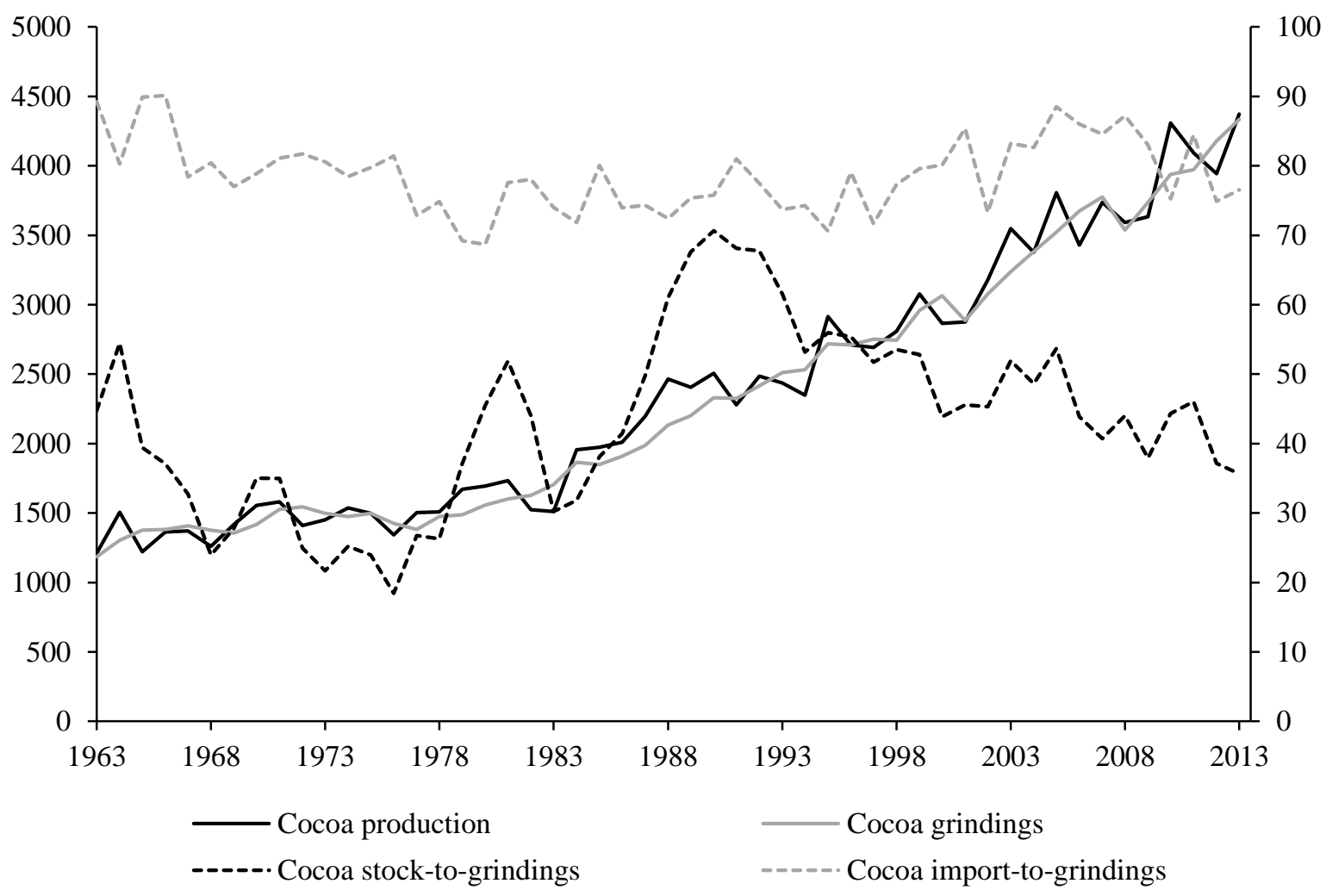

Source: FAO Statistics, ICCO Quarterly Bulletin of Cocoa Statistics.

\subsubsection{World cocoa price}

The world cocoa bean price is determined at the two primary cocoa futures exchanges in New York and London. Because cocoa has very limited uses and no major substitutes, the main influencing factors of the global cocoa price are cocoa supply and demand (Dand, 2011). World cocoa prices usually reflect a long-term pattern connected to the cocoa production cycle, which is judged to be about 25 years long. In the course of cocoa booms a supply surplus is generated that results first in the fall and then in the stagnation of cocoa prices. Continuously low cocoa prices have a negative effect on harvesting, prompting cocoa farmers to shift to alternative crops. This permits world cocoa prices to rise again (Siswoputranto, 1995; UNCTAD, 2006).

The International Cocoa Organization (ICCO), whose 40 members include both exporter and importer countries, was established in 1973 to promote international cooperation, 
to assist a balanced evolution of the global cocoa market, and to manipulate the cocoa buffer stocks and production to stabilize world cocoa price in a zone. However, it has been ineffective in maintaining the stability of cocoa prices due to insufficient funding as well as the absence of the biggest cocoa consumer, the United States (Dand, 2011).

Figure 2.2 shows the development of the world cocoa price. In midst of the general global commodity boom of the 1970s, the value of cocoa beans experienced a striking increase, which later boosted cocoa production in countries such as Indonesia and Malaysia. From the beginning of the 1980s, owing to the higher cocoa stocks-to-grindings ratio (Figure 2.1), cocoa prices plummeted for two decades. The price bottom was reached in 2000 . Then, the nominal value of cocoa rose from 888 to 3064 U.S. dollars/ton and the real value from 1116 to 2836 U.S. dollars/ton, which coincided with the drop of the cocoa stocks-to-use ratio from over 70 percent to under 40 percent. However, it can be observed that the world cocoa price is still low compared with those dominating 40 years ago, while real chocolate prices were maintained since the 1970s. The volatility of the world cocoa price, though, increased considerably in the new millennium (ICCO, 2012).

Figure 2.2: The real and nominal world cocoa price in US dollar/ton (1963-2013).

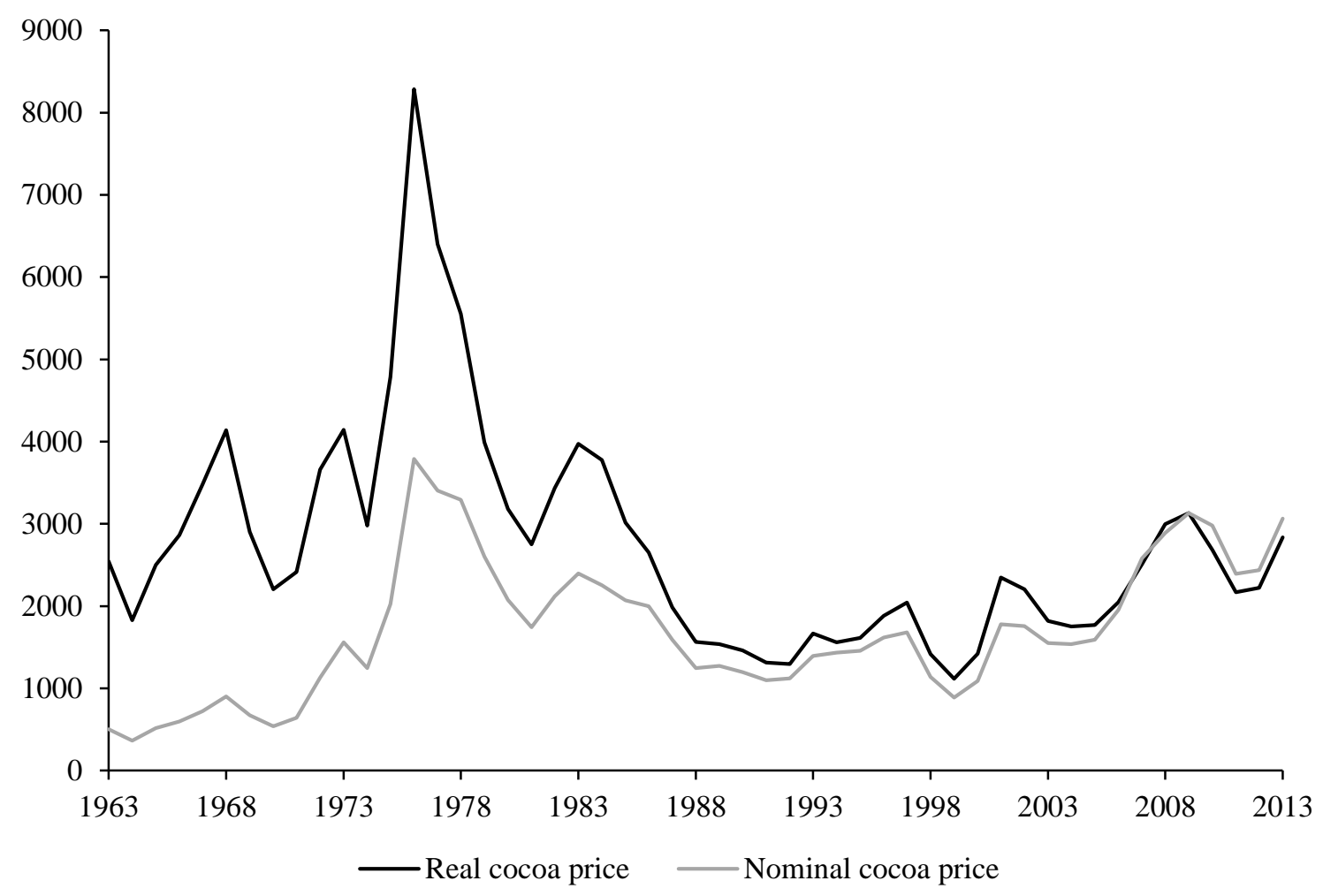

Source: World Bank Global Economic Monitor.

Note: The price index is Manufacture Unit Value (MUV) index from the World Bank and the base year is 2010. 


\subsection{Methodology and literature review}

\subsubsection{Commodity market models}

We use the popular commodity market framework of Hallam (1990) and Labys (2006) to devise our own cocoa market model. This framework is composed of four equations. The supply, demand, and price sub-models in addition to the market equilibrium condition are the following:

$S_{t}=s\left(S_{t-1}, P_{t-1}, P A_{t-1}, W_{t}\right)$

$D_{t}=d\left(D_{t-1}, P_{t}, P S_{t}, Y_{t}\right)$

$P_{t}=p\left(P_{t-1}, I_{t}, D_{t}\right)$

$I_{t}=I_{t-1}+S_{t}-D_{t}$,

where $S_{t}$ is the commodity supply, $D_{t}$ is the commodity demand, $P_{t}$ is the commodity price, $I_{t}$ denotes the commodity inventories, $P A_{t}$ indicates the prices of alternative commodities, $P S_{t}$ represents the prices of substitute commodities, $Y_{t}$ is income, and $W_{t}$ reflects the weather effects.

In this framework, commodity supply is determined by lagged supply, lagged own price, lagged prices of alternative crops, and weather. Moreover, commodity demand depends on lagged demand, own price, prices of substitute commodities, as well as income. Furthermore, lagged commodity price, commodity inventories along with commodity demand are used to explain the commodity price. Finally, the model is closed with the commodity stocks identity which equates commodity quantity demanded with quantity supplied plus the change in commodity inventories.

The framework above is adopted in many price elasticity studies concerning tropical commodities. For example, Behnman and Adams (1976) and Hwa $(1979,1985)$ use it to model various cocoa, rubber, cotton, tea, coffee, and sugar markets. Because we could not find a world cocoa market model, we highlight three preceding domestic cocoa studies in the next three paragraphs.

In the first study, Hameed et al. (2009) investigate the Malaysian cocoa market between 1975 and 2008. They specify three equations: domestic cocoa supply, export demand for Malaysian cocoa, and domestic cocoa price. These equations are estimated with the SUR technique because they find no endogeneity in their model. The four main results of their paper are the following. First, the short-run price elasticities of cocoa supply and demand are low: 
0.39 and -0.37 . Second, palm oil is not a supply substitute for cocoa beans. Third, the world industrial production index greatly affects the cocoa export demand. Finally, the domestic cocoa price is highly determined by the world cocoa price. The weakness of their findings is that they do not use unit root and cointegration tests.

In the second study, Uwakonye et al. (2004) focus on Ghanaian cocoa over the period 1980-2002. They estimate two equations, domestic cocoa supply and cocoa export demand, with the 2SLS method. Their results also suggest price-inelastic cocoa supply and demand: the corresponding estimates are 0.26 and -0.54 . Additionally, they find that the domestic cocoa supply is highly influenced by the world corn price. Moreover, sugar does not turn out to be a cocoa demand substitute in their paper. Finally, the world GDP is highly significant in explaining the cocoa export demand in their model. The weakness of their paper is that they do not apply any unit root, cointegration, or instrumental variables tests.

In the third study, Gilbert and Varangis (2003) examine the cocoa market of the Ivory Coast between 1969 and 1999. By applying the FIML method, they estimate three equations: domestic cocoa supply, world cocoa demand, and domestic cocoa price. Their results also point to the low short-run price elasticities of cocoa supply (0.43) and demand (-0.10). Surprisingly, the world GDP does not shift the world cocoa demand in their model. Finally, they find that the domestic cocoa price in the prior year considerably affects its current value. The weakness of their results is that they do not test for unit roots and cointegration.

\subsubsection{Estimation issues and tests}

In the case of a commodity market framework, it is expected that several variables (commodity supply, commodity demand, commodity price, and commodity inventories) are simultaneously determined (Hallam, 1990). This means that these variables are endogenous. By using instrumental variables (IV), the 2SLS approach is the most common estimation method of simultaneous equations models. Still, it is at least of passing interest to examine the results of the OLS estimation, despite its inconsistency.

Using the 2SLS method, an important question to ask is whether regressors assumed to be endogenous could rather act as exogenous. If the endogenous variables are exogenous then the OLS estimation method is more efficient and we may sacrifice a considerable amount of efficiency with the use of an IV method, thus OLS should be used instead. Therefore, we test for endogeneity with Eichenbaum et al. (1988) method. 
Furthermore, excluded exogenous regressors can be valid instrumental variables only if they are sufficiently correlated with the included endogenous variables. Weakly correlated instruments can lead to bias toward the OLS inference and the standard errors reported can be severely misleading, as well. Therefore, we test the strength of the instruments with the Kleibergen and Paap (2006) method. Its test statistic does not follow a standard distribution, but Stock and Yugo (2005) present a table with critical values for some combinations of instrumental and endogenous variable numbers.

The second validity condition of instrumental variables is that they are not correlated with the error term. However, we can assess this only if the model is overidentified, i.e., the number of instrumental variables is larger than the number of endogenous variables. We evaluate with the Hansen (1982) test whether the second validity premise holds for a subgroup of the instrumental variables but not for the remaining instruments.

Using time series variables, non-stationarity can create severe problems for standard inference methods. Hsiao (1997a, 1997b) provides an updated view of structural equations that takes into consideration non-stationarity and cointegration. His three key conclusions are the following. First, a legitimate drawback (simultaneity bias) also arises in OLS when regressors are integrated. Second, identification conditions for stationary variables hold for integrated ones under proper premises. Third, conventional IV formulas can be applied in parameter estimations, formulating Wald statistics, and testing procedures.

We employ the autoregressive distributed lag (ARDL) bounds framework (Pesaran et al., 2001) to test for cointegration instead of the Johansen procedure, because the latter suffers from serious flaws when regressors are not integrated of the same order. In contrast, the ARDL bounds approach yields unbiased and efficient results in small sample sizes irrespective of whether the underlying variables are stationary or integrated. This method estimates the following equation if there is only one independent variable:

$\Delta \ln Y_{t}=\propto_{0}+\sum_{i=1}^{n} \beta_{i} \Delta \ln Y_{t-i}+\sum_{i=0}^{n} \gamma_{i} \Delta \ln X_{t-i}+\lambda_{1} \ln Y_{t-1}+\lambda_{2} \ln X_{t-1}+\varepsilon_{1, t}$

The first component of the equation with $\beta_{i}$ and $\gamma_{i}$ reflects the short-term relationships of the model whereas the parameters $\lambda_{1}, \lambda_{2}$ represent the long-term dynamics. The null hypothesis of the model is: $H_{0}: \lambda_{1}=\lambda_{2}=0$ (there are no long-term relationships).

The asymptotic distribution of the obtained F-statistic is nonstandard. It is compared with the lower and upper bounds of critical F-values determined by Pesaran et al. (2001). If the test statistic is smaller than the lower bound, the null hypothesis is accepted. Similarly, if the test statistic is larger than the upper bound, the null hypothesis is rejected. However, if the test 
statistic falls between these two bounds, the results are ambiguous. If there is evidence that the variables are cointegrated, we estimate the long-term model:

$\ln Y_{t}=\propto_{1}+\sum_{i=1}^{n} \beta_{i} \ln Y_{t-i}+\sum_{i=0}^{n} \gamma_{i} \ln X_{t-i}+\varepsilon_{2, t}$.

Otherwise we should take first differences to estimate the short-run model:

$\Delta \ln Y_{t}=\propto_{2}+\sum_{i=1}^{n} \beta_{i} \Delta \ln Y_{t-i}+\sum_{i=0}^{n} \gamma_{i} \Delta \ln X_{t-i}+\varepsilon_{3, t}$.

\subsection{Empirical specification}

\subsubsection{Cocoa market model}

Based on the commodity market framework of Labys (2006) and the earlier cocoa market models, we describe the world cocoa bean market with three structural equations in addition to the annual ending stocks identity. The cocoa supply, demand, and price equations are the following:

$$
\begin{aligned}
& \text { Supply }_{t}=\beta_{0}+\sum_{n=0}^{7}\left(\beta_{1 n} \text { CocoaPrice }_{t-n}+\beta_{2 n} \text { CoffeePrice }_{t-n}\right)+\beta_{3} \text { Yield }_{t}+ \\
& \sum_{m=1}^{2} \beta_{4 m} \text { Supply }_{t-m}+\varepsilon_{t 1}
\end{aligned}
$$

Demand $_{t}=\gamma_{0}+\gamma_{1}$ CocoaPrice $_{t}+\gamma_{2}$ PalmoilPrice $_{t}+\gamma_{3} G D P_{t}+\gamma_{4}$ Demand $_{t-1}+\varepsilon_{t 2}$

Cocoaprice $_{t}=\delta_{0}+\delta_{1}$ Stocks $_{t}+\delta_{2}$ Demand $_{t}+\delta_{3}$ Cocoaprice $_{t-1}+\varepsilon_{t 3}$

Supply $_{t}=$ Demand $_{t}+$ Stocks $_{t}-$ Stocks $_{t-1}$.

It is assumed that the $\varepsilon_{t 1}, \varepsilon_{t 2}, \varepsilon_{t 3}$ stochastic disturbances, which express random effects, a number of separately unimportant omitted regressors and measurement errors, are homoscedastic, not autocorrelated, and exhibit normal distributions:

$\varepsilon_{t j} \sim \mathcal{N}\left(0, \sigma_{j}\right)$, for all $t=1 \ldots T$ and $E\left(\varepsilon_{m j} \varepsilon_{n j}\right)=0$ for all $m, n=1 \ldots T, m \neq n, j=1,2,3$.

We specify a dynamic cocoa market model containing both autoregressive and distributed lag components (ARDL), since cocoa farmers and firms spread their responses over time due to adjustment costs and incomplete and lagged information. It includes four jointly determined variables (cocoa supply, cocoa demand, cocoa price, and cocoa stocks), four exogenous variables (cocoa yield, coffee price, palm oil price, and world GDP) and many predetermined variables. Furthermore, we formulate the model in double-log functional form, implying that we can approximate relationships in constant-elasticity form.

In the cocoa supply equation, the current and the lagged values of the cocoa price correspond to the short-run harvesting and the long-run farm investment decisions (Shamsudin 
et al., 1993). We include seven lags for the prices because cocoa trees reach full bearing capacity at the age of seven years. Based on Dand (2011), the coffee price in the cocoa supply sub-model denotes the battle for acreage. We expect that this variable has a negative effect on cocoa production. Moreover, the cocoa yield variable accounts for weather, diseases, and technological advances in cocoa cultivation. Finally, the autoregressive part in the supply model depicts the long-run constraints of cocoa production (Shamsudin et al., 1993).

In the cocoa demand equation, we assume that palm oil is a substitute for cocoa in the manufacture of chocolate because European laws accept a 5 percent content of palm oil in chocolate products (Dand, 2011). Moreover, the world GDP captures the effect of the economic activity on the global cocoa demand. Finally, the autoregressive part in the demand sub-model indicates that cocoa processing adjusts only gradually to changes due to institutional and technological rigidities (Hameed et al., 2009). For instance, sizable cocoa inventories are acquired by chocolate manufacturers to weather price increases (Dand, 2011).

In the cocoa price equation, the price clears the market in a partial adjustment process. Based on Hameed et al. (2009), we stipulate the world cocoa price as a function of annual cocoa ending stocks, cocoa demand, and lagged cocoa price. Because of the four endogenous variables, one more equation is needed in our cocoa market model. Thus, the market equilibrium condition completes the model: it equates the cocoa supply with the cocoa demand plus the change in the annual cocoa ending stocks.

\subsubsection{Data description}

Our cocoa market model estimates are based on annual global observations covering the years 1963 through 2013. We compose this data set from various sources. The cocoa production and grindings data stem from FAO Statistics and ICCO Quarterly Bulletin of Cocoa Statistics. Furthermore, the benchmark commodity prices are drawn from World Bank's Global Economic Monitor, UNCTAD Statistics, and IMF International Financial Statistics. The variable descriptions in addition to the units of measurement are presented in Table 2.1.

A crucial issue we need to tackle is the exact definition of our variables. The measure of a particular commodity world price can be calculated in numerous ways based on various futures, export, or auction prices from different countries. We decide to use the most widespread variable definitions. For example, the world cocoa price is derived from the nearest three trading months on two key cocoa futures markets. Furthermore, we use the ex-dock New 
York Arabica/Robusta coffee composite price as the world coffee price. Additionally, the 5percent-bulk CIF Rotterdam palm oil price in Malaysia represents the world palm oil price.

Table 2.1: Description of the cocoa market variables.

\begin{tabular}{ll}
\hline Variable & Description \\
\hline Supply & World cocoa bean crop (in 1000 metric tons) \\
Yield & World cocoa bean yield (in kilograms/hectare) \\
Demand & World cocoa bean grindings (in 1000 metric tons) \\
Stocks & World cocoa bean ending stocks (in 1000 metric tons) \\
Cocoa price & Average of real daily cocoa futures prices: New York/London (in US dollars/metric ton) \\
Coffee price & Average of real daily ex-dock coffee prices: New York (in US dollars/metric ton) \\
Palm oil price & Average of real daily CIF Rotterdam palm oil prices: Malaysia (in US dollars/metric ton) \\
GDP & World real GDP (in billion US dollars) \\
\hline
\end{tabular}

Another issue we are confronted with is the selection of the price deflator to form real commodity prices. In this matter, we accept the recommendation of the World Bank to calculate with its Manufactures Unit Value Index for imported goods. Furthermore, we obtain the real world GDP from the World Bank World Development Indicators (WDI) to capture the effect of economic activity level. Table 2.2 provides the summary statistics for all the variables in our global cocoa market model before taking natural logarithms.

Table 2.2: Summary statistics of the cocoa market variables.

\begin{tabular}{|c|c|c|c|c|c|}
\hline Variable & Observations & Mean & Standard deviation & Minimum & Maximum \\
\hline Supply & 51 & 2430 & 960 & 1221 & 4373 \\
\hline Yield & 51 & 384 & 47 & 266 & 461 \\
\hline Demand & 51 & 2389 & 947 & 1305 & 4335 \\
\hline Stocks & 51 & 1069 & 535 & 263 & 1892 \\
\hline Cocoa price & 51 & 2742 & 1362 & 1116 & 8283 \\
\hline Coffee price & 51 & 3533 & 1730 & 1285 & 11048 \\
\hline Palm oil price & 51 & 681 & 255 & 290 & 1518 \\
\hline GDP & 51 & 38641 & 17225 & 13793 & 72970 \\
\hline
\end{tabular}

Sources: FAOStat, ICCO Quarterly Bulletin of Cocoa Statistics, UNCTADStat, World Bank Pink Sheet, World Bank WDI.

Notes: We deflate the commodity prices with the MUV Index of the World Bank. The base year is 2010. 
We assess the stationarity of variables with DF-GLS (Elliott et al., 1996) and KPSS (Kwiatkowski et al., 1992) tests, and, to consider one structural break, with Zivot and Andrews (1992) tests. The KPSS tests have a null hypothesis of stationarity, while the DFGLS tests have a null hypothesis of unit root. Furthermore, the Zivot-Andrews tests have a null hypothesis of unit root without structural break. The results of the three unit root tests are mostly consistent. We find that nearly all the variables at level are integrated and none of our variables have unit roots in first differenced form (Table 2.3). Additionally, we test for cointegration with the ARDL bounds technique (Pesaran et al., 2001). Table 2.4 reports the results: the cocoa market equations represent cointegrating relationships.

Table 2.3: Unit root tests of the cocoa market variables.

\begin{tabular}{|c|c|c|c|c|c|c|c|}
\hline \multirow[t]{2}{*}{ Variable } & \multicolumn{2}{|l|}{ KPSS } & \multicolumn{2}{|l|}{ DF-GLS } & \multicolumn{3}{|c|}{ Zivot-Andrews } \\
\hline & $\begin{array}{l}\text { Without } \\
\text { trend }\end{array}$ & $\begin{array}{l}\text { With } \\
\text { trend }\end{array}$ & $\begin{array}{l}\text { Without } \\
\text { trend }\end{array}$ & $\begin{array}{l}\text { With } \\
\text { trend }\end{array}$ & $\begin{array}{l}\text { Break } \\
\text { in const. }\end{array}$ & $\begin{array}{l}\text { Break } \\
\text { in trend }\end{array}$ & $\begin{array}{l}\text { Break } \\
\text { in both }\end{array}$ \\
\hline Supply & $1.980 * * *$ & $0.214 * *$ & 1.518 & $-2.970 *$ & $-6.045 * * *$ & $-5.882 * * *$ & $-7.160 * * *$ \\
\hline Yield & $1.640 * * *$ & $0.270 * * *$ & 0.020 & -1.678 & $-6.070 * * *$ & $-6.494 * * *$ & $-6.982 * * *$ \\
\hline Demand & $1.980 * * *$ & $0.302 * * *$ & 2.427 & -1.838 & -4.088 & -3.930 & -4.147 \\
\hline Stocks & $1.680 * * *$ & $0.186 * *$ & -0.423 & -1.890 & -3.382 & -2.553 & -3.457 \\
\hline Cocoa price & $0.629 * *$ & $0.191 * *$ & -1.326 & -1.406 & -3.500 & -2.084 & -3.140 \\
\hline Coffee price & $0.899 * * *$ & $0.157 * *$ & $-2.038 *$ & -2.261 & -3.756 & -2.736 & -3.345 \\
\hline Palm oil price & $0.821 * * *$ & $0.242 * * *$ & -0.992 & -1.024 & -2.576 & -2.399 & -3.552 \\
\hline GDP & $1.980 * * *$ & $0.392 * * *$ & 1.699 & -0.706 & -3.021 & -3.350 & -3.130 \\
\hline$\Delta$ Supply & 0.046 & 0.035 & $-6.554 * * *$ & $-6.539 * * *$ & $-8.276 * * *$ & $-7.654 * * *$ & $-8.204 * * *$ \\
\hline$\Delta$ Yield & 0.167 & 0.038 & $-7.686 * * *$ & $-7.390 * * *$ & $-9.420 * * *$ & $-9.006 * * *$ & $-9.451 * * *$ \\
\hline$\Delta$ Demand & 0.081 & 0.071 & $-4.904 * * *$ & $-4.910 * * *$ & $-7.269 * * *$ & $-7.098 * * *$ & $-8.226 * * *$ \\
\hline$\Delta$ Stocks & 0.078 & 0.070 & $-4.327 * * *$ & $-4.296 * * *$ & $-6.927 * * *$ & $-6.327 * * *$ & $-6.878 * * *$ \\
\hline$\Delta$ Cocoa price & 0.063 & 0.063 & $-5.849 * * *$ & $-6.104 * * *$ & $-8.216 * * *$ & $-7.106^{* * *}$ & $-8.164 * * *$ \\
\hline$\Delta$ Coffee price & 0.077 & 0.076 & $-4.844 * * *$ & $-4.832 * * *$ & $-7.033 * * *$ & $-6.522 * * *$ & $-7.008 * * *$ \\
\hline$\Delta$ Palm oil price & 0.119 & 0.048 & $-7.864 * * *$ & $-8.492 * * *$ & $-9.589 * * *$ & $-9.505 * * *$ & $-9.603 * * *$ \\
\hline$\Delta \mathrm{GDP}$ & $0.872 * * *$ & 0.115 & $-2.816^{* * *}$ & $-4.908 * * *$ & $-6.464 * * *$ & $-6.130 * * *$ & $-6.445 * * *$ \\
\hline
\end{tabular}

Notes: The KPSS tests (Kwiatkowski et al., 1992) employ the Quadratic Spectral kernel with automatic bandwidth selection. In the Zivot and Andrews (1992) and DF-GLS (Elliott et al., 1996) tests, the Schwarz information criterion selects the lag length with a maximum of 10 lags.

$* p<0.1$. ** $p<0.05$. *** $p<0.01$. 
Table 2.4: Cointegration tests of the cocoa market model.

\begin{tabular}{lcc}
\hline Model & Without trend & With trend \\
\hline Supply equation & $6.92[3.23,4.35]^{* * * *}$ & $2.33[4.01,5.07]$ \\
Demand equation & $2.46[3.23,4.35]$ & $26.81[4.01,5.07]^{* * *}$ \\
Cocoa price equation & $22.36[3.79,4.85]^{* * *}$ & $47.97[4.87,5.85]^{* * *}$ \\
\hline
\end{tabular}

Notes: The statistics are the F-values of the bounds cointegration technique (Pesaran et al., 2001). The numbers in brackets are the critical lower and upper bounds at the 5 percent significance level. The tests use the Bartlett kernel with Newey-West automatic bandwidth selection and small-sample adjustments.

$* p<0.1$. ** $p<0.05$. *** $p<0.01$.

\subsection{Results and discussion}

\subsubsection{Estimator selection}

First, we estimate the cocoa market model with the OLS and 2SLS methods (Tables 6, 7, and 8). In the 2SLS estimation, the instruments consist of the lagged endogenous variables. This means that all the equations are overidentified. Furthermore, the instrumental variable tests show proper instrument choices (Table 2.5). However, similar to Hameed et al. (2009), we find no endogeneity problem in our model. Therefore, both the OLS and 2SLS methods are consistent, but the OLS is more efficient.

Table 2.5: Instrumental variables tests of the cocoa market model.

\begin{tabular}{lcll}
\hline Model & Weak instruments test & Overidentifying restrictions test & Endogeneity test \\
\hline Supply equation & 27.70 & 0.1473 & 0.7135 \\
Demand equation & 192.58 & 0.2854 & 0.7136 \\
Cocoa price equation & 133.81 & 0.1546 & 0.9485
\end{tabular}

Notes: The weak instruments test statistics are the F-values of the Kleibergen and Paap (2006) method. Furthermore, the overidentifying restrictions and the endogeneity test statistics are the p-values of the Hansen (1982) and Eichenbaum et al. (1988) methods. The tests use the Bartlett kernel with Newey-West automatic bandwidth selection and small-sample adjustments. The instruments consist of the lagged endogenous variables: Supply $_{\mathrm{t}-1}$, Demand $\mathrm{t}_{\mathrm{t}-1}$, Cocoa price $\mathrm{t}_{-1}$, and Stocks $_{\mathrm{t}-1}$. The endogeneity tests have a null hypothesis of exogeneity, and the overidentifying restrictions tests have a null hypothesis of instrument exogeneity. As a rule of thumb, the instruments are weak if the Kleibergen and Paap F-statistic is smaller than 10.

We reestimate the cocoa market model with the seemingly unrelated regressions (SUR) method for efficiency gains. This system estimation method is appropriate when all regressors 
are assumed to be exogenous. It takes into account contemporaneous correlations in the errors across equations and heteroscedasticity (Greene, 2011). In contrast to the 2SLS technique, we find that the OLS and SUR methods produce largely coherent results. However, we reject the hypothesis of the SUR approach that the regressions are related because the p-value of the Breusch and Pagan (1980) test for independent equations is 0.136. Therefore, we discuss only the OLS results in detail.

\subsubsection{Cocoa supply model}

The estimates of the cocoa supply model are presented in Table 2.6. We find that all significant coefficients carry the a priori anticipated signs. According to our results, the current and lagged prices of cocoa beans are significant determinants of the global cocoa production. They reflect the effect of the short-run harvesting and the long-run farm investment decisions. Furthermore, we find that the world cocoa supply is extremely price-inelastic: the corresponding short- and long-run estimates are 0.07 and $0.57 .^{2} \mathrm{We}$ attribute this to the long cocoa production cycle and the large fixed farm investments (Dand, 2011).

In addition, the prices of coffee lagged three and seven years are also factors influencing cocoa supply, which reveals that farmers decide about crop production many years in advance. However, coffee appears to be a weak cocoa supply substitute. This is a plausible result: the land suitable for cocoa is very able to support coffee, but uprooting and replanting an existing plantation costs labor, time, and money, and the new crop gives no return for a couple of years (Dand, 2011).

Moreover, the yield of cocoa turns out to be a significant factor in the cocoa supply model due to its explicit association with production. Finally, the previous years' cocoa production also emerges as a major determinant. Agreeing with the national cocoa market models, supply adjusts slowly to its equilibrium value, again partially as a result of the long cultivation process.

\footnotetext{
${ }^{2}$ To compute long-term elasticities, the lagged values of the explained variables are equated with the current values of the regressands.
} 
Table 2.6: Estimates of the cocoa supply equation.

\begin{tabular}{|c|c|c|c|}
\hline Variable & OLS & $2 S L S$ & SUR \\
\hline Cocoa price $_{t}$ & $0.069(0.027)^{* *}$ & $0.254(0.066)^{* * *}$ & $0.090(0.040)^{* *}$ \\
\hline Cocoa price $_{t-1}$ & $0.083(0.060)$ & $-0.130(0.117)$ & $0.060(0.058)$ \\
\hline Cocoa price $_{t-2}$ & $-0.026(0.050)$ & $0.084(0.089)$ & $-0.029(0.060)$ \\
\hline Cocoa price $_{t-3}$ & $0.079(0.038)^{* *}$ & $0.070(0.044)$ & $0.083(0.058)$ \\
\hline Cocoa price $_{t-4}$ & $-0.042(0.037)$ & $-0.039(0.075)$ & $-0.048(0.057)$ \\
\hline Cocoa price $_{t-5}$ & $0.005(0.035)$ & $-0.002(0.065)$ & $0.008(0.055)$ \\
\hline Cocoa price $_{t-6}$ & $0.013(0.041)$ & $0.013(0.060)$ & $0.013(0.050)$ \\
\hline Cocoa price $_{t-7}$ & $0.029(0.018)$ & $0.045(0.021)^{* *}$ & $0.028(0.038)$ \\
\hline Coffee price $_{t}$ & $-0.078(0.051)$ & $-0.150(0.051)^{* * *}$ & $-0.077(0.035)^{* *}$ \\
\hline Coffee price $_{t-1}$ & $0.063(0.068)$ & $0.119(0.092)$ & $0.066(0.038)^{*}$ \\
\hline Coffee price $e_{t-2}$ & $-0.032(0.052)$ & $-0.055(0.062)$ & $-0.033(0.038)$ \\
\hline Coffee price $_{t-3}$ & $-0.071(0.032)^{* *}$ & $-0.088(0.028)^{* * *}$ & $-0.062(0.037)^{*}$ \\
\hline Coffee price $_{t-4}$ & $0.004(0.030)$ & $-0.001(0.032)$ & $0.004(0.038)$ \\
\hline Coffee price $_{t-5}$ & $-0.024(0.032)$ & $-0.026(0.036)$ & $-0.024(0.036)$ \\
\hline Coffee price $_{t-6}$ & $0.042(0.032)$ & $0.086(0.033)^{* *}$ & $0.041(0.036)$ \\
\hline Coffee price $_{t-7}$ & $-0.095(0.035)^{* *}$ & $-0.162(0.053) * * *$ & $-0.093(0.039)^{* *}$ \\
\hline Yield $_{t}$ & $1.022(0.118)^{* * *}$ & $1.254(0.101)^{* * *}$ & $1.013(0.108) * * *$ \\
\hline Supplyt-1 & $0.410(0.056)^{* * *}$ & $0.504(0.067)^{* * *}$ & $0.429(0.080)^{* * *}$ \\
\hline Supply $_{\mathrm{t}-2}$ & $0.331(0.067)^{* * *}$ & $0.165(0.083)^{*}$ & $0.322(0.089)^{* * *}$ \\
\hline$\overline{R^{2}}$ & 0.991 & 0.987 & 0.991 \\
\hline
\end{tabular}

Notes: Small-sample standard errors are in parentheses. The OLS and 2SLS statistics use the Bartlett kernel with Newey-West automatic bandwidth selection. The instruments consist of the lagged endogenous variables: Supply $_{\mathrm{t}-1}$, Demand $\mathrm{D}_{\mathrm{t}-1}$, Cocoa price $_{\mathrm{t}-1}$, and Stocks $\mathrm{D}_{\mathrm{t}-1}$.

$* p<0.1 . * * p<0.05$. *** $p<0.01$.

\subsubsection{Cocoa demand model}

The estimated cocoa demand parameters along with their statistical significances are shown in Table 2.7. Conforming to our hypothesis, they indicate that the world cocoa demand is negatively linked to the world cocoa price and the connection between the two variables is statistically significant. Furthermore, the own-price elasticity of cocoa demand falls into the extremely inelastic range: the corresponding short- and long-run estimates are -0.06 and -0.34 . 
We attribute this to the luxury good nature of cocoa and also to the fact that chocolate bars and confectionary products contain less than 10 percent cocoa by value (Dand, 2011).

In addition, our results show that the global cocoa demand is sensitive to the world palm oil price: chocolate manufacturers are induced to shift away from cocoa if it becomes more expensive relative to palm oil. However, the magnitude of the coefficient (0.036) concludes that palm oil is a weak demand substitute. The substitution of cocoa with vegetable oils is limited because of the legal restrictions and the unique properties of cocoa butter (Dand, 2011).

Similar to the previous cocoa country studies, we find that the economic activity level has a significant positive effect on cocoa demand. This is expected since most of the cocoa bean consumption is to feed the grinding industry and consumers with a rising income buy more cocoa products. However, our long-term GDP coefficient (0.721) falls into the inelastic range.

Finally, the parameter of the lagged cocoa demand is statistically significant in our estimation. Its value (0.817) signals that global cocoa processing adapts slowly to its equilibrium level. This is a plausible result: cocoa firms spread their responses over time due to incomplete information and additional costs (Shamsudin, 1998).

Table 2.7: Estimates of the cocoa demand equation.

\begin{tabular}{llll}
\hline Variable & OLS & 2SLS & SUR \\
\hline Cocoa price $_{\mathrm{t}}$ & $-0.063(0.021)^{* * *}$ & $-0.058(0.028)^{* *}$ & $-0.033(0.020)^{*}$ \\
Palm oil price $_{\mathrm{t}}$ & $0.036(0.011)^{* * *}$ & $0.032(0.017)^{*}$ & $0.014(0.019)$ \\
GDP $_{\mathrm{t}}$ & $0.132(0.030)^{* * *}$ & $0.124(0.025)^{* * *}$ & $0.224(0.061)^{* * *}$ \\
Demand $_{\mathrm{t}-1}$ & $0.817(0.042)^{* * *}$ & $0.828(0.038)^{* * *}$ & $0.744(0.072)^{* * *}$ \\
\hline$R^{2}$ & 0.992 & 0.992 & 0.992
\end{tabular}

Notes: Small-sample standard errors are in parentheses. The OLS and 2SLS statistics use the Bartlett kernel with Newey-West automatic bandwidth selection. The instruments consist of the lagged endogenous variables: Supply $\mathrm{t}_{\mathrm{t}-1}$, Demand $\mathrm{D}_{\mathrm{t}-1}$, Cocoa price $\mathrm{t}_{\mathrm{t}-1}$, and Stocks $_{\mathrm{t}-1}$.

$* p<0.1 . * * p<0.05 . * * * p<0.01$.

\subsubsection{Cocoa price model}

The results of the cocoa price model estimations are displayed in Table 2.8. They show that the short-term stocks and consumption elasticities of the world cocoa price are -0.517 and 0.547. Furthermore, we find that their long-term counterparts are rather high with absolute 
values exceeding 1.5. In the domestic cocoa studies, these elasticities are usually insignificant, owing to the vast influence of the world cocoa price (Hameed, 2009).

In addition, the coefficient of the lagged cocoa price (0.660) indicates that the adjustment process to achieve the equilibrium is relatively slow. It is slower than for most agricultural commodities and is comparable to industrial commodities (Radetzki, 2008).

Table 2.8: Estimates of the cocoa price equation.

\begin{tabular}{llll}
\hline Variable & OLS & 2SLS & SUR \\
\hline Stocks $\mathrm{t}_{\mathrm{f}}$ & $-0.517(0.041)^{* * *}$ & $-0.701(0.064)^{* * *}$ & $-0.534(0.099)^{* * *}$ \\
Demand $_{\mathrm{t}}$ & $0.547(0.070)^{* * *}$ & $0.797(0.094)^{* * *}$ & $0.647(0.169)^{* * * *}$ \\
Cocoa price $_{\mathrm{t}-1}$ & $0.660(0.030)^{* * *}$ & $0.617(0.046)^{* * *}$ & $0.710(0.076)^{* * *}$ \\
\hline$R^{2}$ & 0.830 & 0.817 & 0.850
\end{tabular}

Notes: Small-sample standard errors are in parentheses. The OLS and 2SLS statistics use the Bartlett kernel with Newey-West automatic bandwidth selection. The instruments consist of the lagged endogenous variables: Supply $_{\mathrm{t}-1}$, Demand D $_{\mathrm{t}-1}$, Cocoa price $_{\mathrm{t}-1}$, and Stockst $\mathrm{D}_{\mathrm{t}-1}$.

$* p<0.1$. ** $p<0.05$. *** $p<0.01$.

\subsection{Conclusion}

The economic and population growth in Africa and Asia have largely boosted the world demand cocoa and triggered an extraordinary volatility in the world cocoa price in this new century. This price volatility makes the millions of cocoa farmers in the developing world highly vulnerable to poverty. A large volatility in the value of an agricultural commodity is linked to the inelasticity of its supply or demand. Therefore, we test the hypothesis that the price elasticities of the global cocoa supply and demand are low.

We describe the world cocoa market is described with three cointegration dynamic structural sub-models (supply, demand, and price) in addition to the market equilibrium condition identity. Integrating a number of variables from a global data set that covers half a century (1963-2013), we estimate the models with the OLS, 2SLS, and SUR methods. Furthermore, we employ rigorous unit root, cointegration, and instrumental variable testing.

Our results compare favorably with theory: all significant variables carry the a priori expected signs. Furthermore, we find that the world cocoa supply is extremely price-inelastic: the corresponding short- and long-run estimates are 0.07 and 0.57 . In addition, coffee appears to be a weak cocoa supply substitute. The price elasticity of global cocoa demand also falls 
into the extremely inelastic range: the short- and long-run estimates are -0.06 and -0.34 . Finally, palm oil seems to be a weak cocoa demand substitute.

Based on these empirical results, we consider the prospects for cocoa price stabilization. The cocoa price volatility resulting from factors above was treated with various unsuccessful methods in the past: planned economies, marketing boards, and explicit supply or price manipulations (Dand, 2011). These experiments caused inefficiencies, lead to market failures, and are unlikely to win wide support (Sarris and Hallam, 2006). In 1973, the International Cocoa Organization (ICCO) was established to manipulate the global cocoa buffer stocks and production to stabilize world cocoa price in a zone. However, it has been ineffective in maintaining the stability of cocoa prices due to insufficient funding as well as the absence of the biggest cocoa consumer, the United States (Dand, 2011). According to Piot-Lepetit and M'Barek (2011), a possible solution for reducing the price volatility would be the encouragement of crop diversification. This increases the price elasticity of cocoa supply by adjusting the effort and money allocation between the crops, thus decreasing price volatility.

\subsection{References}

Behnman, J., Adams, G. (1976): Econometric Models of World Agricultural Commodity Markets: Cocoa, Coffee, Tea, Wool, Cotton, Sugar, Wheat, Rice. Cambridge, MA: Ballinger.

Breusch, T.S., Pagan, A.R. (1980): The Lagrange multiplier test and its applications to model specification in econometrics. The Review of Economic Studies 47, 239-53.

Dand, R. (2011): The International Cocoa Trade. Sawston: Woodhead Publishing.

Eichenbaum, M., Hansen, L.P., Singleton, K.J. (1988): A time series analysis of representative agent models of consumption and leisure choice under uncertainty. The Quarterly Journal of Economics 103, 51-78.

Elliott, G., Rothenberg, T.J., Stock, J.H. (1996): Efficient tests for an autoregressive unit root Econometrica 64, 813-36.

Fountain, A.C., Hütz-Adams, F. (2015): Cocoa Barometer 2015. VOICE Network, The Netherlands.

Gilbert, C., Varangis, P. (2003): Globalization and International Commodity Trade with Specific Reference to the West African Cocoa Producers. NBER Working Paper No. 9668.

Greene, W. (2011): Econometric Analysis. Upper Saddle River, NJ: Prentice Hall. 
Hallam, D. (1990): Econometric Modelling of Agricultural Commodity Markets. London: Routledge.

Hameed, A.A.A., Hasanov, A., Idris, N., Abdullah, A.M., Arshad, F.M., M.N. Shamsudin (2009): "Supply and Demand Model for the Malaysian Cocoa Market" in Papers at the Workshop on Agricultural Sector Modeling in Malaysia: Quantitative Models For Policy Analysis, Johor Bahru, Malaysia, 26-28 October.

Hansen, L.P. (1982): Large sample properties of generalised method of moments estimators. Econometrica 50, 1029-54.

Hsiao, C. (1997a): Cointegration and Dynamic Simultaneous Equations Model. Econometrica $65,647-670$.

Hsiao, C. (1997b): Statistical Properties of the Two-Stage Least Squares Estimator Under Cointegration. The Review of Economic Studies 64, 385-398.

Hwa, E. (1979): Price Determination in Several International Primary Commodity Markets: A Structural Analysis. IMF Staff Papers, No. 26, 157-188.

Hwa, E. (1985): A Model of Price and Quantity Adjustments in Primary Commodity Markets. Journal of Policy Modeling 7, 305-338.

ICCO (2012): The World Cocoa Economy: Past and Present. London: International Cocoa Organization.

ICCO (2016): Quarterly Bulletin of Cocoa Statistics. London: International Cocoa Organization.

Kleibergen, F., Paap, R. (2006): Generalized reduced rank tests using the singular value decomposition. Journal of Econometrics 133, 97-126.

Kwiatkowski, D., Phillips, P.C.B., Schmidt, P., Shin, Y. (1992): Testing the null hypothesis of stationarity against the alternative of a unit root. Journal of Econometrics 54, 159-78.

Labys, W. (2006): Modeling and Forecasting Primary Commodity Prices. Burlington, VT: Ashgate.

Pesaran, M.H., Shin, Y., Smith, R.J. (2001): Bounds testing approaches to the analysis of level relationships. Journal of Applied Econometrics 16, 289-326.

Piot-Lepetit, I., M'Barek, R. (2011): Methods to Analyse Agricultural Commodity Price Volatility. New York, NY: Springer.

Radetzki, M. (2008): A Handbook of Primary Commodities in the Global Economy. Cambridge: Cambridge University Press. 
Sarris, A., Hallam, D. (2006): Agricultural Commodity Markets and Trade: New Approaches to Analyzing Market Structure and Instability. Cheltenham: Edward Elgar Publishing and FAO.

Shamsudin, M.N., Rosdi, M.L., Ann, C.T. (1993): "Malaysian Cocoa Market Model” in Agricultural Commodity Forecasting and Policy Modelling by F.M. Arshad, M.N. Shamsudin and S.H. Othman, Eds., Universiti Putra Malaysia: Serdang, 57-67.

Siswoputranto, F. (1995): Cocoa Cycles: The Economics of Cocoa Supply. Sawston: Woodhead Publishing.

Stock, J., Yogo, M. (2005): “Testing for Weak Instruments in Linear IV Regression.” In: Andrews, D. and Stock, J. (eds.): Identification and Inference for Econometric Models: Essays in Honor of Thomas Rothenberg, pp. 80-108. New York, NY: Cambridge University Press.

UNCTAD (2006): Market Information on Cocoa. Geneva: UNCTAD.

Uwakonye, M., Nazemzadeh, A., Osho, G.S., W.J. Etundi, W.J. (2004): Social welfare effect of Ghana cocoa price stabilization: time series projection and analysis. International Business \& Economics Research Journal 3, 45-54.

Zivot, E., Andrews, D. (1992): Further evidence on the Great Crash, the oil-price shock, and the unit-root hypothesis. Journal of Business \& Economic Statistics 10, 251-70. 


\title{
3. How can the productivity of Indonesian cocoa farms be increased? ${ }^{3}$
}

\begin{abstract}
This study investigates the Indonesian cocoa production to reveal the possibilities for poverty alleviation while considering the threats to environmental sustainability. We estimate, based on a large household panel data set and stochastic frontier analysis, the technical efficiency of cocoa production and decompose productivity growth. According to our results, the productivity of Indonesian cocoa farming increased by 75 percent between 2001 and 2013. Technical efficiency growth and the increased chemicals use supported by government subsidies were responsible for the majority of this gain. Furthermore, we find large distortions in the input allocations. Hence, policies that encourage the adjustment of the cocoa farms' input use would be highly beneficial. Moreover, because of the weather-induced volatility in cocoa production, policy makers should also promote investment in agricultural research and transfer of drought-resistant cocoa varieties to farmers. Additionally, the average efficiency of cocoa farmers is estimated to be around 50 percent. We find that farmers' educational attainment and their experience in cocoa farming are significant factors that can increase the efficiency levels.
\end{abstract}

Keywords: cocoa, Indonesia, productivity change decomposition, technical efficiency.

JEL codes: D24, O13, Q01, Q12.

\footnotetext{
${ }^{3}$ This paper is a joint work with Verina Ingram (Wageningen UR). We would like to thank Stephan von CramonTaubadel, Bernhard Brümmer, and Malte Ehrich for their comments. Furthermore, we are also grateful to Stephan Klasen for providing us the data set. Finally, this project would have been impossible without the funding from the German Research Foundation.
} 


\subsection{Introduction}

\subsubsection{Background}

Cocoa, one of the main ingredients of chocolate is primarily cultivated by smallholders in developing countries. Most of these producers live below the poverty line and have never tasted chocolate (Hütz-Adams and Fountain, 2012). After the Ivory Coast and Ghana, Indonesia is the third largest cocoa producer in the world with 10 percent of the global production (ICCO, 2016). Nearly 1.5 million Indonesian households depend on cocoa farming (ICCO, 2012). On the island of Sulawesi, which accounts for two thirds of Indonesia's cocoa production (Ministry of Agriculture, 2015), 60 percent of cocoa farmers were living below the World Bank poverty threshold of 1.90 US dollar per day in 2009 (van Edig et al., 2010).

Cocoa is consumed mainly by the developed countries such as the US and Germany (21 and 13 percent of the total net imports in 2012). The average chocolate consumption per capita in both countries is over 10 kilograms (ICCO, 2012). The global demand for cocoa grew steeply over the last 15 years. This growth was primarily due to the Asian and African countries (Squicciarini and Swinnen, 2016). The prospect for cocoa demand growth is still high in China and India because the average chocolate consumption there is under 1 kilograms per capita (ICCO, 2012). However, cocoa growing countries can barely meet this expanding demand due to lack of appropriate production procedures and resources (ICCO, 2016). This generated an imbalance between the cocoa supply and demand in the global market and, because of their low price elasticity (Tothmihaly, 2017), an increase and high volatility in world cocoa prices (Onumah et al., 2013b).

Cocoa demand can be met and the income of cocoa farmers can be improved by increasing the cocoa growing area, by increasing input use, or by increasing technical efficiency (Onumah et al., 2013b). Both in Indonesia and Africa, most expansion in the cocoa cultivation was achieved by the first route (Nkamleu et al., 2010). The increased cocoa prices, together with the incentives provided by government subsidies for the sector, triggered farmers to increase cocoa production by raising cultivated land. This led to the conversion of virgin tropical forests to cocoa plantations (Teal et al., 2006).

This procedure usually includes tree felling, slash-and-burning, followed by the planting of cocoa and other crop trees (for example, banana) together. The latter trees provide shade for the young cocoa plants for two years. After three years, the cocoa trees start to produce and until about 10 years after planting, production rises yearly (Dand, 2010). Then, 
the cocoa yield starts to decrease gradually because of the higher frequency of cocoa diseases, erosion, and the decrease of soil nutrients (Smaling and Dixon, 2006). Some 20 years after planting, cocoa farmers have to either invest in uprooting, soil improvement, replanting, and disease reduction or shift to a new area. In places with low population density, it is easier to move the cocoa production than to use the old growing area (Asase et al., 2009). Also, replanting is usually more costly for smallholders with regard of intermediate inputs, labor, crops risks, and capital demand.

As a consequence of acreage expansion, cocoa plantations are increasingly intruding into the Indonesian rainforest, which is a world biodiversity hotspot hosting a large number of endemic species (REDD, 2012). ${ }^{4}$ In Sulawesi, 80 percent of the rainforests were gone by 2010 causing, sometimes, irreversible losses of biodiversity (FAO, 2010). Findings from Frimpong et al. (2007) show a similar phenomenon in Africa.

Cocoa production can also be enhanced by increasing the cocoa yield with input intensification. Cocoa yields in Indonesia average just above 400 kilograms/hectare. This number is much lower than the potential 1500 kilograms/hectare based on the best performances of Indonesian cocoa farmers (ICCO, 2012). Various pests (mainly the vascular streak dieback and the cocoa pod borer) and the fact that most of the cocoa plants are more than 15 years old have contributed to the decline in cocoa yields (Ministry of Agriculture, 2015). In the face of this situation, the Indonesian Government announced the 3-year, 350million US dollar Gernas Pro Kakao revitalization program (KKPOD, 2013) for the cocoa industry in 2009. It was established to increase the adoption of pesticides and fertilizers to restore soil nutrients and the use of enhanced cocoa seedlings to boost productivity. However, the support of intensification and the ensuing increase in cocoa production can cause environmental deterioration and raise concerns about biodiversity conservation (Asare, 2005).

The third method to increase cocoa production is to improve technical efficiency. For environmental sustainability, this is the most desirable option. According to the Ministry of Agriculture (2015), the main causes of the low productive efficiency in Indonesia are aging farmers, aging farms, lack of knowledge, poor farming techniques, and capital problems (high bank interests). To tackle these issues, the government introduced a number of measures such

\footnotetext{
${ }^{4}$ Indonesia has only 1.2 percent of the world's land area. However, its forests host 11 percent of all plant species, 12 percent of all mammal species, 17 percent of all bird species, 16 percent of all reptile and amphibian species, 33 percent of all insect species, and 24 percent of all fungi species. In this country, 772 species are threatened or endangered, among them 147 mammal species. Moreover, 20 of Indonesia's 40 primate species have lost more than 50 percent of their original habitat in the last ten years, among them orangutans (FAO, 2010).
} 
as the formation of agricultural extension services and later the expansion of credit access (Ministry of Agriculture, 2015).

Negating the adverse environmental outcomes of the low productivity systems requires large investments from both the private and public sectors. The first important question for decision makers is to what extent and how cocoa cultivation can be made more technically efficient. The second question is how the proposed measures affect the environment.

\subsubsection{Contribution}

Our research investigates the scope for improving the efficiency of Indonesian cocoa production as a means of alleviating poverty and fostering environmental sustainability. We estimate based on household, agricultural, and environmental surveys and stochastic frontier analysis (Coelli et al., 2005), the technical efficiency of production and decompose the total factor productivity change. With the results, we aim to determine the magnitude of the attainable efficiency increases and the methods that can be used to attain them.

We extend the previous research on the technical efficiency of cocoa farming. Technical efficiency estimations are available for the large producing countries such as Ghana: Aneani et al. (2011), Besseah and Kim (2014), Danso-Abbeam et al. (2012), Kyei et al. (2011), Nkamleu et al. (2010), Ofori-Bah and Asafu-Adjaye (2011), Onumah et al. (2013a), Onumah et al. (2013b) and Nigeria: Adedeji et al. (2011), Agom et al.(2012), Amos (2007), Awotide et al. (2015), Nkamleu et al. (2010), Ogundari and Odefadehan (2007), Ogunniyi et al. (2012), Oladapo et al. (2012), Oyekale (2012). However, they all use cross-sectional data. With the information gain of our panel data, which contains 4 time periods over 13 years, we decompose the total factor productivity change and characterize inefficiencies more realistically. We can track changes in time and control for omitted and mismeasured variables to produce more reliable estimates (Hsiao, 2007). Furthermore, previous cocoa studies analyze the effect of shading trees and intercropping only on efficiency and this leads to inconclusive results (Besseah and Kim, 2014; Nkamleu et al., 2010; Ofori-Bah and Asafu-Adjaye, 2011). We include these variables in the production frontier because we assume that they have a direct effect on cocoa production.

In Indonesia, Effendi et al. (2013) assess the technical efficiency of cocoa smallholders. However, additionally to the previous issues, they do not include the Gernas Pro Kakao government program in their model and work with just a small sample size of 98. Table 3.A1 summarizes the estimated average technical efficiencies and the sample sizes in previous cocoa 
studies. With 1290 observations, our sample size is larger than in any previous study on the technical efficiency of cocoa production.

Our results can be used to inform policies and practices to sustainably improve yields and income, thus reducing deforestation. The estimates could tell us which investments produce the highest marginal benefits: for example, improving education, access to financing or to extension services, or fostering the formation of farmer groups (Ingram et al., 2014).

\subsection{Methodology}

\subsubsection{Stochastic frontier analysis}

Efficiency is the capability to maximize outputs given a level of inputs used in the production. Debreu (1951) introduced the first concept of creating a production frontier to measure efficiency. This has led to two main empirical methods for frontier estimation: the deterministic Data Envelopment Analysis (DEA) and the parametric Stochastic Frontier Analysis (SFA). We assess efficiency using the parametric method since it can differentiate between technical inefficiency and the effects of random shocks (Coelli et al., 2005). It is used by various researchers including Brümmer et al. (2006).

Based on Coelli et al. (2005), we can write the basic frontier model the following way:

$\ln y_{i}=\ln f\left(\boldsymbol{x}_{\boldsymbol{i}} ; \beta_{i}\right)+v_{i}-u_{i}$

where $y_{i}$ represents the output, $f\left(\boldsymbol{x}_{\boldsymbol{i}} ; \beta_{i}\right)$ denotes the production function at complete efficiency with $\boldsymbol{x}_{\boldsymbol{i}}$ as input vectors and $\beta_{i}$ as the parameters to be estimated, $v_{i}$ is a random error term independently and identically distributed as $N\left(0, \sigma_{v}^{2}\right)$, and $u_{i}$ is a non-negative unobservable term assumed to be independently and identically distributed as $N\left(0, \sigma_{u}^{2}\right)$ and independent of $v_{i}$. The last component measures the shortfall of the output from its maximum attainable level and, therefore, captures the effect of technical inefficiency. In this case, the technical efficiency of farm $i$ can be written as

$T E_{i}=\exp \left(-u_{i}\right)$

The parameters of the production function in equation (3.1) must theoretically satisfy the regularity conditions: monotonicity and curvature (Coelli et al., 2005). We specify a translog production function. In this function, the inclusion of squared and interaction terms provides a high level of flexibility. 
The extension of our model in equation (3.1) enables us to measure how household characteristics influence efficiency. We choose a specification proposed by Coelli et al. (2005), which models the technical inefficiency $\left(u_{i}\right)$ as a function of several variables:

$u_{i}=\varphi Z_{i}+e_{i}$

where $Z_{i}$ is a vector with farm-specific factors that are assumed to affect efficiency, $\varphi$ is a vector with the parameters to be estimated, and $e_{i}$ is an independent and identically distributed random error term. If the estimated parameter is positive, then the corresponding variable has a negative influence on technical efficiency.

\subsubsection{Estimation issues}

We have to look at four issues of the statistical inference: the estimation technique of the frontier model, the estimation technique of the inefficiency model, the estimation with panel data, and endogeneity.

First, standard techniques such as OLS are inappropriate for estimating the unobservable frontier function from observable input and output data because they focus on describing average relationships. Therefore, we base the parameters on ML. Before carrying out the estimation, each variable is normalized by its sample mean. Given this transformation, the first-order coefficients can be viewed as partial production elasticities at the sample mean (Coelli et al., 2005).

Regarding the second inference issue, Greene (2008) points out that researchers often incorporate inefficiency effects using two-step estimation techniques. In the first step, the production function is specified and the technical inefficiency is predicted. The second step regresses the assumed characteristics on the predicted inefficiency values via OLS. This approach leads to severely biased results. The issue is addressed by using a simultaneous estimation that includes the efficiency effects in the production frontier estimation.

With the availability of a large panel dataset, we can characterize inefficiencies more realistically. However, panel data also causes some issues in the estimation. The common feature of pooled SFA models is that the intercept is the same across productive units, thus generating a misspecification bias in presence of unobserved time-invariant variables. As a consequence, the inefficiency term may capture the influences of these variables, generating biased results. Greene (2008) approaches this problem with unit-specific intercepts. In contrast to the pooled model, his true fixed-effect (TFE) and true random-effect (TRE) panel 
specifications allow to differentiate between time-varying inefficiency and unit-specific unobservable time-invariant heterogeneity. The TFE model assumes the non-randomness while the TRE model the randomness of the unobserved unit-specific heterogeneity.

The ML estimation of the TFE specification needs the solution of the so-called incidental parameters problem. This inferential issue arises when the length of the panel is relatively small compared with the number of units, causing the inconsistent estimation of the parameters. As shown in Belotti and Ilardi (2012), the dummy variable approach for estimation appears to be suitable only when the panel length is large enough $(T>10)$. Our sample is highly unbalanced and contains just 5 time periods. The common method to solve this problem is based on the elimination of the individual effects through within transformation, i.e., working with the deviations from the means. The consistent estimation of the TFE variant is proposed by Belotti and Ilardi (2012). However, the disadvantage of these methods is that they do not permit the use of time-invariant factors such as gender and education, which we assume are significant determinants of inefficiency. In our estimations, we use both the TRE and TFE specifications and choose between the two according to the Mundlak (1978) approach.

As pointed out by Greene (2008), neither the pooled nor the "true" formulation is completely satisfactory. Although the "true" model may appear to be the most flexible choice, it can be argued that a portion of the time-invariant unobserved heterogeneity does belong to inefficiency or that these two components should not be disentangled at all. Therefore, we estimate both extremes: the Coelli et al. (2005) model in which all timeinvariant unobserved heterogeneity is considered as inefficiency and the TRE/TFE specification in which all time-invariant unobserved heterogeneity is ruled out from the inefficiency component.

Finally, the direct inference of a stochastic frontier may be susceptible to simultaneity bias that occurs if each farmer selects the output and input levels to maximize profit for given prices. But no simultaneity bias ensues if farmers maximize expected rather than actual profit (Coelli et al., 2005). We make this reasonable assumption meaning that technical efficiency is unknown to producers before they make their input decisions. Thus, the quantities of variable inputs are largely predetermined and uncorrelated with technical efficiency. 


\subsubsection{Total factor productivity change}

We base our calculations of total factor productivity (TFP) change on Brümmer et al. (2006). The TFP change is decomposed into technical efficiency change (TEC), scale efficiency change (SEC), allocative efficiency change (AEC), and technical change (TC) to control for productivity adjustments connected to these factors:

$T F P C_{1}=T E C+S E C+A E C+T C$

According to Zhu and Lansink (2010), we can disaggregate technical efficiency change further:

$T E C=T E C_{E V}+T E C_{T C}+T E C_{U F}$

where $T E C_{E V}, T E C_{T C}$, and $T E C_{U F}$ are effects of the change in various inefficiency model variables, technical change of the inefficiency component, and unspecified factors.

Because we have dummy variables that further describe the production technology, we also calculate an augmented TFP change that includes two additional components connected to technology:

$T F P C_{2}=T F P C_{1}+T_{I U}+T_{G K}$

where $T_{I U}$ and $T_{G K}$ are contributions from input use change and the Gernas Pro Kakao program. Thus, we arrive at the following detailed decomposition:

$T F P C_{2}=T E C_{E V}+T E C_{T C}+T E C_{U F}+T C+T_{G K}+T_{W P}+S E C+A E C$

\subsection{Empirical specification}

\subsubsection{Production frontier model}

The translog production function for the cocoa farm $i$ with four inputs, and seven dummy variables is specified as:

$$
\begin{aligned}
& \ln y_{i t}=\alpha_{0}+\sum_{k=1}^{4} \beta_{k} \ln x_{k i t}+\frac{1}{2} \sum_{j=1}^{4} \sum_{k=1}^{4} \beta_{j k} \ln x_{j i t} \ln x_{k i t}+\sum_{j=1}^{7} \delta_{j} D_{j i t}+\sum_{j=1}^{3} \theta_{j} T_{j t}+ \\
& v_{i t}-u_{i t}
\end{aligned}
$$

where $y_{i}$ is the amount of cocoa beans harvested in kilograms, $x_{k}$ is a vector of observations on inputs, $D_{j}$ is a vector of observations on dummy variables characterizing the production process, $T_{j}$ represents time dummies controlling for unobservable influences that vary between the years, such as technical change, the $\alpha$ 's, $\beta$ 's, $\delta$ 's, and $\theta$ 's are unknown parameters to be estimated, $v$ is a random error term, and finally $u$ is a non-negative 
unobservable variable describing inefficiency. We do not include tree biomass and other crop outputs in the production function because of the small number of forest and other crop trees on the cocoa farms in our sample area.

We draw on Nkamleu et al. (2010) and Ofori-Bah and Asafu-Adjaye (2011) to identify the production factors that we consider in our analysis (Table 3.1). The variables used in these and other previous cocoa technical efficiency studies are summarized in Table 3.A2. According to the classical model, with a given technology, output is determined by land $\left(x_{1}\right)$, labor $\left(x_{2}\right)$, and intermediate inputs $\left(x_{3}\right)$. In our model, land indicates the total cultivated cocoa area measured in ares, while labor is calculated in Rupiah and involves all harvest and maintenance tasks on the cocoa farm. ${ }^{5}$ We assume that the latter is a good approximation for quality-adjusted labor input. Furthermore, intermediate inputs are measured as the cost of fertilizers, pesticides, transport, and processing in Rupiah. We aggregate these inputs to avoid multicollinearity (Brümmer et al., 2006) and presume that the value of material inputs reflects the quality of inputs better than quantity because of the different concentrations of active components and nutrients (Wollni and Brümmer, 2012). The age of cocoa trees $\left(x_{4}\right)$ is also added to the classical production factors. It influences the cocoa output the following way. Cocoa trees begin to produce pods only from about three years after planting, reach full bearing capacity around the age of 10 years, and their output starts to diminish gradually thereafter (Dand, 2010). In some previous studies, the sign of this variable is positive and in other studies, negative depending on the average tree age in the sample (Table 3.A2).

We enhance the basic production frontier with seven dummy variables to describe the cocoa cultivation process more accurately (Wollni and Brümmer, 2012). Because zero values of input variables can cause biased inference, a dummy variable is added that equals one if intermediate inputs equal zero $\left(D_{1}\right)$. The second dummy variable is equal to one if the smallholder participated in the Gernas Pro Kakao government program. The objective of this program is to rehabilitate cocoa farms and expand intensification by providing easier access to inputs (KKPOD, 2013). The third dummy variable equals one if hybrid cocoa variety is cultivated by the farmer. We anticipate that hybrids produce higher yields than the local varieties (Dand, 2010). Moreover, the pruning of cocoa trees $\left(D_{4}\right)$ is expected to improve output levels because it gives room for sufficient sunlight that stimulates the growth of

\footnotetext{
${ }^{5} 1$ hectare equals 100 ares. During the last 15 years, 1 euro fluctuated between 10000 and 17000 Indonesian Rupiahs.
} 
flowers. Additionally, it keeps the farm environment clean, preventing the development and spread of pests (Danso-Abbeam et al., 2012; Effendi et al., 2013; Amos, 2007). Furthermore, a dummy for yield loss is used to reflect the effect of pests and adverse weather on the cocoa harvest quantity.

Table 3.1: Description of the cocoa farm variables.

\begin{tabular}{|c|c|}
\hline Variable & Description \\
\hline \multicolumn{2}{|l|}{ Output } \\
\hline Cocoa & Cocoa quantity harvested on the farm (kilograms) \\
\hline \multicolumn{2}{|l|}{ Input } \\
\hline Tree age & Average cocoa tree age (years) \\
\hline Land & Total area planted with cocoa (ares) \\
\hline Labor & Maintenance and harvest labor costs for the cocoa farm (constant 2001 Rupiah) \\
\hline Intermediate inputs & Fertilizer, pesticide, transport, and processing costs for the farm (constant 2001 Rupiah) \\
\hline \multicolumn{2}{|l|}{ Technology } \\
\hline No input & Dummy, $1=$ household did not use intermediate inputs for the cocoa farm \\
\hline Gernas & Dummy, $1=$ household joined the Gernas Pro Kakao program in the last 3 years \\
\hline Hybrid & Dummy, 1 = hybrid cocoa variety was cultivated by the farmer \\
\hline Pruning & Dummy, $1=$ cocoa trees were pruned \\
\hline Intercrop & Dummy, $1=$ there was intercropping on the cocoa farm \\
\hline Shade 60 & Dummy, $1=$ shade level of the cocoa farm is larger than 60 percent \\
\hline Crop loss & Dummy, 1 = cocoa yield loss because of adverse weather or pests \\
\hline \multicolumn{2}{|l|}{ Inefficiency } \\
\hline Male & Dummy, 1 = household head is male \\
\hline Age & Age of the household head (years) \\
\hline High school & Dummy, 1 = household head completed the senior high school \\
\hline Extension & Dummy, 1 = household head had agricultural extension contacts \\
\hline Credit & Dummy, 1 = household head obtained credit in the last 3 years \\
\hline Association & Dummy, $1=$ household head was member in a cocoa cooperative in the last 3 years \\
\hline \multicolumn{2}{|l|}{ Time } \\
\hline Year 2004 & Dummy, $1=$ observation is in 2004 \\
\hline Year 2006 & Dummy, $1=$ observation is in 2006 \\
\hline Year 2013 & Dummy, $1=$ observation is in 2013 \\
\hline
\end{tabular}
Notes: All variables refer to the last 12 months with the mentioned exceptions. Labor and intermediate input costs are adjusted for inflation with the Indonesian Consumer Price Index (2001=1.00).

Some cocoa is grown in an agroforestry or an intercropping system (Ofori-Bah and Asafu-Adjaye, 2011). Ruf and Zadi (1998) and Asare (2005) suppose that cocoa yields can be maintained in the long run only with the use of forest tree species in cocoa cultivation. Cocoa agroforests also support conservation policies because they connect rainforest areas and 
provide habitat for native plants and animals. However, the influence of shading trees on cocoa yields is highly debated. Although some papers report the advantages of these trees because they decrease plant stress, others provide evidence that shade can limit cocoa yields (Frimpong et al., 2007). The current consensus on this issue implies that shade starts to reduce cocoa yields beyond a level of around 30 percent. Following Bentley et al. (2004), we add a sixth dummy variable to our model that captures the influence of the high shade (larger than 60 percent) production system and expect the sign to be negative.

To assess the effect of crop diversification on cocoa production (Ofori-Bah and AsafuAdjaye, 2011), a seventh dummy variable for intercropping is also added to the model. Farmers can grow a variety of fruit-bearing trees to help cope with the volatile cocoa prices by supplementing their income. In Indonesia, banana and coconut are mainly intercropped with cocoa at its fruit-bearing age (Ministry of Agriculture, 2015). But crop diversification has also another advantage. An increasing number of studies demonstrate that intercropping improves erosion control (soil and water retention), nutrient cycling, carbon dioxide capture, biodiversity, and the relationship of fauna and flora (Scherer-Lorenzen et al., 2005; Gockowski and Sonwa, 2011). Therefore, interplanting is often supported to take advantage of the mutualism between different plants and to compensate for the low level of intermediate inputs (Pretzsch, 2005). We anticipate that intercropping has a positive effect on cocoa yields.

\subsubsection{Inefficiency model}

In addition to the production frontier model above, we specify the following inefficiency equation for cocoa farm $i$ :

$u_{i t}=\varphi_{0}+\sum_{j=1}^{6} \varphi_{j} Z_{j i t}+\sum_{j=1}^{3} \omega_{j} T_{j t}+e_{i t}$

where $u$ are the inefficiency estimates that follow a truncated normal distribution (Coelli et al., 2005), $Z_{j}$ is a vector of observations on six factors that are expected to affect the efficiency level, $T_{j}$ again denotes the three time dummies that account for variations in mean efficiency between the years, the $\varphi$ 's and $\omega$ 's are the unknown parameters to be estimated, and $e$ is the random error term. We include explanatory variables in the inefficiency model that express the management skills of cocoa smallholders and their access to productive resources and knowledge (Wollni and Brümmer, 2012).

The first two explanatory variables reflect the household structure (Wollni and Brümmer, 2012). First, we expect that it is more difficult for households with female heads 
to access markets. They are also usually widows, which can limit labor availability to accomplish agricultural work timely (Onumah et al., 2013b). As a result, we expect femaleheaded households to display lower efficiency levels (Table 3.A2).

Furthermore, farmer age is thought to increase technical inefficiency partly because older smallholders take up less likely the latest technologies (Coelli et al., 2005). They are also less energetic than their younger counterparts. However, Onumah et al. (2013b) suggest that older farmers might develop a higher technical efficiency level than younger farmers because of their longer farming experience.

The next variable refers to the inner capabilities of the household head (Ofori-Bah and Asafu-Adjaye, 2011). The education dummy equals one if the head of the household completed high school. We expect that it affects positively the management skills of the cocoa farmers and hence efficiency (Ingram et al., 2014). However, a number of papers show that smallholders with higher educational attainment reveal lower technical efficiency levels (Teal et al., 2006). An explanation of these findings is that smallholders with higher educational levels have more likely additional sources of income and they concentrate more on these off-farm activities than on the farm management.

The last three variables indicate the external support for cocoa farming households (Nkamleu et al., 2010; and Ofori-Bah and Asafu-Adjaye, 2011). Contacts with extension agents are commonly considered to influence efficiencies positively since the information circulated in extension services should enhance farming methods (Dinar et al., 2007). However, some factors such as other information sources, the ability and willingness of smallholders to employ the distributed information, and the quality of agricultural extension services can confound the results of extension contacts (Feder et al., 2004; Table 3.A2).

Furthermore, the credit dummy variable indicates whether the cocoa farmer has access to credit. If smallholders can buy intermediate inputs with credit when required and not just when they have sufficient cash, then input use can become more optimal. Consequently, the economic literature underlines the failure of credit markets as the cause of non-profit maximizing behaviors and poverty traps (Dercon, 2003). Additionally, reducing capital constraints decreases the opportunity cost of intermediate inputs relative to family labor and allows the application of labor-saving technologies such as enhanced cocoa hybrid-fertilizer methods (Nkamleu et al., 2010). Thus, many economists view the spread of feasible agricultural credit services crucial for raising the productivity of labor and land (Zeller et al., 1997). 
Finally, we include a dummy variable for membership in a cocoa association. We expect that associations assist smallholders in reducing transaction costs and, therefore improve their access to various resources and increase their technical efficiency (Binam et al., 2004; Hafid et al., 2013).

\subsection{Data description}

\subsubsection{Data sources}

We acquire the data using the STORMA (Stability of Rainforest Margins in Indonesia) project survey data from Göttingen. ${ }^{6}$ This project conducted four rounds of household and agricultural surveys in Indonesia in 2001, 2004, 2006, and 2013. The survey data were collected from 722 cocoa farmer households in 15 random villages near the Lore Lindu National Park in Central Sulawesi province. This province is the second largest cocoa producer in Indonesia with 17 percent of the Indonesian production in 2014 (Ministry of Agriculture, 2015). The park provides habitat for some of the most unique animal and plant species in the world. However, the increase of land used for farming is threatening its integrity.

In each sample village, the head of the village and the leaders of the hamlets listed the names of every household head living in the village. Next, the sample households were randomly selected from these lists and interviewed using standardized structured questionnaires. The researchers edited the questionnaire in English first, then translated it into Indonesian and tested it with a pilot survey. The interviews lasted, on average, about 2 hours. Because some farmers cultivated several cocoa plots simultaneously, output and input details were collected at plot level to increase data accuracy. In the four rounds, those panel and splitoff households were tracked who were still living in those 15 villages.

\subsubsection{Descriptive statistics}

Table 3.2 shows the summary statistics of the independent and dependent variables in the production frontier and inefficiency equations. The dataset is an unbalanced panel of 722 cocoa farms and contains 1290 observations. Therefore, on average, one farm appears in just 1.8 rounds.

\footnotetext{
${ }^{6}$ Funded by the German Research Foundation (DFG).
} 
Over the 12 years, the average output of the cocoa farms rose almost twofold, while the average farm size remained almost constant at around 0.75 hectares, which is about one third of the African average (Nkamleu et al., 2010; ICCO, 2012). This resulted in an almost twofold increase in the average cocoa yield, which was in 2013 with around $600 \mathrm{~kg} / \mathrm{hectare}$ above the world average of about $500 \mathrm{~kg} /$ hectare and well above the Indonesian average of about 400 $\mathrm{kg} /$ hectare (ICCO, 2016). We can list two reasons for this. First, cocoa trees reached their most productive age around 2011 and they were, on average, 12 years old in 2013. According to Nkamleu et al. (2010), this is just one half of the African average because of the later start of cocoa cultivation in Indonesia. Second, the use of labor and intermediate inputs (mostly, fertilizer and pesticide) increased more than threefold and the ratio of cocoa farms that used both increased from 15 percent to 42 percent. The Gernas Pro Kakao government program implemented in 2009 could have contributed to this phenomenon by providing easier access to intermediate inputs (KKPOD, 2013). However, the use of labor and intermediate inputs is still just one third and one half of the African average (Nkamleu et al., 2010; Maytak, 2014).

Over the years, we could also observe the spread of hybrid cocoa varieties: in 2013, they were planted on 10 percent of the cocoa farms. This is significantly larger than the world average of 5 percent (ICCO, 2012). Furthermore, the practice of tree pruning fluctuated around 95 percent in the last three survey rounds which is much higher than in Africa (Maytak, 2014). According to the data, cocoa in our sample area is cultivated mostly in a full-sun monoculture system, in contrast to Africa (Gockowski and Sonwa, 2011; Nkamleu et al., 2010). The ratio of intercropping decreased to 8 percent in 2013 , while the share of high shade farms stood at just 2 percent. Finally, in accordance with the world average, 43 percent of the cocoa farms experienced significant yield losses due to adverse weather and pests (Dand, 2010).

The statistics of the inefficiency variables point to a slow cultural change in our sample area, to more female household heads. The share of female household heads stood at 10 percent in 2013, which is consistent with past studies that show cocoa cultivation as a male-dominated livelihood (Nkamleu et al., 2010; Maytak, 2014). Moreover, the age and the educational attainment of the average household head increased considerably over the years. The average farmer age of 49 years in 2013 is consistent with data collected by Nkamleu et al. (2010) and Vigneri (2007). Furthermore, we do not observe an increase in extension services from the initial 25 percent but do see that credit access rose dramatically from almost zero to 23 percent. Finally, in 2013 about every third household was member of a cocoa farmer group. All the last three statistical values are close to the African averages (Nkamleu et al., 2010). 
Table 3.2: Summary statistics of the cocoa farm variables.

\begin{tabular}{|c|c|c|c|c|c|c|c|c|c|c|}
\hline \multirow{2}{*}{ Variable } & \multicolumn{2}{|l|}{2001} & \multicolumn{2}{|l|}{2004} & \multicolumn{2}{|l|}{2006} & \multicolumn{2}{|l|}{2013} & \multicolumn{2}{|l|}{ Pooled } \\
\hline & Mean & SD & Mean & SD & Mean & SD & Mean & SD & Mean & SD \\
\hline \multicolumn{11}{|l|}{ Output } \\
\hline Cocoa & 315 & 464 & 379 & 618 & 300 & 328 & 607 & 729 & 427 & 589 \\
\hline \multicolumn{11}{|l|}{ Input } \\
\hline Tree age & & & 6.9 & 3.8 & 7.2 & 4.3 & 12.0 & 6.5 & & \\
\hline Land & 75 & 67 & 73 & 59 & 72 & 57 & 77 & 70 & 74 & 64 \\
\hline Labor & 43838 & 139602 & 58497 & 257185 & 64283 & 195650 & 338792 & 822868 & 157764 & 535064 \\
\hline Int. inputs & 152520 & 307663 & 122226 & 232994 & 77799 & 226500 & 319243 & 701444 & 185231 & 476924 \\
\hline \multicolumn{11}{|l|}{ Technology } \\
\hline No input & 0.85 & 0.36 & 0.86 & 0.35 & 0.79 & 0.41 & 0.58 & 0.49 & 0.74 & 0.44 \\
\hline Gernas & 0 & 0 & 0 & 0 & 0 & 0 & 0.14 & 0.35 & 0.05 & 0.22 \\
\hline Hybrid & & & 0.03 & 0.16 & 0.11 & 0.31 & 0.10 & 0.31 & & \\
\hline Pruning & & & 0.95 & 0.22 & 0.97 & 0.18 & 0.93 & 0.26 & & \\
\hline Intercrop & & & 0.16 & 0.36 & 0.11 & 0.32 & 0.08 & 0.27 & & \\
\hline Shade 60 & & & & & & & 0.02 & 0.14 & & \\
\hline Crop loss & & & & & & & 0.43 & 0.50 & & \\
\hline \multicolumn{11}{|l|}{ Inefficiency } \\
\hline Male & 0.99 & 0.12 & 0.97 & 0.18 & 0.93 & 0.25 & 0.90 & 0.30 & 0.94 & 0.24 \\
\hline Age & 45 & 14 & 47 & 14 & 46 & 14 & 49 & 15 & 47 & 14 \\
\hline High school & 0.12 & 0.33 & 0.15 & 0.36 & 0.19 & 0.40 & 0.17 & 0.38 & 0.17 & 0.37 \\
\hline Extension & 0.31 & 0.46 & 0.25 & 0.44 & 0.22 & 0.41 & 0.25 & 0.43 & 0.25 & 0.43 \\
\hline Credit & & & 0.01 & 0.09 & 0.09 & 0.28 & 0.23 & 0.42 & & \\
\hline Association & & & & & & & 0.36 & 0.48 & & \\
\hline \multicolumn{11}{|l|}{ Time } \\
\hline Year 2004 & 0 & 0 & 1 & 0 & 0 & 0 & 0 & 0 & 0.19 & 0.40 \\
\hline Year 2006 & 0 & 0 & 0 & 0 & 1 & 0 & 0 & 0 & 0.29 & 0.45 \\
\hline Year 2013 & 0 & 0 & 0 & 0 & 0 & 0 & 1 & 0 & 0.36 & 0.48 \\
\hline$N$ & & 207 & & 251 & & 372 & & 460 & & 1290 \\
\hline
\end{tabular}

\subsection{Results and discussion}

\subsubsection{Production frontier}

Table 3.3 displays the parameter estimates of the production frontiers. Because the Mundlak (1978) approach selects the random-effect specification over the fixed-effect model, we include only the random-effect results in this table. To check for the correct functional form of the models, we use likelihood ratio (LR) tests and the Akaike Information Criterion (AIC). 
They suggest that the Cobb-Douglas production function is preferred with our panel data and the translog function with the 2013 data. Thus, we report only these estimation results.

For the translog functional form, regularity properties must be checked after estimation since they are not automatically satisfied (Wollni and Brümmer, 2012). Therefore, we test for monotonically increasing marginal products and decreasing marginal returns regarding tree age, land, labor, and intermediate inputs in the 2013 model. The first-order coefficients are interpreted as partial output elasticities at the sample mean because we mean-correct each variable. We find both positive elasticities and diminishing marginal productivities at the sample mean. The monotonicity assumptions are violated in less than 1 percent of the observations for land, labor, and intermediate inputs but in 57 percent of the cases for tree age. We can explain the latter by the fact that, in 2013, the average age of cocoa trees was a little higher than their most productive age.

In the pooled panel model, the output elasticities of land, labor, and intermediate inputs are $0.622,0.118$, and 0.079 . We employ a t-test to evaluate whether the elasticity of scale $(0.819)$ at the sample mean significantly differs from one. The null hypothesis of constant returns to scale is rejected at the 5 percent level, according to the test results. This implies that cocoa production exhibits a diminishing returns to scale. Normally, undertakings with this characteristics are viewed as too big. However, the average cocoa farm size in our sample is smaller than one hectare. A plausible cause of the diminishing return to scale can be some impediments to growth (Brümmer et al., 2006).

Additionally, various dummy variables are incorporated into the models to describe cocoa farming more accurately. The variable "No input" is negative and significant at the 1 percent level. This means that, as anticipated, farms not using intermediate inputs have lower cocoa output levels. Furthermore, the variable "Gernas" indicates that smallholders who participated in the Gernas Pro Kakao government program achieve higher cocoa output levels. Finally, the negative signs of the 2004 and 2006 year dummies reflect lower cocoa production levels in these two years compared with the other years. This is the consequence of an exceptionally strong negative El Niño weather effect between 2004 and 2006.

The outcomes of the true random effect model are similar to pooled panel model. In the 2013 model, the square of the tree age variable is significant and negative. This points to the maturing and aging process of the cocoa trees. Furthermore, the output elasticities of land, labor, and intermediate inputs are $0.505,0.257$, and 0.088 . According to the t-test results, the scale elasticity amounts to 0.850 and significantly differs from one. Therefore, we can also conclude here that cocoa farms exhibit a decreasing returns to scale. Finally, all dummy 
variables of the 2013 model confirm the expected signs, but two of them are not significant. Our findings show the positive effect of intermediate input use, pruning, and the Gernas Pro Kakao program, but the negative effect of high shade on cocoa production.

Table 3.3: Parameter estimates of the cocoa production frontier models.

\begin{tabular}{|c|c|c|c|}
\hline Variable & Pooled panel model & TRE panel model & 2013 model \\
\hline \multicolumn{4}{|l|}{ Input } \\
\hline ln Tree age & & & $0.071(0.086)$ \\
\hline ln Land & $0.622(0.033)^{* * *}$ & $0.616(0.034)^{* * *}$ & $0.505(0.062)^{* * *}$ \\
\hline ln Labor & $0.118(0.028)^{* * *}$ & $0.123(0.028)^{* * *}$ & $0.257(0.051)^{* * *}$ \\
\hline ln Int. inputs & $0.079(0.026)^{* * *}$ & $0.081(0.026)^{* * *}$ & $0.088(0.045)^{* *}$ \\
\hline $0.5(\ln \text { Tree age })^{2}$ & & & $-0.584(0.154)^{* * *}$ \\
\hline $0.5(\ln \text { Land })^{2}$ & & & $0.006(0.072)$ \\
\hline $0.5{\text { (ln Labor })^{2}}^{2}$ & & & $0.002(0.096)$ \\
\hline 0.5 (ln Int. inputs $)^{2}$ & & & $-0.010(0.054)$ \\
\hline ln Tree age $*$ ln Land & & & $0.285(0.093)^{* * *}$ \\
\hline ln Tree age $* \ln$ Labor & & & $-0.210(0.095)^{* *}$ \\
\hline $\ln$ Tree age $* \ln$ Int. inputs & & & $-0.099(0.070)$ \\
\hline $\ln$ Land $* \ln$ Labor & & & $-0.038(0.094)$ \\
\hline ln Land $*$ ln Int. inputs & & & $0.070(0.052)$ \\
\hline $\ln$ Labor $* \ln$ Int. inputs & & & $0.022(0.035)$ \\
\hline \multicolumn{4}{|l|}{ Technology } \\
\hline No input & $-0.531(0.058)^{* * *}$ & $-0.506(0.059)^{* * *}$ & $-0.389(0.114)^{* * *}$ \\
\hline Gernas & $0.359(0.145)^{* *}$ & $0.308(0.141)^{* *}$ & $0.323(0.122)^{* * *}$ \\
\hline Hybrid & & & $0.170(0.154)$ \\
\hline Pruning & & & $0.494(0.171)^{* * *}$ \\
\hline Intercrop & & & $0.058(0.232)$ \\
\hline Shade 60 & & & $-0.422(0.208)^{* *}$ \\
\hline Crop loss & & & $-0.144(0.087)^{*}$ \\
\hline \multicolumn{4}{|l|}{ Time } \\
\hline Year 2004 & $-0.201(0.117)^{*}$ & $-0.235(0.116)^{* *}$ & \\
\hline Year 2006 & $-0.410(0.091)^{* * *}$ & $-0.405(0.091)^{* * *}$ & \\
\hline Year 2013 & $0.130(0.143)$ & $0.182(0.141)$ & \\
\hline Constant & $1.061(0.087)^{* * *}$ & $1.004(0.090)^{* * *}$ & $0.419(0.195)^{* *}$ \\
\hline \multicolumn{4}{|l|}{ Variance } \\
\hline$\sigma_{\mathrm{u}}$ & $2.258(0.377)^{* * *}$ & $2.301(0.411)^{* * *}$ & $1.633(0.313)^{* * *}$ \\
\hline$\sigma_{\mathrm{v}}$ & $0.535(0.039) * * *$ & $0.475(0.048)^{* * *}$ & $0.493(0.065)^{* * *}$ \\
\hline$R T S$ & 0.819 & 0.820 & 0.850 \\
\hline
\end{tabular}

Notes: Robust standard errors are in the parentheses. $*: \mathrm{p}<0.10, * *: \mathrm{p}<0.05, * * *: \mathrm{p}<0.01$. 


\subsubsection{Efficiency levels}

Generalized likelihood ratio tests are employed to evaluate whether average response functions would fit the models or inefficiency effects are present in the models. We reject the null hypothesis for all three specifications at the 1 percent level, which means that the stochastic frontier model represents the data better than the OLS model.

Table 3.4 documents the average annual rates of technical efficiency, while Figure 3.A1 presents the efficiency distributions of the sample farms. Based on the panel models, the mean technical efficiency of cocoa farmers is estimated to be around 50 percent, but the range is very wide (1-90) and many scores are inside the bottom quarter of the range of the distribution. This means that most cocoa farmers have an ample scope to expand cocoa output without increasing input use. African cocoa farmers (Table 3.A1) seem to have higher technical efficiencies which can be partly explained by the much longer cultivation of cocoa on the African continent. In terms of technical efficiency change over time, we find an overall increasing trend. This is not surprising, since cocoa production was introduced in Indonesia only in the 1990s and farmers had to learn to know-hows of cultivation.

Table 3.4: Descriptive statistics of the cocoa farm efficiency estimates (percentages).

\begin{tabular}{lrrrrrrrrrrrr}
\hline \multirow{2}{*}{ Year } & \multicolumn{3}{l}{ Pooled panel model } & \multicolumn{4}{c}{ TRE panel model } & \multicolumn{3}{c}{2013 model } \\
\cline { 2 - 12 } & Mean & SD & Min & Max & Mean & SD & Min & Max & Mean & SD & Min & Max \\
\hline 2001 & 36 & 24 & 1 & 83 & 37 & 24 & 1 & 86 & & & \\
2004 & 46 & 22 & 1 & 87 & 48 & 24 & 1 & 89 & & & \\
2006 & 51 & 22 & 1 & 83 & 52 & 23 & 1 & 85 & & & \\
2013 & 50 & 22 & 2 & 88 & 51 & 23 & 2 & 90 & 50 & 22 & 3 \\
$2001-2013$ & 47 & 23 & 1 & 88 & 49 & 24 & 1 & 90 & & & \\
\hline
\end{tabular}

\subsubsection{Inefficiency effects}

Table 3.5 presents the results of the inefficiency model estimations: both the estimated coefficients and the corresponding marginal effects at the means. For dummy variables, the marginal effects are calculated for a discrete change from zero to one. A negative sign indicates that the variable in question has a negative influence on inefficiency, which means a positive influence on efficiency. We check the joint significance of the possible inefficiency effects with likelihood ratio tests. Based on the results, we reject at the 1 percent level for all three models that all inefficiency variables are insignificant. 
In the panel models, the cocoa farmers' age and the year dummies are the only significant factors that affect the productive efficiencies. As anticipated, efficiency increases with farmer age, which is also a proxy for experience in cocoa cultivation in our study. According to our model, every additional year provides a 0.7 percent increase in technical efficiency, on average. Furthermore, the significant year dummies identify an overall increasing trend in technical efficiency. The 2013 model finds an additional significant factor: educational attainment. As expected, a higher educational level enhances an individual's understanding of farming.

Finally, we find that credit access, extension services, and farmer associations do not significantly affect efficiency. These results are inconsistent with many African cocoa studies which show positive linkages (Table 3.A2). For example, many economists view the spread of feasible agricultural credit services crucial for raising technical efficiency (Zeller et al, 1997). The limited effect of agricultural extension programs on efficiency can be due to the inherent deficiencies of public information systems, flawed service design ("top-down" manner), or bureaucratic inefficiency (Nkamleu et al., 2010). Furthermore, the ineffectiveness of farmer groups can be attributed to the missing social capital, that is, the lack of assistance to each other in the times of need (Ingram et al., 2014).

Table 3.5: Estimates and average marginal effects of the cocoa farm inefficiency models.

\begin{tabular}{lllllll}
\hline Variable & Pooled panel & & TRE panel model & & 2013 model \\
\cline { 2 - 6 } & Coefficients & Marg. eff. & Coefficients & Marg. eff. & Coefficients & Marg. eff. \\
\hline Male & $-0.173(1.112)$ & -0.029 & $-0.164(1.204)$ & -0.025 & $0.530(0.911)$ & 0.121 \\
Age & $-0.041(0.018)^{* *}$ & $-0.007 * *$ & $-0.041(0.020)^{* *}$ & $-0.006^{* *}$ & $-0.029(0.016)^{*}$ & $-0.007^{*}$ \\
High school & $0.084(0.595)$ & 0.014 & $0.092(0.652)$ & 0.014 & $-1.272(0.729)^{*}$ & $-0.291^{*}$ \\
Extension & $-0.108(0.417)$ & -0.018 & $-0.100(0.446)$ & -0.015 & $0.780(0.494)$ & 0.178 \\
Credit & & & & & $-0.137(0.528)$ & -0.031 \\
Association & & & & & $0.039(0.437)$ & 0.009 \\
Time & & & & & \\
Year 2004 & $-1.769(0.940)^{*}$ & $-0.296^{*}$ & $-2.078(1.060)^{* *}$ & $-0.320^{* *}$ & & \\
Year 2006 & $-2.705(0.800)^{* * *}$ & $-0.453^{* * *}$ & $-2.840(0.881)^{* * *}$ & $-0.437 * * *$ & & \\
Year 2013 & $-2.549(0.950)^{* * *}$ & $-0.426^{* * *}$ & $-2.853(1.111)^{* * *}$ & $-0.439 * * *$ & & $0.336(1.437)$ \\
Constant & $2.241(1.346)^{*}$ & & $2.323(1.418)$ & & \\
\hline
\end{tabular}

Notes: Robust standard errors are in the parentheses. ${ }^{*}: \mathrm{p}<0.10, * *: \mathrm{p}<0.05, * * *: \mathrm{p}<0.01$.

\subsubsection{Productivity change}

Table 3.6 shows the decomposition of the total factor productivity change into several sources: technical efficiency factors, technical change, scale and allocative efficiency effects, 
and additional factors connected to technology. Land allocative effects are not calculated because if the size of a cocoa farm was changed over the years, we consider it a different farm. Since the pooled and random-effect model results are similar, we discuss only the RE estimates.

The total productivity growth of the cocoa farms over the 12 years amounts to around 75 percent. This means about a 6 percent annual improvement, on average. The fastest productivity growth (more than 36 percent) was accomplished in the third observation period, between 2006 and 2013. In the first and second periods, cocoa farms experienced total factor productivity increases of about 13 and 27 percent.

Examining the individual components of TFP change, we find that the growth in the 2001-2004 period is primarily caused by technical efficiency change, especially by its TEC $_{\mathrm{TC}}$ component (30.4 percent increase). The distribution of this effect is shown in Figure 3.A2. This improvement might be the result of the fact that cocoa production in our sample area started just in the 1990s and farmers needed to gain knowledge and experience in the early stages of cultivation. In our first sample period, the sharp decrease (-23.5 percent) of the standard technology component was counteracting this growth. This could be mainly due to the very dry 2004 cocoa growing season. The allocative effect of the intermediate inputs had an additional negative influence (-12.8 percent) on productivity. Finally, we find that changes in scale and labor allocative efficiency are relatively small compared with the other elements.

The TFP increase between 2004 and 2006 is dominated by the technical efficiency change (16.4 percent) and the allocative effects of the intermediate inputs (14.9 percent). The value of the former points to the slowdown of the technical efficiency increase, while the latter shows a tremendous improvement in the input allocation. The allocative effect induced by labor input and the technology effect of the input use had a further positive influence on productivity. Again, the technical change component was offsetting the improvement because of the unfavorable weather conditions (-17 percent).

In contrast to the first two periods, the main driver for productivity growth in the last observation period was technical progress (40.5 percent increase). This is due to the positive effect of the La Niña climate pattern. However, the distortion in the allocation of intermediate inputs (-33.1 percent change) was counterbalancing this improvement. We can also notice the increasing technology effect of input use and the Gernas Pro Kakao government program. However, technical efficiency growth continued to slow down. A possible explanation for this finding could be the deterioration of land infrastructure because of the heavy rains. 
Table 3.6: Decomposition of the total factor productivity change in cocoa farming (percentages).

\begin{tabular}{|c|c|c|c|c|c|c|c|c|c|c|c|}
\hline Time period & $\mathrm{TEC}_{\mathrm{EV}}$ & $\mathrm{TEC}_{\mathrm{TC}}$ & $\mathrm{TEC}_{\mathrm{UF}}$ & $\mathrm{C}$ & SEC & $\mathrm{AEC}_{\mathrm{LA}}$ & $\mathrm{AEC}_{\mathrm{II}}$ & TFPC $_{1}$ & $\mathrm{~T}_{\mathrm{IU}}$ & $\mathrm{T}_{\mathrm{GK}}$ & $\mathrm{TFPC}_{2}$ \\
\hline \multicolumn{12}{|l|}{ Pooled model } \\
\hline 2001-2004 & 2.3 & 29.3 & 18.7 & -20.1 & -1.3 & -3.5 & -12.6 & 12.8 & 1.2 & 0.0 & 14.0 \\
\hline 2004-2006 & 0.9 & 12.6 & 4.8 & -20.9 & -0.1 & 5.8 & 14.6 & 17.7 & 6.8 & 0.0 & 24.5 \\
\hline 2006-2013 & 2.9 & -2.1 & 3.7 & 41.0 & -1.5 & 8.7 & -32.4 & 20.3 & 10.5 & 6.1 & 36.9 \\
\hline $2001-2013$ & 6.1 & 39.8 & 27.2 & 0.0 & -2.9 & 11.0 & -30.4 & 50.8 & 18.5 & 6.1 & 75.4 \\
\hline Average annual & 0.5 & 3.3 & 2.3 & 0.0 & -0.2 & 0.9 & -2.5 & 4.3 & 1.5 & 0.5 & 6.3 \\
\hline \multicolumn{12}{|l|}{ TRE model } \\
\hline 2001-2004 & 2.1 & 30.4 & 20.7 & -23.5 & -1.3 & -3.5 & -12.8 & 12.1 & 1.1 & 0.0 & 13.2 \\
\hline 2004-2006 & 0.8 & 9.6 & 6.0 & -17.0 & 0.0 & 5.8 & 14.9 & 20.1 & 6.5 & 0.0 & 26.6 \\
\hline 2006-2013 & 2.6 & 0.2 & 3.0 & 40.5 & -1.6 & 9.2 & -33.1 & 20.8 & 10.0 & 5.3 & 36.1 \\
\hline 2001-2013 & 5.5 & 40.2 & 29.7 & 0.0 & -2.9 & 11.5 & -31.0 & 53.0 & 17.6 & 5.3 & 75.9 \\
\hline Average annual & 0.5 & 3.4 & 2.5 & 0.0 & -0.2 & 1.0 & -2.6 & 4.5 & 1.5 & 0.4 & 6. \\
\hline
\end{tabular}

Notes: $\mathrm{TEC}_{\mathrm{EV}}=$ technical efficiency change from the variable "age of household head", $\mathrm{TEC}_{\mathrm{TC}}=$ technical efficiency change from technical change, $\mathrm{TEC}_{\mathrm{UF}}=$ technical efficiency change from unspecified factors, $\mathrm{TC}=$ technical change, $\mathrm{SEC}=$ scale efficiency change, $\mathrm{AEC}_{\mathrm{LA}}=$ allocative efficiency change (labor), $\mathrm{AEC}_{\mathrm{II}}=$ allocative efficiency change (intermediate inputs), $\mathrm{TFPC}_{1}=$ standard total factor productivity change, $\mathrm{T}_{\mathrm{IU}}=$ the effect of non-zero intermediate input use, $\mathrm{T}_{\mathrm{GK}}=$ the effect of the Gernas Pro Kakao program, $\mathrm{TFPC}_{2}=$ augmented total factor productivity change. Values are calculated according to Brümmer et al. (2002), and Zhu and Lansink (2010).

\subsection{Conclusion}

The surge in cocoa demand and price prompts us to search for sustainable ways to improve cocoa yields and thus, farmer income. We investigate the productivity and efficiency of the Indonesian cocoa production using a panel survey data of 1290 observations and a stochastic frontier model. The results indicate a decreasing return to scale in production. Given the small average cocoa farm size, this could reflect the impediments to growth.

According to our results, the productivity of Indonesian cocoa farming increased by 75 percent between 2001 and 2013. We decompose total factor productivity change into several sources: technical efficiency factors, technical change, scale and allocative efficiency effects, and additional factors connected to technology. The calculations show large distortions in input allocation. Hence, policies that encourage the adjustment of the cocoa farms' input use would be highly beneficial. Furthermore, the technical change component points to a weather-induced volatility in cocoa production. Thus, policy makers should also promote investment in agricultural research and transfer of drought-resistant cocoa varieties to farmers. The estimates 
also show the important role of the increasing input use and the Gernas Pro Kakao government program in achieving productivity growth.

Finally, the biggest growth in cocoa productivity was caused by the increasing technical efficiency. However, the average technical efficiency in Indonesia is still under 50 percent, which is much smaller than the West African average. To sustainably boost cocoa productivity further, we have to look at the possible sources in our detailed technical efficiency results. The significant factors identified to have a positive influence on the efficiency levels are the smallholders' educational attainment and their experience in cocoa farming. Our findings also show that the extension services, the rural credit system, and the farmer groups do not have a significant effect on the efficiency of cocoa farms in our research area.

The limited effect of existing agricultural extension programs on efficiency can be due to the inherent deficiencies of public information systems, flawed service design, or bureaucratic inefficiency. Furthermore, the ineffectiveness of farmer groups can be attributed to the missing social capital, that is, the lack of assistance to each other in the times of need. Hence, policy should focus on adjusting the public extension programs, fostering the mutual benefits in the farmer groups, and developing viable credit institutions to expand the Indonesian cocoa output without increasing input use.

\subsection{References}

Adedeji, I.A., Ajetomobi, J.O., Olapade-Ogunwole, F. (2011): Technical efficiency of cocoa production in Oyo State, Nigeria. Continental Journal of Agricultural Economics 5, $30-40$.

Agom, D.I., Ohen, S.B., Itam, K.O., Inyang, N.N. (2012): Analysis of technical efficiency of smallholder cocoa farmers in Cross River State, Nigeria. International Journal of Agricultural Management \& Development 2, 177-185.

Amos, T.T. (2007): An analysis of productivity and technical efficiency of smallholder cocoa farmers in Nigeria. Journal of Social Sciences 15, 127-133.

Aneani, F., Anchirinah, V.M., Asamoah, M., Owusu-Ansah, F. (2011): Analysis of economic efficiency in cocoa production in Ghana. African Journal of Food, Agriculture, Nutrition and Development 11, 4507-4526. 
Asare, R., 2005. Cocoa agroforests in West Africa: a look at activities on preferred trees in the farming systems. Forestry and Landscape Working Paper No. 6, University of Copenhagen, Copenhagen.

Asase, A., Ofori-Frimpong, K., Ekpe, P.K. (2009): Impact of cocoa farming on vegetation in an agricultural landscape in Ghana. African Journal of Ecology 48, 338-346.

Awotide D.O., Kehinde, A.L., Akorede, T.O. (2015): Metafrontier analysis of access to credit and technical efficiency among smallholder cocoa farmers in Southwest Nigeria. International Business Research 8, 132-144.

Barrett, C.B. (1996): On price risk and the inverse farm size - productivity relationship. Journal of Development Economics 51, 193-215.

Belotti, F., Ilardi, G. (2012): Consistent estimation of the true fixed-effects stochastic frontier model. Centre for Economic and International Studies (CEIS) Research Papers No. 231, University of Rome Tor Vergata, Rome.

Bentley, J., Boa, E., Stonehouse, J. (2004): Neighbor trees: shade, intercropping and cocoa in Ecuador. Human Ecology 32, 241-270.

Besseah, F.A., Kim, S. (2014): Technical efficiency of cocoa farmers in Ghana. Journal of Rural Development 37, 159-182.

Binam, J.N., Tonye, J., Wandji, N., Nyambi, G., Akoa, M. (2004): Factors affecting the technical efficiency among smallholder farmers in the slash and burn agriculture zone of Cameroon. Food Policy 29, 531-545.

Brümmer, B., Glauben, T., Lu, W. (2006): Policy reform and productivity change in Chinese agriculture: a distance function approach. Journal of Development Economics 81, 61-79.

Coelli, T.J., Rao, D.S.P., O'Donnell, C.J., Battese, G.E. (2005): An Introduction to Efficiency and Productivity Analysis. Springer, New York.

Dand, R. (2010): The International Cocoa Trade, 3rd ed. Woodhead Publishing, Sawston.

Danso-Abbeam, G., Aidoo R., Agyemang K.O., Ohene-Yankyera, K. (2012): Technical efficiency in Ghana's cocoa industry: evidence from Bibiani -Anhwiaso-Bekwai District. Journal of Development and Agricultural Economics 4, 287-294.

Debreu, G. (1951): The coefficient of resource utilization. Econometrica 19, 273-292.

Dercon, S. (2003): Poverty Traps and Development: The Equity-Efficiency Debate Revisited. 1st AFD/EUDN Conference on Growth, Inequality, and Poverty, November 13, Paris.

Dinar, A., Karagiannis, G., Tzouvelekas, V. (2007): Evaluating the impact of agricultural extension on farms' performance in Crete: a nonneutral stochastic frontier approach. Agricultural Economics 36, 135-146. 
Effendi, Hanani, N., Setiawan, B., Muhaimin, A.W. (2013): Characteristics of farmers and technical efficiency in cocoa Farming at Sigi Regency - Indonesia with approach stochastic frontier production function. Journal of Economics and Sustainable Development 4, 154-160.

FAO (2010): Global Forest Resources Assessment. FAO, Rome.

Feder, G., Murgai, R., Quizon, J.B. (2004): Sending farmers back to school: the impact of farmer field schools in Indonesia. Review of Agricultural Economics 26, 45-62.

Frimpong, K.O., Asase, A., Yelibora, M. (2007): Cocoa Farming and Biodiversity in Ghana. An Annual Project Report for the Earthwatch Institute, Accra.

Gockoswki, J., Sonwa, D. (2011): Cocoa intensification scenarios and their predicted impact on $\mathrm{CO} 2$ emissions, biodiversity conservation, and rural livelihoods in the guinea rain forest of West Africa. Environmental Management 48, 307-321.

Greene, W. H. (2008): The econometric approach to efficiency analysis. In: Fried, H. O., Lovell, C. A. K., Schmidt, S. S. (Eds), The Measurement of Productive Efficiency and Productivity Growth. Oxford University Press, New York, pp. 92-250.

Hafid, H., Neilson, J., Mount, T., McKenzie, F. (2013): Sustainability Impact Assessment of a Certification Scheme in the Indonesian Cocoa Industry: 2012 Pilot Survey Results. University of Sydney, Sydney.

Hsiao , C. (2007): Panel data analysis - advantages and challenges. TEST 16, 1-22.

Huppes, G.,Ishikawa, M. (2005): Eco-efficiency and its terminology. Journal of Industrial Ecology 9, 43-46.

Hütz-Adams, F., Fountain, A. (2012): Cocoa Barometer. VOICE Network, London.

ICCO (2012): The World Cocoa Economy: Past and Present. International Cocoa Organization, London.

ICCO (2016): Quarterly Bulletin of Cocoa Statistics. International Cocoa Organization, London. Ingram, V., Waarts, Y., Ge, L., van Vugt, S., Wegner, L., Puister-Jansen, L., Ruf, F., Tanoh, R. (2014): The IDH Cocoa Productivity and Quality Programme (CPQP) in Côte d'Ivoire; Impact assessment framework and baseline. Wageningen, LEI Wageningen UR (University \& Research centre), LEI Report 2014-016.

KKPOD (2013): National Movement of Cocoa Production and Quality improvement (GERNAS KAKAO). KKPOD, Jakarta.

Kyei, L., Foli, G., Ankoh, J. (2011): Analysis of factors affecting the technical efficiency of cocoa farmers in the Offinso district-Ashanti region, Ghana. American Journal of Social and Management Sciences 2, 208-216. 
Maytak, L. (2014): Report on Farm Level Sustainability of Cocoa in Côte d'Ivoire: A Synthesis of Five Studies. International Finance Corporation, New York.

Ministry of Agriculture (2015): Directorate General of Estate Crops. Ministry of Agriculture, Indonesia, Jakarta.

Mundlak, Y. (1978): On the pooling of time series and cross section data. Econometrica 46, 69-85.

Nkamleu, G.B., Nyemeck, J., Gockowski, J. (2010): Technology Gap and Efficiency in Cocoa Production in West and Central Africa: Implication for Cocoa Sector Development. Working Papers Series No. 104, African Development Bank, Tunis.

Ofori-Bah, A., Asafu-Adjaye, J. (2011): Scope economies and technical efficiency of cocoa agroforestry systems in Ghana. Ecological Economics 70, 1508-1518.

Ogundari, K., Odefadehan, O. (2007): Comparative analysis of resource-productivity and technical efficiency of cocoa producers: a study of farmers under training \& visit and farmer field school extension systems in Nigeria. Quarterly Journal of International Agriculture 46, 205-219.

Ogunniyi, L.T., Ajao, O.A, Adeleke, O.A. (2012): Gender comparison in production and productivity of cocoa farmers in Ile Oluji Local Government Area of Ondo State, Nigeria. Global Journal of Science Frontier Research Agriculture \& Biology 12, 59-64.

Oladapo, A., Shittu, A.M., Agbonlahor, M.U., Fapojuwo, O.E (2012): Credit use and production efficiency of cocoa farms in Ondo State Nigeria. Proceedings of the 8th Africa Farm Management Association Congress, November 25-29, Nairobi.

Onumah, J.A., Al-Hassan, R.M., Onumah, E.E. (2013a): Productivity and technical efficiency of cocoa production in Eastern Ghana. Journal of Economics and Sustainable Development 4, 106-117.

Onumah, J.A., Onumah, E.E., Al-Hassan, R.M., Brümmer, B. (2013b): Meta-frontier analysis of organic and conventional cocoa production in Ghana. Agricultural Economics Czech 59, 271-280.

Oyekale, A.S. (2012): Impact of climate change on cocoa agriculture and technical efficiency of cocoa farmers in South-West Nigeria. Journal of Human Ecology 40, 143-148.

Pretzsch, H. (2005): Diversity and productivity in forests: evidence from long-term experimental plots. In: Scherer-Lorenzen, M., Korner, C., Schulze, E. (Eds.), Forest Diversity and Function: Temperate and Boreal Systems. Springer, Berlin, pp. 41-64.

REDD (2012): Opportunity Costs of Major Land Uses in Central Sulawesi. UN Reducing Emissions from Deforestation and Forest Degradation, Geneva. 
Ruf, F., Zadi, H. (1998): Cocoa: from deforestation to reforestation. Proceedings of the First International Workshop on Sustainable Cocoa Growing. March 30-April 2, Panama City.

Scherer-Lorenzen, M., Korner, C., Schulze, E. (2005): The functional significance of forest diversity: the starting point. In: Scherer-Lorenzen, M., Korner, C., Schulze, E. (Eds.), Forest Diversity and Functions: Temperate and Boreal Systems. Springer, Berlin, pp. $3-12$.

Smaling, E.M.A., Dixon, J. (2006): Adding a soil fertility dimension to the global farming systems approach, with cases from Africa. Agriculture, Ecosystems and Environment $116,15-26$.

Squicciarini, M. P., Swinnen, J. (2016): The Economics of Chocolate. Oxford University Press, Oxford.

Teal, F., Zeitlin, A.,Maamah, H. (2006): Ghana Cocoa Farmers Survey 2004. Report to Ghana Cocoa Board. Centre for the Study of African Economies, University of Oxford, Oxford. Tothmihaly, A. (2017): How Low is the Price Elasticity in the Global Cocoa Market? Manuscript.

van Edig, X., Schwarze, S., Zeller, M. (2010): The robustness of indicator based poverty assessment tools in changing environments - empirical evidence from Indonesia. In: Tscharntke, T., Leuschner, C., Veldkamp, E., Faust, H., Guhardja, E., Bidin, A. (Eds.), Tropical Rainforests and Agroforests under Global Change: Ecological and Socioeconomic Valuations. Springer, Berlin, pp. 191-211.

Vigneri, M. (2007): Drivers of Cocoa Production Growth in Ghana. Project Briefing No 4. Overseas Development Institute, London.

WBCSD (1992): Changing Course. World Business Council for Sustainable Development, Washington D.C.

Wollni, M., Brümmer, B. (2012): Productive efficiency of specialty and conventional coffee farmers in Costa Rica: Accounting for technological heterogeneity and self-selection. Food Policy 37, 67-76.

Zeller, M., Diagne, A., Mataya, C. (1997): Market access by smallholder farmers in Malawi: Implications for technology adoption, agricultural productivity, and crop income. Agricultural Economics 19, 219-229.

Zhu, X., Lansink, A.O. (2010): Impact of CAP subsidies on technical efficiency of crop farms in Germany, the Netherlands and Sweden. Journal of Agricultural Economics 61, 545564. 


\subsection{Appendix}

Table 3.A1: Technical efficiencies in previous cocoa studies.

\begin{tabular}{|c|c|c|c|c|}
\hline Country & No. of datasets & Weighted mean TE & Mean sample size & Total sample size \\
\hline Ghana & 10 & 56 & 313 & 3125 \\
\hline Ivory Coast & 1 & 58 & 1372 & 1372 \\
\hline Cameroon & 1 & 65 & 1003 & 1003 \\
\hline Nigeria & 11 & 72 & 246 & 2701 \\
\hline Indonesia & 1 & 81 & 98 & 98 \\
\hline World & 24 & 63 & 346 & 8299 \\
\hline
\end{tabular}

Sources: Own calculations from Aneani et al. (2011), Awotide et al. (2015), Besseah and Kim (2014), DansoAbbeam et al. (2012), Kyei et al. (2011), Nkamleu et al. (2010), Ofori-Bah and Asafu-Adjaye (2011), Onumah et al. (2013a), Onumah et al. (2013b), Adedeji et al. (2011), Agom et al.(2012), Amos (2007), Ogundari and Odefadehan (2007), Ogunniyi et al. (2012), Oladapo et al. (2012), Oyekale (2012), and Effendi et al. (2013).

Notes: There are 24 datasets in 17 studies. We used the sample sizes as weights for the aggregation of the technical efficiency scores. $\mathrm{TE}=$ technical efficiency. 
Table 3.A2: Determinants of production and inefficiency in previous cocoa studies.

\begin{tabular}{|c|c|c|c|c|}
\hline Variable & $\begin{array}{l}\text { No. of positive } \\
\text { effects }\end{array}$ & $\begin{array}{l}\text { Number of negative } \\
\text { effects }\end{array}$ & $\begin{array}{l}\text { No. of insignificant } \\
\text { effects }\end{array}$ & $\begin{array}{l}\text { No. of } \\
\text { datasets }\end{array}$ \\
\hline \multicolumn{5}{|l|}{ Production } \\
\hline Tree age & 6 & 5 & 3 & 14 \\
\hline Farm size & 19 & & 2 & 21 \\
\hline Labor cost & 20 & & 3 & 23 \\
\hline Fertilizer cost & 10 & 1 & 6 & 17 \\
\hline Pesticide cost & 19 & 1 & 4 & 24 \\
\hline Processing cost & 3 & & 1 & 4 \\
\hline Transport cost & 2 & & & 2 \\
\hline Pruning & 1 & & 2 & 3 \\
\hline \multicolumn{5}{|l|}{ Inefficiency } \\
\hline Male & 1 & 10 & 3 & 14 \\
\hline Farmer age & 3 & 5 & 12 & 20 \\
\hline Educational level & 3 & 11 & 9 & 23 \\
\hline Extension services & 1 & 8 & 8 & 17 \\
\hline Credit access & & 6 & 4 & 10 \\
\hline Association member & 1 & 5 & 4 & 10 \\
\hline Intercropping & & 1 & 1 & 2 \\
\hline Shade cover & 1 & 2 & 2 & 5 \\
\hline
\end{tabular}

Sources: Own calculations from Aneani et al. (2011), Awotide et al. (2015), Besseah and Kim (2014), DansoAbbeam et al. (2012), Kyei et al. (2011), Nkamleu et al. (2010), Ofori-Bah and Asafu-Adjaye (2011), Onumah et al. (2013a), Onumah et al. (2013b), Adedeji et al. (2011), Agom et al.(2012), Amos (2007), Ogundari and Odefadehan (2007), Ogunniyi et al. (2012), Oladapo et al. (2012), Oyekale (2012), and Effendi et al. (2013).

Notes: There are 24 datasets in 17 studies. 
Figure 3.A1: Distribution of efficiencies in the cocoa production models.

a) Pooled panel model, 2001-2013

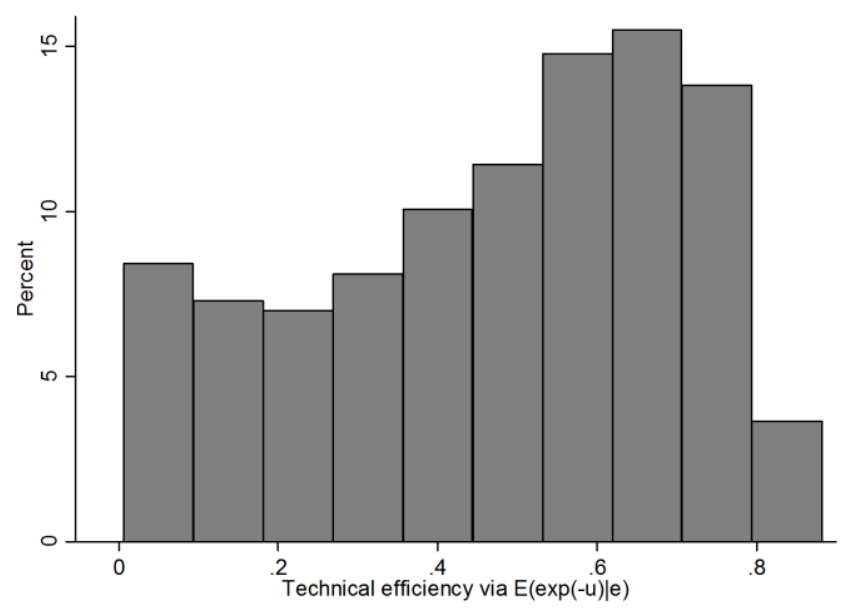

b) TRE panel model, 2001-2013

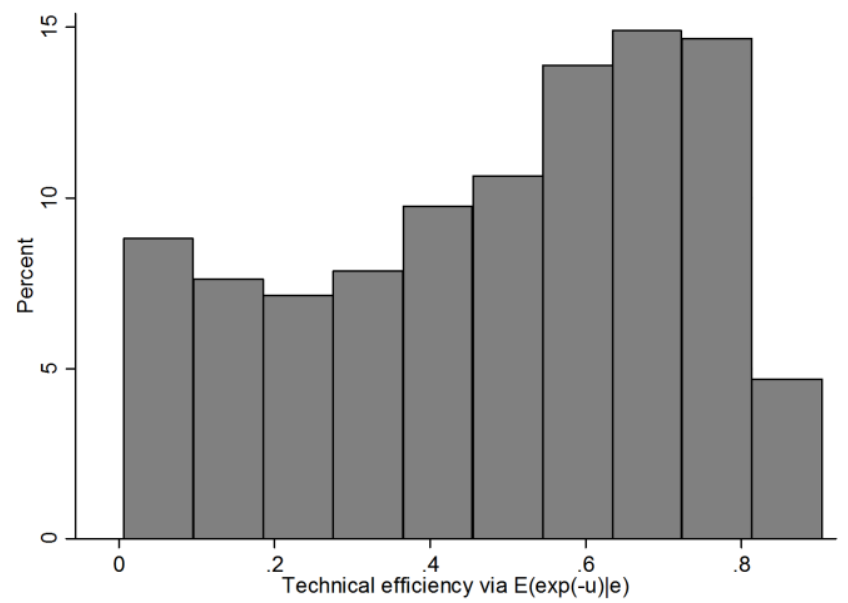

c) 2013 model

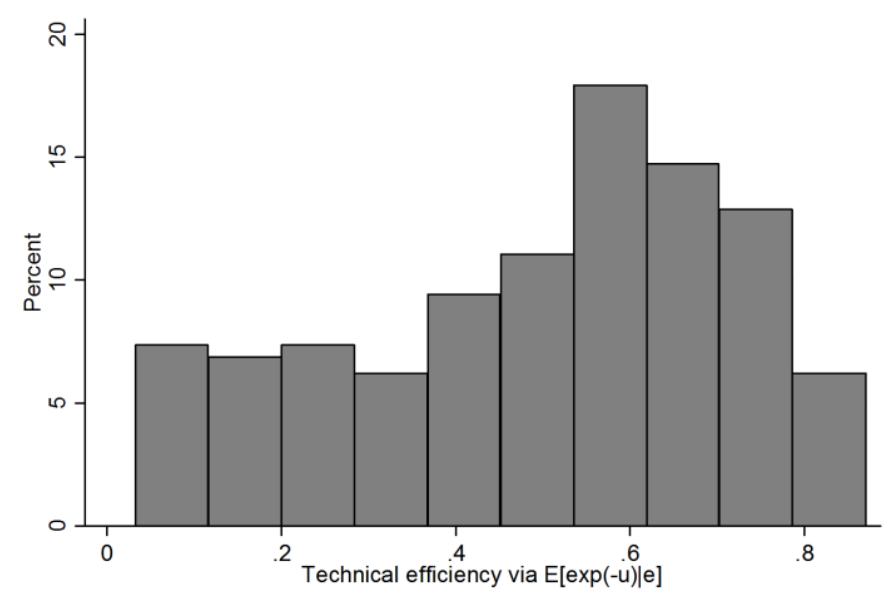


Figure 3.A2: Distribution of the $\mathrm{TEC}_{\mathrm{TC}}$ productivity change component in 2004.

a) Pooled panel model

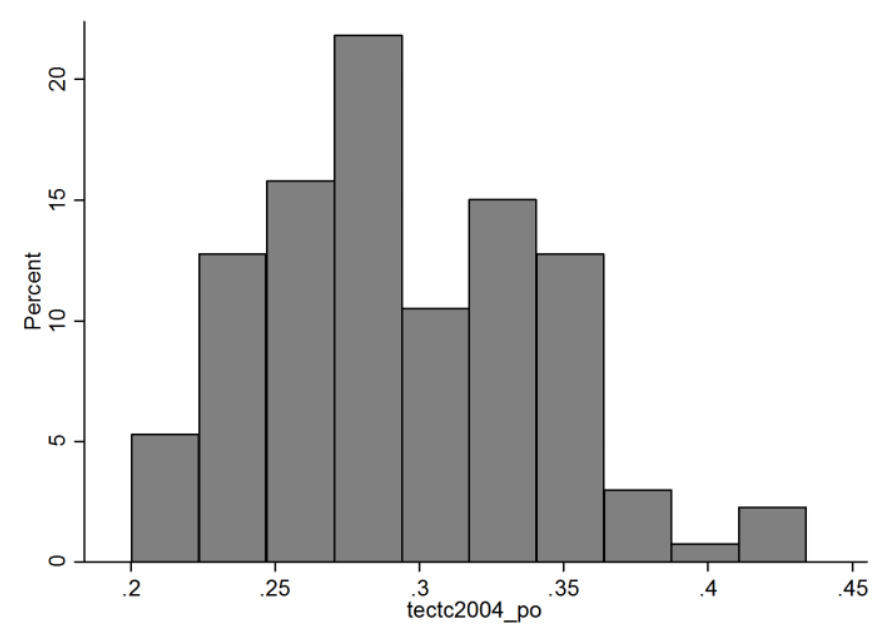

b) TRE panel model

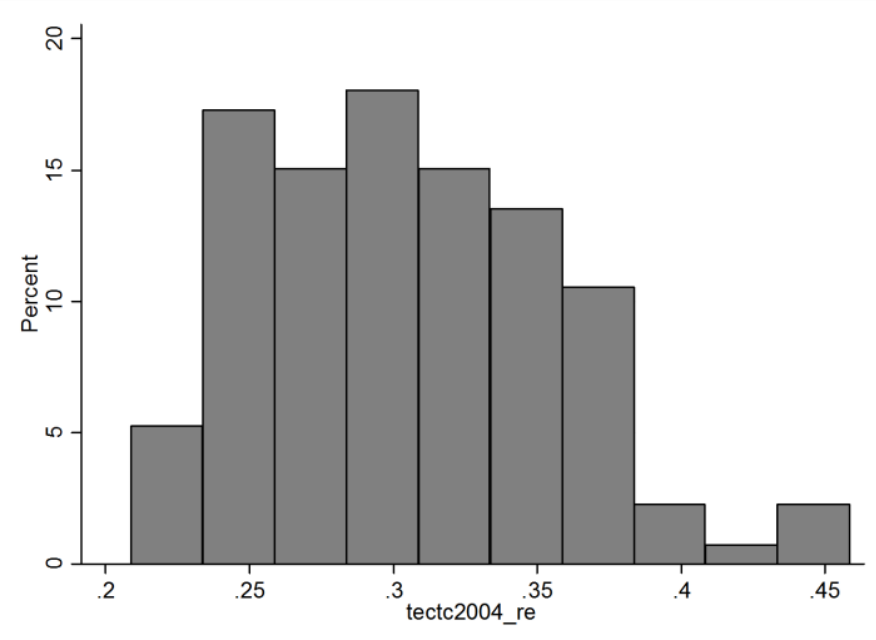




\title{
4. How can the environmental efficiency of Indonesian cocoa farms be increased?7
}

\begin{abstract}
We look at the trade-off between smallholder cocoa intensification and the ecosystem in Indonesia and investigate the determinants of environmental efficiency in cocoa production. In our analysis, we apply a distance output function that includes cocoa production and the abundance of native rainforest plants as outputs. Our data set, based on a household and environment survey conducted in 2015, allows us to analyze 208 cocoa producers with both measured and self-reported data. We find that the intensification of cocoa farms results in higher ecosystem degradation. Additionally, the estimations show substantial mean inefficiencies (50 percent). On average, the efficiency scores point to a possible production expansion of $367 \mathrm{~kg}$ of cocoa per farm and year, to a possible increase of 43680 rainforest plants per farm, or to a possible acreage reduction of 0.52 hectares per farm. Finally, our results show that agricultural extension services have a substantial role in increasing efficiency.
\end{abstract}

Keywords: cocoa production, Indonesia, environmental efficiency.

JEL codes: O13, Q01, Q12.

\footnotetext{
${ }^{7}$ This paper is a joint work with Stephan von Cramon-Taubadel and Verina Ingram (Wageningen UR). We would like to thank Bernhard Brümmer for his comments. This project would have been impossible without the funding from the German Research Foundation and the Fiat Panis Foundation. We are also grateful to Aiyen Tjoa, Yulianti Kalaba, the University of Tadulako (UNTAD), the Indonesian Ministry of Research (RISTEK), Yann Clough, Anne Mareike Holtkamp, Rivayani Darmawan, Katharina van Treeck, the enumerators, drivers, village heads, and farmers for their contributions to data collection.
} 


\subsection{Introduction}

\subsubsection{Background}

The global demand for cocoa grew steeply over the last 15 years. This increase was primarily due to the population and economic growth of the Asian and African countries (ICCO, 2014; Squicciarini and Swinnen, 2016). Growing demand led to increased cocoa prices which, together with the incentives provided by government subsidies for the sector, triggered farmers to increase production by raising cultivated land and intensification (Teal et al., 2006).

As a consequence of the acreage expansion, the more fertile rainforest soils, and the lack of other available land, cocoa plantations are increasingly intruding into the Indonesian rainforest, which is a world biodiversity hotspot hosting a large number of endemic species (REDD, 2012). ${ }^{8}$ Findings from Frimpong et al. (2007) show a similar phenomenon in Africa. The production expansion into rainforest areas threatens biodiversity conservation and the functionality of ecological systems, and it contributes to climate change (Asare, 2005).

The Indonesian Government announced the Gernas Pro Kakao revitalization program (KKPOD, 2013) for the cocoa industry in 2009. It was established to increase the adoption of pesticides and fertilizers to restore soil nutrients and the use of enhanced cocoa seedlings to boost productivity. However, the support of intensification and the ensuing increase in cocoa production can also cause environmental deterioration and raise concerns about biodiversity conservation (Asare, 2005).

Welford (1995) consolidates the widespread definition of sustainable development into three components. First, the environment is not observed separately from the economic process but is included in it. Second, the prospective recognition of resources and third, the equal distribution of goods between all members of society.

Agriculture is a crucial source of income for many low-income households in countries such as Indonesia. However, the benefits of income generation must be weighed against possible environmental effects such as nutrient losses, pollution, biodiversity losses, and climate change effects. The concept of environmental efficiency was developed in the economics literature to describe how the performance of environmental elements meet human

\footnotetext{
${ }^{8}$ Indonesia has only 1.2 percent of the world's land area. However, its forests host 11 percent of all plant species, 12 percent of all mammal species, 17 percent of all bird species, 16 percent of all reptile and amphibian species, 33 percent of all insect species, and 24 percent of all fungi species. In this country, 772 species are threatened or endangered, among them 147 mammal species. Moreover, 20 of Indonesia's 40 primate species have lost more than 50 percent of their original habitat in the last ten years, among them orangutans (FAO, 2010).
} 
demand (Huppes and Ishikawa, 2005). The World Business Council for Sustainable Development (WBCSD, 1992) probably first provided a formal definition of environmental efficiency. They describe environmental efficiency as a ratio of reduced environmental impact and increased production value.

The goal of this paper is to study the environmental efficiency of cocoa production in Sulawesi, Indonesia. This region is an important example of environmental degradation due to economic development in terms of agricultural expansion and intensification. On this island, 80 percent of the rainforests were gone by 2010 causing, sometimes, irreversible losses of biodiversity (FAO, 2010).

\subsubsection{Contribution}

Our research investigates the scope for increasing the environmental efficiency of Indonesian cocoa production as a means of fostering sustainability. We estimate based on household, agricultural and environmental surveys and stochastic frontier analysis (Coelli et al., 2005), the environmental efficiency of production. With the results, we aim to determine the magnitude of the attainable efficiency increases, and the methods that can be used to attain them.

A number of studies (Ruf and Schroth, 2004; Schroth et al., 2004; Scherer-Lorenzen et al., 2005a) address various issues related to the environmental effects of cocoa farming. However, these papers do not deal with efficiency. Efficiency estimations are available for the large producing countries such as Ghana: Besseah and Kim (2014), Nigeria: Awotide et al. (2015), and Indonesia: Effendi et al. (2013). However, none of them consider the environmental effect of production. In order to do this, we include an environmentally relevant variable, the abundance of native rainforest plants, in the analysis. We use this, together with the cocoa production quantity, as multiple outputs in an output distance function (Fare et al., 2005).

Furthermore, previous studies analyze the effect of shading trees and intercropping only on efficiency and this leads to inconclusive results (Besseah and Kim, 2014; Nkamleu et al., 2010; Ofori-Bah and Asafu-Adjaye, 2011). We include these variables in the production frontier because we assume that they have a direct effect on production. Additionally, unlike previous studies in Indonesia, we include the Gernas Pro Kakao government program in our analysis. 
Moreover, based on Maytak (2014), we collect both measured and self-reported data to improve the reliability of estimation. He synthesizes results from cocoa studies using household data and shows that self-reported data can exhibit significant bias. For example, he reports an average of 10 percent underestimation of farm size when self-reported, with substantial deviations from farm sizes 10 hectares and above.

Our research sheds more light on the environmental effects of cocoa production and on the dissonances between economic and environmental objectives. We focus on yield expansion because, with appropriate technologies, it has a smaller negative effect than acreage expansion. Our results help to inform policies and practices to sustainably improve yields and income, thus reducing deforestation. The results indicate which investments produce the highest marginal benefits: for example, improving education or access to financing or to extension services (Ingram et al., 2014).

\subsection{Methodology}

\subsubsection{Multi-output frontier model}

In the economic literature, there are three main frameworks to measure environmental efficiency. First, one can compare the environmental performances of production units (Yaisawarng and Klein, 1994). Second, one can use environmental variables as inputs in the production function (Reinhard et al., 2002). In the latest methodology, environmental effects are treated as outputs of production (Fare et al., 2005). Following Picazo-Tadeo et al. (2014), we choose this third framework to account for environmental outputs.

Efficiency is the capability to maximize outputs given a level of inputs used in the production. Debreu (1951) introduced the first concept of creating a production frontier to measure efficiency. This led to two main empirical methods for frontier estimation: the deterministic Data Envelopment Analysis (DEA) and the parametric Stochastic Frontier Analysis (SFA). We assess efficiency using the parametric method since it can differentiate between technical inefficiency and the effects of random shocks (Coelli et al., 2005). The most established SFA model is based on the output distance function. It is used by a number of researchers including Brümmer et al. (2006).

According to Coelli et al. (2005), the output distance function treats inputs as fixed and extends output vectors as long as the outputs are still technically feasible: 
$D_{o}(\boldsymbol{x}, \boldsymbol{y})=\inf \left\{\theta>0: \frac{\boldsymbol{y}}{\theta} \in P(\boldsymbol{x})\right\}$

where $P(\boldsymbol{x})$ represents the set of feasible output vectors $(\boldsymbol{y})$ which can be produced using the input vectors $(\boldsymbol{x}) . D_{o}(\boldsymbol{x}, \boldsymbol{y})$ describes the technology completely and gives the reciprocal of the maximum proportional expansion of the output vector with given inputs. It is linearly homogeneous, non-decreasing, and convex in outputs and non-increasing and quasi-convex in inputs. For two outputs, Figure 4.1 depicts the distance function in output space (Brümmer et al., 2006). The output set $P(\boldsymbol{x})$ is bounded by the production-possibility frontier (PPF), which represents the technically efficient points for all output combinations, given the input combination $\boldsymbol{x}$. To determine the value of the distance function, all observed points of production are scaled radially toward the output set boundary. The distance function shows the relation of a given output vector $(\overline{O A}$ in Figure 4.1$)$ to the maximal feasible output with unchanged output mix $(\overline{O B}$ in Figure 4.1$)$. The output orientated measure of technical efficiency equals the reciprocal of the output distance function:

$T E=1 / D_{o}(\boldsymbol{x}, \boldsymbol{y})$.

It is difficult to estimate the output distance function directly with ordinary least squares (OLS) or maximum likelihood (ML) methods because its value is unobserved. However, we can transform the function into an estimatable equation by exploiting its linear homogeneity property in outputs. A possible way to impose this condition is by normalizing the output distance function by an output (Coelli et al., 2005). We choose $y_{1}$, which leads to the following expression:

$D_{o}\left(\boldsymbol{x}_{\boldsymbol{i}}, \frac{\boldsymbol{y}_{\boldsymbol{i}}}{y_{1 i}}\right)=\frac{1}{y_{1 i}} D_{o}\left(\boldsymbol{x}_{\boldsymbol{i}}, \boldsymbol{y}_{\boldsymbol{i}}\right)$.

Subsequently, taking the log of both sides and rearranging yields

$\ln y_{1 i}=-\ln D_{o}\left(\boldsymbol{x}_{\boldsymbol{i}}, \frac{\boldsymbol{y}_{\boldsymbol{i}}}{y_{1 i}}\right)+\ln D_{o}\left(\boldsymbol{x}_{\boldsymbol{i}}, \boldsymbol{y}_{\boldsymbol{i}}\right)$

In this case, the technical efficiency of farm $i$ can be written as

$T E_{i}=\exp \left(-u_{i}\right)$

where $u_{i}$ is a non-negative unobservable term assumed to be independently and identically distributed as $N\left(\mu_{i}, \sigma_{u}^{2}\right)$. Finally, substituting equations (4.2) and (4.5) into (4.4), and then adding a random error term $v_{i}$ that is independently and identically distributed as $N\left(\mu_{i}, \sigma_{u}^{2}\right)$ and independent of $u_{i}$ gives

$\ln y_{1 i}=-\ln D_{o}\left(\boldsymbol{x}_{\boldsymbol{i}}, \frac{\boldsymbol{y}_{\boldsymbol{i}}}{y_{1 i}}\right)+v_{i}-u_{i}$ 
The parameters of the distance function in equation (4.6) must theoretically satisfy the regularity conditions: monotonicity and curvature (Coelli et al., 2005). Because the CobbDouglas production function has the wrong curvature in the $y_{i} / y_{1 i}$ space of a distance function framework, we use a translog functional form. In this function, the inclusion of squared and interaction terms provides a high level of flexibility, an easy calculation, and the possibility to impose homogeneity (Brümmer et al., 2006).

The extension of our model in equation (4.6) enables us to measure how household characteristics influence efficiency. We choose a specification proposed by Coelli et al. (2005), which models the technical inefficiency $\left(u_{i}\right)$ as a function of several variables:

$u_{i}=\varphi Z_{i}+e_{i}$

where $Z_{i}$ is a vector of farm-specific factors that are assumed to affect efficiency, $\varphi$ is a vector with parameters to be estimated, and $e_{i}$ is an independent and identically distributed random error term. If the estimated parameter is positive, then the corresponding variable has a negative influence on technical efficiency.

Figure 4.1: Output distance function for two outputs

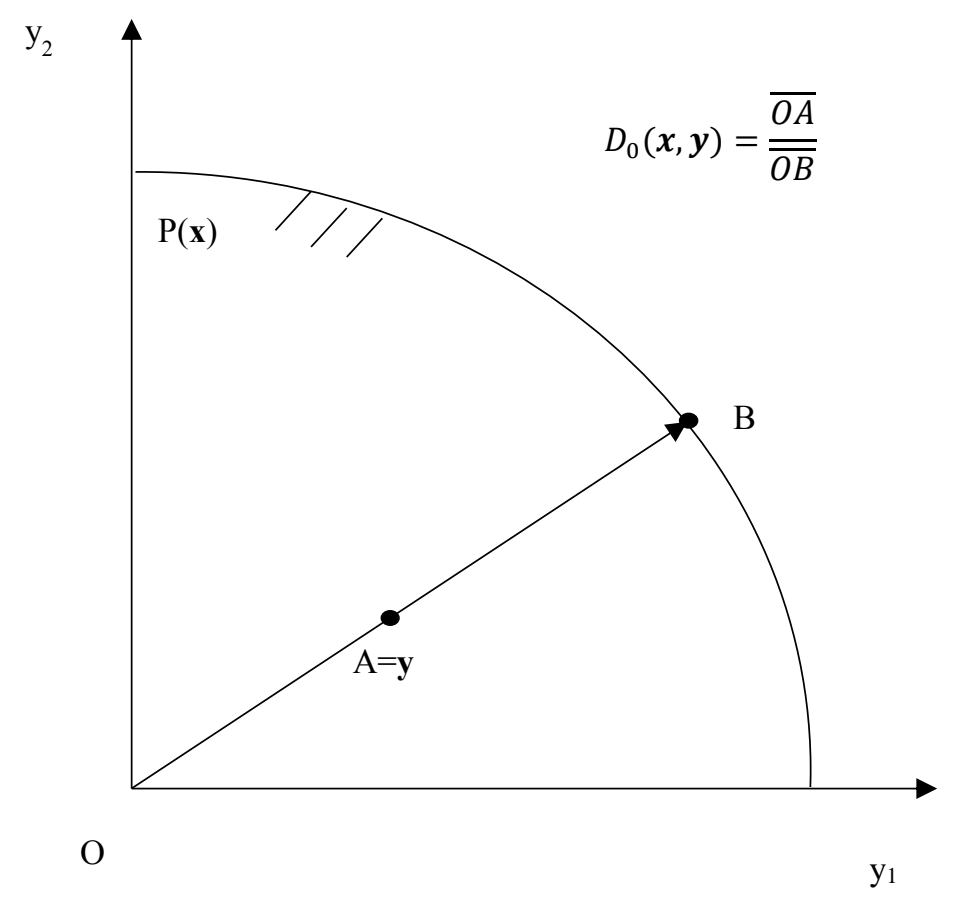

Source: Brümmer et al. (2006). 


\subsubsection{Estimation issues}

We look at three issues of the statistical inference: the estimation technique of the frontier model, the estimation technique of the inefficiency model, and endogeneity.

First, standard techniques such as OLS are inappropriate for estimating the unobservable frontier function from observable input and output data because they focus on describing average relationships. Therefore, we base the parameters on ML. Before carrying out the estimation, each variable is normalized by its sample mean. Given this transformation, the first-order coefficients can be viewed as partial production elasticities at the sample mean (Coelli et al., 2005).

Regarding the second inference issue, Greene (2008) points out that researchers often incorporate inefficiency effects using two-step estimation techniques. In the first step, the production function is specified and the technical inefficiency is predicted. The second step regresses the assumed characteristics on the predicted inefficiency values via OLS. This approach leads to severely biased results. The issue is addressed by using a simultaneous estimation that includes the efficiency effects in the production frontier estimation.

Furthermore, the direct inference of a stochastic frontier may be susceptible to simultaneity bias that occurs if each farmer selects the output and input levels to maximize profit for given prices. But no simultaneity bias ensues if farmers maximize expected rather than actual profit (Coelli et al., 2005). We make this reasonable assumption meaning that technical efficiency is unknown to producers before they make their input decisions. Thus, the quantities of variable inputs are largely predetermined and uncorrelated with technical efficiency.

Finally, according to Brümmer et al. (2006), several studies also question the transformation of the distance function by applying the ratio method. For example, Kumbhakar and Lovell (2000) argue that the Euclidean norm of output model, which avoids the choice of a specific output, might be less susceptible to the endogeneity bias than the ratio model. However, Sickles et al. (2002) conclude that in the stochastic production frontier context, the ratio of two output variables is not endogenous, even if the output levels are. Another advantage of the ratio transformation is that in this model, the degree of multicollinearity is considerably smaller than in the norm model. 


\subsection{Empirical specification}

\subsubsection{Production frontier model}

The translog output distance function for the observation $i$ with two outputs, three inputs, and five dummy variables is specified as:

$$
\begin{aligned}
& \ln y_{1 i}=-\alpha_{1}-\alpha_{2} \ln \frac{y_{2 i}}{y_{1 i}}-\sum_{k=1}^{3} \beta_{k} \ln x_{k i}-\frac{1}{2} \alpha_{11} \ln \frac{y_{2 i}}{y_{1 i}} \ln \frac{y_{2 i}}{y_{1 i}}-\frac{1}{2} \sum_{j=1}^{3} \sum_{k=1}^{3} \beta_{j k} \ln x_{j i} \ln x_{k i}- \\
& \sum_{k=1}^{3} \gamma_{1 k} \ln \frac{y_{2 i}}{y_{1 i}} \ln x_{k i}-\sum_{j=1}^{5} \delta_{j} D_{j i}+v_{i}-u_{i}
\end{aligned}
$$

where the unit of observation is the farm of household $i, y_{1 i}$ is the amount of cocoa beans harvested in kilograms, $y_{2 i}$ is the environmental output, $x_{k}$ is a vector of observations on inputs, $D_{j}$ is a vector of observations on dummy variables characterizing the production process, the $\alpha$ 's, $\beta$ 's, $\gamma$ 's, and $\delta$ 's are unknown parameters to be estimated, $v$ is a random error term, and finally $u$ is a non-negative unobservable variable representing inefficiency.

Based on Gockowski and Sonwa (2011), we use plant abundance as a measure of the environmental output $y_{2}$. We did not include tree biomass and other crop outputs in the production function because of the small number of forest and other crop trees on the sample cocoa farms.

We draw on Nkamleu et al. (2010) and Ofori-Bah and Asafu-Adjaye (2011) to identify the production factors that we consider in our analysis (Table 4.1). These include land $\left(x_{1}\right)$, costs $\left(x_{2}\right)$, tree age $\left(x_{3}\right)$, and dummies representing the cocoa farmers' management capabilities (Wollni and Brümmer, 2012). In our model, land indicates the total cultivated cocoa area measured in ares, while costs are calculated in Rupiah and involve all labor, fertilizer, and pesticide costs used on the cocoa farm. ${ }^{9}$ We aggregate the latter inputs to avoid multicollinearity (Brümmer et al., 2006) and assume that the value of material inputs and labor costs reflects the quality of inputs better than quantity (Wollni and Brümmer, 2012). The age of cocoa trees $\left(x_{4}\right)$ is also added to the classical production factors. It influences the cocoa output the following way. Cocoa trees begin to produce pods only from about three years after planting, reach full bearing capacity around the age of 10 years, and their output starts to diminish gradually thereafter (Dand, 2010). Hence, the sign and magnitude of the effect of tree age varies depending on the average tree age in the sample.

\footnotetext{
${ }^{9} 1$ hectare equals 100 ares. In December 2015, 1 euro cost around 15000 Rupiahs.
} 
Following Wollni and Brümmer (2012), we enhance the basic production frontier with five dummy variables to describe the cocoa cultivation process more accurately. The first dummy variable equals one if only family labor (no material inputs or hired labor) was used for maintenance and harvesting tasks. According to Binswanger and Rosenzweig (1986), if family members cannot get off-farm jobs in imperfect input and labor markets, their time may be allocated to work on the cocoa farms up to the extent where the marginal utility of production is equal to the marginal utility of leisure. Therefore, using exclusively family workers may negatively affect production if cocoa plantations are used to absorb surplus family labor. The second dummy variable equals one if the smallholder participated in the Gernas Pro Kakao government program. The objective of this program is to rehabilitate cocoa farms and expand intensification by providing easier access to inputs (KKPOD, 2013). The third dummy variable for yield loss is used to reflect the effect of pests and adverse weather on cocoa harvest quantity.

Some cocoa is grown in an agroforestry or an intercropping system (Ofori-Bah and Asafu-Adjaye, 2011). Ruf and Zadi (1998) and Asare (2005) suppose that cocoa yields can be maintained in the long run only with the use of forest tree species in cocoa cultivation. Cocoa agroforests also support conservation policies because they connect rainforest areas and provide habitat for native plants and animals. However, the influence of shading trees on cocoa yields is highly debated. Although some papers report the advantages of these trees because they decrease plant stress, others provide evidence that shade can limit cocoa yields (Frimpong et al., 2007). Following Bentley et al. (2004), we add a fourth dummy variable to our model that captures the influence of the higher shade (larger than 35 percent) production system and expect the sign to be negative.

To assess the effect of crop diversification on cocoa production (Ofori-Bah and AsafuAdjaye, 2011), a fifth dummy variable for intercropping is also added to the model. Farmers can grow a variety of fruit-bearing trees to help cope with the volatile cocoa prices by supplementing their income. In Indonesia, banana, durian, and coconut are mainly intercropped with cocoa at its fruit-bearing age (Ministry of Agriculture, 2015). But crop diversification has also another advantage. An increasing number of studies demonstrate that intercropping improves erosion control (soil and water retention), nutrient cycling, carbon dioxide capture, biodiversity, and the relationship of fauna and flora (Scherer-Lorenzen et al., 2005b; Gockowski and Sonwa, 2011). Therefore, interplanting is often supported to take advantage of the mutualism between different plants and to compensate for the low level of intermediate inputs (Pretzsch, 2005). We anticipate that intercropping has a positive effect on cocoa yields. 
Table 4.1: Description of the cocoa farm variables.

\begin{tabular}{|c|c|}
\hline Variable & Description \\
\hline \multicolumn{2}{|l|}{ Output } \\
\hline Cocoa & Cocoa quantity harvested on the farm (kilograms) \\
\hline Plants & Number of native rainforest plants in a random $5 * 5 \mathrm{~m}$ area on the cocoa farm \\
\hline \multicolumn{2}{|l|}{ Input } \\
\hline Tree age_M & Average cocoa tree age (years), measured \\
\hline Tree age_S & Average cocoa tree age (years), self-reported \\
\hline Land_M & Total area planted with cocoa, measured (ares) \\
\hline Land_S & Total area planted with cocoa, self-reported (ares) \\
\hline Costs & Fertilizer, pesticide, transport, processing, and labor costs for the farm (1000 Rupiah) \\
\hline \multicolumn{2}{|l|}{ Technology } \\
\hline No expense & Dummy, 1 = household used only family labor (no material inputs or hired labor) \\
\hline Gernas & Dummy, $1=$ household joined the Gernas Pro Kakao program in the last 3 years \\
\hline Intercrop_M & Dummy, $1=$ there was intercropping on the cocoa farm, measured \\
\hline Intercrop_S & Dummy, $1=$ there was intercropping on the cocoa farm, self-reported \\
\hline Shade_M & Dummy, 1 = shade level of the cocoa farm is larger than 35 percent, measured \\
\hline Shade_S & Dummy, $1=$ shade level of the cocoa farm is larger than 35 percent, self-reported \\
\hline Crop loss & Dummy, 1 = yield loss because of adverse weather or pests \\
\hline \multicolumn{2}{|l|}{ Inefficiency } \\
\hline Male & Dummy, 1 = household head is male \\
\hline High school & Dummy, $1=$ household head completed the junior high school \\
\hline Extension & Dummy, 1 = household head had extension contacts \\
\hline Credit & Dummy, $1=$ household head obtained credit in the last 3 years \\
\hline
\end{tabular}

Notes: All variables refer to the last 12 months with the mentioned exceptions.

\subsubsection{Inefficiency model}

We specify six elements in the vector $\boldsymbol{Z}$ in equation (4.7) that express the management skills of cocoa smallholders and their access to productive resources and knowledge (Wollni and Brümmer, 2012). First, we anticipate that it is more difficult for households with female heads to access markets (Wollni and Brümmer, 2012). They are also usually widows, which can limit labor availability to accomplish agricultural work timely (Onumah et al., 2013b). As a result, we expect female-headed households to display lower efficiency levels.

Second, the education dummy equals one if the head of the household completed junior high school. We expect that it affects positively the management skills of the cocoa farmers and hence efficiency (Ingram et al., 2014). However, a number of papers show that smallholders with higher educational attainment reveal lower technical efficiency levels (Teal et al., 2006). An explanation of these findings is that smallholders with higher educational 
levels have more likely additional sources of income and they concentrate more on these offfarm activities than on the farm management.

The next two variables indicate the external support for cocoa farming households (Nkamleu et al., 2010; and Ofori-Bah and Asafu-Adjaye, 2011). Contacts with extension agents are commonly considered to influence efficiencies positively since the information circulated in extension services should enhance farming methods (Dinar et al., 2007). However, some factors such as other information sources, the ability and willingness of smallholders to employ the distributed information, and the quality of agricultural extension services can confound the results of extension contacts (Feder et al., 2004).

Furthermore, the credit dummy variable indicates whether the cocoa farmer has access to credit. If smallholders can buy intermediate inputs with credit when required and not just when they have sufficient cash, then input use can become more optimal. Consequently, the economic literature underlines the failure of credit markets as the cause of non-profit maximizing behaviors and poverty traps (Dercon, 2003). Additionally, reducing capital constraints decreases the opportunity cost of intermediate inputs relative to family labor and allows the application of labor-saving technologies such as enhanced cocoa hybrid-fertilizer methods (Nkamleu et al., 2010). Therefore, many economists view the spread of feasible agricultural credit services crucial for raising the productivity of labor and land (Zeller et al., 1997).

Based on Rao et al. (2012), we also include production frontier variables in the inefficiency model. Following Wollni and Brümmer (2012) and Waarts et al. (2015), the size of the farm reflects households' endowments. It influences the technical efficiency ambiguously. If farmers with larger plantations specialize less in cocoa cultivation, then the size of the farm may negatively affect efficiency. However, farm size as a proxy for total wealth is anticipated to positively influence technical efficiency if financial markets are constrained (Binswanger and Rosenzweig, 1986).

The Gernas variable is also part of the inefficiency specification because we expect that this government program did not just influence the output directly but also indirectly through the efficiency. In particular, we hypothesize that, although Gernas increases output, it reduces efficiency temporarily due to a learning curve effect: it shifts out the production frontier but producers are not able to keep pace in the short run (Brümmer et al., 2006). 


\subsection{Data description}

\subsubsection{Data sources}

We acquire the data using the survey infrastructure of the earlier STORMA (Stability of Rainforest Margins in Indonesia) project in Göttingen. This project conducted four rounds of household and agricultural surveys in Indonesia between 2001 and 2013. The survey data were collected from 722 randomly selected cocoa farmer households in 15 random villages near the Lore Lindu National Park in Central Sulawesi province. This province is the second largest cocoa producer in Indonesia with 17 percent of the Indonesian production in 2014 (Ministry of Agriculture, 2015). The park provides habitat for some of the most unique animal and plant species in the world. However, the increase of land used for farming is threatening its integrity (Zeller et al., 2002).

For our survey, we randomly selected one third (240) of the STORMA households in 2015. First, these households were interviewed using standardized structured questionnaires. The researchers edited the questionnaire in English first, then translated it into Indonesian and tested it with a pilot survey. The interviews lasted, on average, about 2 hours. Because some farmers cultivated several cocoa plots simultaneously, output and input details were collected at plot level to increase data accuracy (Rao et al., 2012).

Second, we extended this data by verifying the self-reported values of variables and by measuring environmental outputs such as native plant abundance on the farm of every sampled household. Based on Maytak (2014), we expect that estimations with measured and selfreported data lead to significantly different results. In particular, we hypothesize that selfreported data overestimates efficiencies because farmers tend to paint a too rosy picture of their operations.

The data collection protocol for our survey was developed with the help of the EFFORTS (Ecological and Socioeconomic Functions of Tropical Lowland Rainforest Transformation Systems) project at Göttingen. ${ }^{10}$ We tested this protocol on 12 cocoa farms to improve it. To implement it, we hired six BA graduates in botany from the University of Tadulako in Palu, Central Sulawesi, who also carried out the household interviews. A representative 5 meter by 5 meter area in the middle of the each cocoa farm was selected for plant counting and plant identification in the understory vegetation (Gockowski and Sonwa,

\footnotetext{
${ }^{10}$ Funded by the German Research Foundation (DFG).
} 
2011). Furthermore, cameras with GPS reception were used to photograph all the unknown plants for later identification and to verify the farm size and the other farm characteristics.

\subsubsection{Descriptive statistics}

Table 4.2 shows the summary statistics of the independent and dependent variables in the production frontier and inefficiency equations. On average, we find 106 native rainforest plants on the $5 \times 5$ meter sampling areas. However, the standard deviation and the extreme values reveal huge differences between the farms. Compared with the last survey done in our sample area in 2012, the average output of the cocoa farms almost halved in 2015, while the average farm size remained almost constant at around one hectare, which is about one third of the African average (ICCO, 2016). This resulted in an almost 50 percent decrease in the average cocoa yield, which was in 2015 around $350 \mathrm{~kg} / \mathrm{hectare}$. We can list two reasons for this. First, cocoa trees are now considerably older than the most productive age: in 2015, they were on average 15 years old. This is still just one half of the African average because of the later start of cocoa cultivation in Indonesia. Second, a record drought hit Sulawesi in 2015 because of the latest El Niño cycle. Due to the extremely dry weather, 90 percent of the households reported significant yield losses.

Labor, fertilizer, and pesticide use more than doubled in the last three years. The continued expansion of the Gernas Pro Kakao government program could have contributed to this phenomenon by providing easier access to intermediate inputs (KKPOD, 2013). According to our survey data, the level of labor and intermediate input use is now approaching the African average (Maytak, 2014). Furthermore, we find that cocoa in our sample area is cultivated mostly in a full-sun monoculture system, in contrast to Africa (Gockowski and Sonwa, 2011; Nkamleu et al., 2010).

The statistics of the inefficiency variables show that the share of female household heads stood at 6 percent in 2015, which is consistent with past studies that show cocoa cultivation as a male-dominated livelihood (Nkamleu et al., 2010; Maytak, 2014). Moreover, the educational attainment of the average household head increased considerably over the years: in 2015, more than 50 percent of the household heads completed junior school. Furthermore, we could observe an increase of extension services in the last three years: 40 percent of household heads had extension contacts in 2015. However, credit access fell back significantly just to 8 percent in 2015 . 
Finally, let us compare the measured and self-reported variables. Two dummy variables have both values: intercropping and shade cover. As we can see from Table 4.A1, the selfreported dummy variables differ in about 5-10 percent of observations from the measured ones and there are no clear directions in the inaccuracies. Figure 4.A1 shows us the differences in the two continuous variables: tree age and farm size. We can find alternative values in 30 and 80 percent of the observations. Again, the inaccuracies seem to be random. T-tests confirm that there are no significant differences in the means of the four self-reported and measured variables.

Table 4.2: Summary statistics of the cocoa farm variables.

\begin{tabular}{|c|c|c|c|c|c|}
\hline Variable & Observations & Mean & Standard & Minimum & Maximum \\
\hline \multicolumn{6}{|l|}{ Output } \\
\hline Cocoa & 208 & 372 & 542 & 15 & 4500 \\
\hline Plants & 208 & 106 & 65 & 10 & 315 \\
\hline \multicolumn{6}{|l|}{ Input } \\
\hline Tree age_M & 208 & 14.9 & 5.8 & 3 & 40 \\
\hline Tree age_S & 208 & 15.0 & 5.6 & 3 & 40 \\
\hline Land_M & 208 & 104 & 73 & 20 & 500 \\
\hline Land_S & 208 & 106 & 74 & 17 & 540 \\
\hline Costs & 208 & 1557 & 2027 & 30 & 11735 \\
\hline \multicolumn{6}{|l|}{ Technology } \\
\hline No expense & 208 & 0.02 & 0.14 & 0 & 1 \\
\hline Gernas & 208 & 0.26 & 0.44 & 0 & 1 \\
\hline Intercrop_M & 208 & 0.13 & 0.34 & 0 & 1 \\
\hline Intercrop_S & 208 & 0.14 & 0.35 & 0 & 1 \\
\hline Shade_M & 208 & 0.15 & 0.36 & 0 & 1 \\
\hline Shade_S & 208 & 0.16 & 0.37 & 0 & 1 \\
\hline Crop loss & 208 & 0.90 & 0.30 & 0 & 1 \\
\hline Inefficiency & & & & 0 & 1 \\
\hline Male & 208 & 0.94 & 0.24 & 0 & 1 \\
\hline High school & 208 & 0.51 & 0.50 & 0 & 1 \\
\hline Extension & 208 & 0.40 & 0.49 & 0 & 1 \\
\hline Credit & 208 & 0.08 & 0.27 & 0 & 1 \\
\hline
\end{tabular}

\subsection{Results and discussion}

\subsubsection{Production frontier}

Table 4.3 shows the parameter estimates of the frontier models. According to equation (4.8), a positive rainforest plants distance elasticity implies a negative effect on the cocoa 
production. Similarly, a negative input distance elasticity is interpreted as a positive contribution of the input to the cocoa production.

The coefficients of the native plants variable are significant and have the expected positive signs. Their values, 0.651 and 0.698 , mean that a one percent increase in the number of rainforest plants on the cocoa farm reduces the cocoa output by almost 0.7 percent. Each significant first-order input distance elasticity possesses the expected sign and, therefore, satisfies the monotonicity property at the sample mean. In the measured variables model, the partial production elasticities of land and costs are 0.699 and 0.194 . The values from the model using the self-reported variables are similar. We use t-tests to evaluate whether the scale elasticities of 0.893 and 0.906 at the sample mean significantly differ from one. The null hypothesis of constant returns to scale is rejected at the 5 percent level, according to the test results. This implies that cocoa production exhibits a diminishing returns to scale. Normally, undertakings with this characteristics are viewed as too big. However, the average cocoa farm size in our sample is small: just around one hectare. A plausible cause of the diminishing return to scale can be some impediments to growth (Brümmer et al., 2006).

The positive square terms of plants and tree age fulfil the curvature conditions of the production function at the sample mean. The values for the tree age variable point to the maturing and aging process of the cocoa trees, although the coefficient in the self-reported variables model is not significant. Moving to the cross-term coefficients, we find evidence of input complementary effect between land and costs. In the case of the measured variables model, two additional interaction terms are significant. They show complimentary effect between plants and costs, and substitution effect between plants and tree age.

Additionally, various dummy variables are incorporated into the models to describe cocoa farming more accurately. The coefficient of the Gernas Pro Kakao government program is negative and significant at the 1 percent level in both models. This means that, as anticipated, farms participating in this program have higher cocoa output levels. However, it seems that the self-reported variables substantially overestimate the effect of Gernas Pro Kakao. The crop loss variable is also significant in both models and possesses the expected sign. This points to the exceptionally dry El Niño weather. However, the self-reported variables largely underestimated its effect. Finally, high shade cover seems to decrease production, but its coefficient is only significant in the self-reported model. 
Table 4.3: Parameter estimates of the cocoa production frontier models.

\begin{tabular}{|c|c|c|}
\hline Variable & TE measured variables & TE self-reported variables \\
\hline \multicolumn{3}{|l|}{ Input } \\
\hline ln Plants & $0.651(0.058)^{* * *}$ & $0.698(0.065)^{* * *}$ \\
\hline ln Tree age_M/S & $0.221(0.165)$ & $0.042(0.123)$ \\
\hline ln Land_M/S & $-0.699(0.355)^{* *}$ & $-0.697(0.165)^{* * *}$ \\
\hline $\ln$ Costs & $-0.194(0.080)^{* *}$ & $-0.209(0.071)^{* * *}$ \\
\hline 0.5 (ln Plants $)^{2}$ & $0.113(0.039)^{* * *}$ & $0.143(0.047)^{* * *}$ \\
\hline $0.5(\ln \text { Tree age_M M/S })^{2}$ & $0.609(0.283)^{* *}$ & $0.242(0.197)$ \\
\hline $0.5(\ln \text { Land_M/S })^{2}$ & $0.026(0.362)$ & $-0.118(0.165)$ \\
\hline $0.5(\ln \text { Costs })^{2}$ & $-0.048(0.064)$ & $-0.062(0.051)$ \\
\hline $\ln$ Plants * $\ln$ Tree age_M/S & $0.082(0.039)^{* *}$ & $0.028(0.054)$ \\
\hline ln Plants * ln Land_M/S & $0.024(0.081)$ & $-0.090(0.059)$ \\
\hline $\ln$ Plants * $\ln$ Costs & $-0.078(0.022)^{* * *}$ & $-0.044(0.039)$ \\
\hline ln Tree age_M/S * ln Land_M/S & $0.019(0.180)$ & $-0.059(0.115)$ \\
\hline $\ln$ Tree age_M/S $* \ln$ Costs & $0.072(0.075)$ & $0.038(0.081)$ \\
\hline ln Land_M M/S * $\ln$ Costs & $-0.195(0.051)^{* * *}$ & $-0.232(0.065)^{* * *}$ \\
\hline \multicolumn{3}{|l|}{ Technology } \\
\hline No expense & $0.380(0.240)$ & $0.170(0.336)$ \\
\hline Gernas & $-0.357(0.031)^{* * *}$ & $-0.516(0.121)^{* * *}$ \\
\hline Intercrop_ $\mathrm{M} / \mathrm{S}$ & $0.153(0.117)$ & $0.103(0.094)$ \\
\hline Shade_M/S & $0.121(0.080)$ & $0.212(0.072)^{* * *}$ \\
\hline Crop loss & $0.459(0.195)^{* *}$ & $0.282(0.133)^{* *}$ \\
\hline Constant & $-0.389(0.098)^{* * *}$ & $-0.007(0.152)$ \\
\hline \multicolumn{3}{|l|}{ Variance } \\
\hline$\sigma_{\mathrm{u}}$ & $0.487(0.052)^{* * *}$ & $0.501(0.071)^{* * *}$ \\
\hline$\sigma_{\mathrm{v}}$ & $0.000(0.000)^{* * *}$ & $0.154(0.049)^{* * *}$ \\
\hline RTS & 0.893 & 0.906 \\
\hline
\end{tabular}

Notes: Robust standard errors are in the parentheses. *: $\mathrm{p}<0.10,{ }^{* *}: \mathrm{p}<0.05,{ }^{* * *}: \mathrm{p}<0.01$.

\subsubsection{Efficiency levels}

Generalized likelihood ratio tests are employed to evaluate whether average response functions would fit the models or inefficiency effects are present in the models. We reject the null hypothesis for both specifications at the 1 percent level, which means that the stochastic frontier model represents the data better than the OLS model.

Table 4.4 documents the average degree of technical efficiency, while Figure 4.A2 presents the distributions of efficiencies for the sample farms. Based on the measured variables, we estimate that the average technical efficiency of cocoa farms is around 50 percent. Low values such as this tend to indicate a less specialized and less competitive market (Coelli et al., 
2005). According to our field observations, this coincides with smallholder cocoa markets in Sulawesi, where the only controllable characteristic is the quality of the raw product and many producers do not pay too much attention to this. Compared with this value, the self-reported variables model overestimates the efficiency by 7 percentage points. The histogram of the differences is depicted in Figure 4.A3. Using a t-test, we find that the difference in means is statistically significant.

In both cases, the range of efficiency estimates is very wide and many scores are inside the bottom quarter of the distribution range. This means that most cocoa farmers have an ample scope to expand cocoa output or increase the number of native rainforest plants without increasing input use. The efficiency scores point, on average, to a possible expansion of production by $367 \mathrm{~kg}$ of cocoa per farm and year or to a possible increase of 43680 rainforest plants per farm.

By plotting the individual efficiencies against the numbers of rainforest plants on the corresponding farms, we can detect a logistic increase of efficiencies with the increasing number of native plants (Figure 4.2). This means that native plants can positively affect the output level via efficiency. Furthermore, the efficiency distributions show, at the mean, a higher degree of efficiency for producers with smaller farms. Other factors such as allocation of labor, fertilizer, and pesticide are also lower on farms with higher efficiencies, suggesting a more efficient use of the available labor force and materials.

Table 4.4: Descriptive statistics of the cocoa farm efficiency estimates (percentages).

\begin{tabular}{|c|c|c|c|c|c|}
\hline Model & Observations & Mean & Standard deviation & Minimum & Maximum \\
\hline TE measured variables & 208 & 50 & 22 & 13 & 100 \\
\hline TE self-reported & 208 & 57 & 21 & 12 & 93 \\
\hline TE difference & 208 & 7 & 9 & -24 & 32 \\
\hline
\end{tabular}


Figure 4.2: Scatter plot of the cocoa farm efficiencies and the number of native rainforest plants.

a) technical efficiency estimated using measured explanatory variables

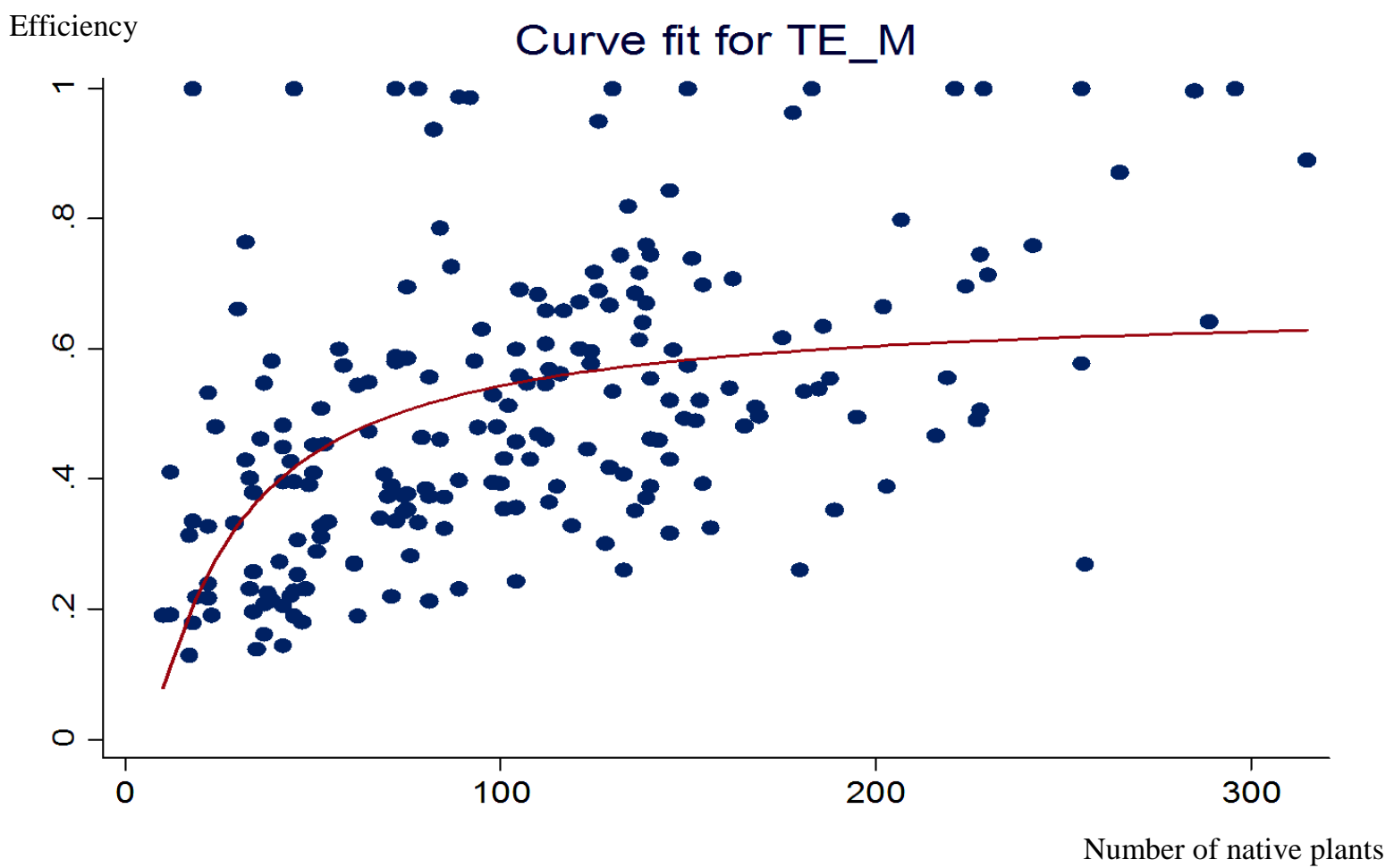

b) technical efficiency estimated using self-reported explanatory variables

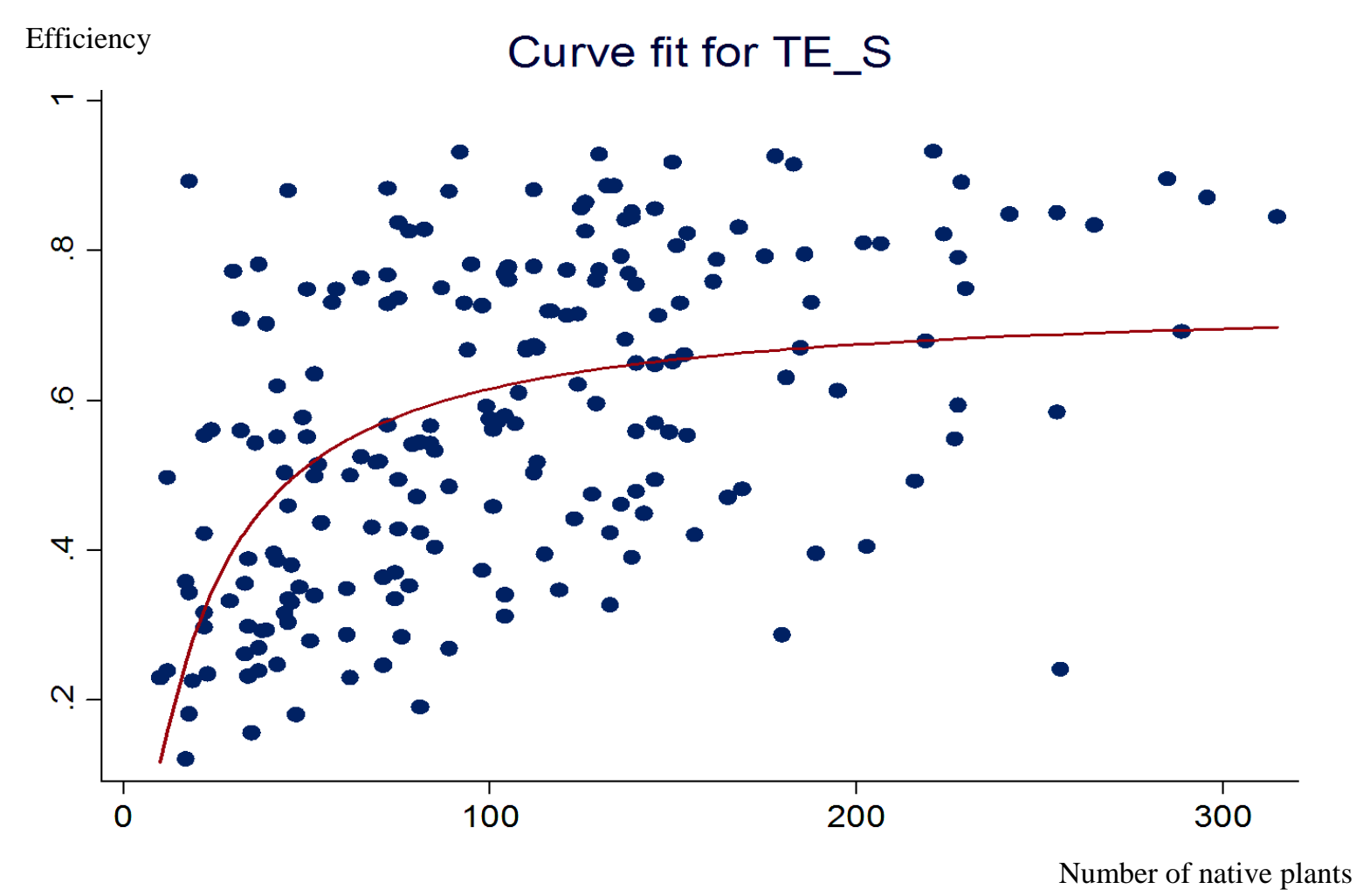




\subsubsection{Inefficiency effects}

Table 4.5 presents the results of the inefficiency model estimations: both the estimated coefficients and the corresponding marginal effects at the means. For dummy variables, the marginal effects are calculated for a discrete change from zero to one. A negative sign indicates that the variable in question has a negative influence on inefficiency, which means a positive influence on efficiency. We check the joint significance of the possible inefficiency effects with likelihood ratio tests. Based on the results, we reject at the 1 percent level for all three models that all inefficiency variables are insignificant.

In both models, the Gernas Pro Kakao government program has a significant influence on farm-specific productive efficiencies. Efficiency decreases by 34 percent, on average, with participation in this program in the measured variables model. This is plausible because Gernas farmers have to apply new production methods due to new hybrid cocoa varieties and chemicals. The model using the self-reported data substantially overestimates the effect of the Gernas Pro Kakao program. Agricultural extension is the other variable that is significant in both cases. In the measured variables model, it increases efficiency by 21 percent. Again, the coefficient is largely overestimated with the self-reported variables.

Finally, we find that credit access does not have a significant effect on efficiency. This result does not match with African studies which show positive linkages (Nkamleu et al., 2010; Awotide et al., 2015). For example, many economists view the spread of feasible agricultural credit services crucial for raising technical efficiency (Zeller et al, 1997).

Table 4.5: Estimates and average marginal effects of the cocoa farm inefficiency models.

\begin{tabular}{|c|c|c|c|c|}
\hline \multirow[t]{2}{*}{ Variable } & \multicolumn{2}{|c|}{ TE measured variables } & \multicolumn{2}{|c|}{ TE self-reported variables } \\
\hline & Coefficients & Marginal effects & Coefficients & Marginal effects \\
\hline In Land_M/S & $0.321(0.317)$ & 0.236 & $0.309(0.216)$ & 0.184 \\
\hline Gernas & $0.337(0.99) * * *$ & $0.248 * * *$ & $0.660(0.233) * * *$ & $0.394 * * *$ \\
\hline Male & $0.408(0.226)^{*}$ & $0.300 *$ & $0.547(0.341)$ & 0.326 \\
\hline High school & $0.148(0.105)$ & 0.109 & $0.186(0.116)$ & 0.111 \\
\hline Extension & $-0.211(0.104)^{* *}$ & $-0.155^{* *}$ & $-0.318(0.155)^{* *}$ & $-0.190 * *$ \\
\hline Credit & $-0.254(0.204)$ & -0.187 & $-0.242(0.216)$ & -0.144 \\
\hline Constant & $0.306(0.337)$ & & $-0.134(0.433)$ & \\
\hline
\end{tabular}

Notes: Robust standard errors are in the parentheses. *: $\mathrm{p}<0.10, * *: \mathrm{p}<0.05, * * *: \mathrm{p}<0.01$. 


\subsubsection{Shadow prices}

To understand the trade-off between the cocoa output and the native rainforest plants, the monetary quantification of this connection is desirable. Because markets for these herbaceous plants in our specification do not exist, we estimate the shadow price based on our output distance function and the corresponding revenue function. In combination with the cocoa bean price, we can calculate the absolute price for the native plants. According to FAO Statistics, the aggregated Indonesian cocoa price was 1.74 US dollars/kg in 2015. We compute the shadow price with the following equation (Fare et al., 2005):

$q=-p * \frac{\partial D_{o}\left(x, y_{1}, y_{2}\right) / \partial y_{2}}{\partial D_{o}\left(x, y_{1}, y_{2}\right) / \partial y_{1}} * \frac{\mu_{y 1}}{\mu_{y 2}}$

Because of the normalization of our variables, we have to multiply the derivatives in the equation by the ratio of output averages to obtain real values. The shadow price of a rainforest plant describes the monetary value of production that must be forgone to increase the number of native plants by one moving along the efficient points on the production frontier. According to the measured variables model (Table 4.6), the average price for one plant is 3.7 US cents. The t-test did not find a significant difference (Figure 4.A4) between the results of two estimates. Due to violations of monotonicity, two observations of the shadow price estimations are dropped to prevent scaling in the reverse direction on the production frontier (Fare et al., 2005).

The connection between the abundance of native plants and the shadow price gives an additional insight on the shape of the trade-off function. It appears that farms with lower abundance of rainforest plants are linked to higher shadow prices than farms with a high abundance. Plotting the individual shadow prices against the characteristics of producers also reveals that bigger farm sizes and costs are connected to lower prices.

Table 4.6: The calculated shadow prices of the native rainforest plants in US cents.

\begin{tabular}{|c|c|c|c|c|c|}
\hline Model & Observations & Mean & Standard deviation & Minimum & Maximum \\
\hline SP measured variables & 206 & 3.71 & 4.93 & 0.47 & 48.47 \\
\hline SP self-reported & 206 & 3.57 & 2.79 & 0.60 & 20.48 \\
\hline SP difference & 206 & -0.14 & 3.06 & -27.98 & 3.94 \\
\hline
\end{tabular}

\subsection{Conclusion}

The surge in cocoa demand and price prompts us to search for sustainable ways to improve cocoa yields. We look at the trade-off between smallholder cocoa intensification 
and the ecosystem in Central Sulawesi and investigate the determinants of environmental efficiency in cocoa production. We apply a distance output function that includes cocoa production and the abundance of native rainforest plants as outputs. Our data set, based on a household and environmental survey conducted in 2015, allows us to analyze 208 cocoa producers with both measured and self-reported data.

We find that there is a trade-off between cocoa yields and abundance of native rainforest plants. According to this connection, the intensification of cocoa farms results in higher ecosystem degradation. By computing the shadow prices of these rainforest plants, we estimate the monetary value of reductions in their abundance. Additionally, each significant first-order input distance elasticity possesses the expected sign and the results indicate that most cocoa farmers operate under diminishing returns to scale. Given the small average farm size, the latter could reflect the impediments to growth. As expected, the Gernas Pro Kakao government program helps the participating farmers to increase their output.

The estimations show substantial inefficiencies for the majority of cocoa farmers. The low average efficiency value of 50 percent indicates a less specialized and less competitive market with low pressure for cocoa producers. Increasing efficiency could lead to a win-winwin situation: more production coming from less hectares, with more native plants co-existing with cocoa on the remaining hectares. On average, the efficiency scores point to a possible production expansion of $367 \mathrm{~kg}$ of cocoa per farm and year, to a possible increase of 43680 rainforest plants per farm, or to a possible acreage reduction of 0.52 hectares per farm.

Looking at the inefficiency effects, we can see that the participation in the Gernas Pro Kakao program decreases efficiency. This is plausible because Gernas farmers have to learn new production methods due to new cocoa varieties and chemicals and they are not able to catch up to the outward-shifting production frontier in the short run. Furthermore, we find that agricultural extension services have a substantial role in increasing efficiency, confirming evidence from West Africa. We can also observe that the model using self-reported variables overestimates the inefficiency effects, as well as the distance elasticities and efficiencies.

Finally, we find that credit access does not have a significant effect on efficiency. This result is inconsistent with African studies which show positive linkages. Feasible agricultural credit services are viewed by numerous economists as a crucial prerequisite for improving efficiency, a critical part of encouraging development. We recommend linking credit to extension services as part of this effort. 


\subsection{References}

Asare, R. (2005): Cocoa agroforests in West Africa: a look at activities on preferred trees in the farming systems. Forestry and Landscape Working Paper No. 6, University of Copenhagen, Copenhagen.

Awotide D.O., Kehinde, A.L., Akorede, T.O. (2015): Metafrontier analysis of access to credit and technical efficiency among smallholder cocoa farmers in Southwest Nigeria. International Business Research 8, 132-144.

Bentley, J., Boa, E., Stonehouse, J. (2004): Neighbor trees: shade, intercropping and cocoa in Ecuador. Human Ecology 32, 241-270.

Besseah, F.A., Kim, S. (2014): Technical efficiency of cocoa farmers in Ghana. Journal of Rural Development 37, 159-182.

Binam, J.N., Tonye, J., Wandji, N., Nyambi, G., Akoa, M. (2004): Factors affecting the technical efficiency among smallholder farmers in the slash and burn agriculture zone of Cameroon. Food Policy 29, 531-545.

Binswanger, H.P., Rosenzweig, M. (1986): Contractual Arrangements, Employment, and Wages in Rural Labor Markets in Asia. Yale University Press, New Haven.

Brümmer, B., Glauben, T., Lu, W. (2006): Policy reform and productivity change in Chinese agriculture: a distance function approach. Journal of Development Economics 81, 6179.

Clough, Y., Barkmann, J., Juhrbandt, J., Kessler, M., Wanger, T.C., Anshary, A. ... Tscharntke, T. (2011): Combining high biodiversity with high yields in tropical agroforests. Proceedings of the National Academy of Sciences 108, 8311-8316.

Coelli, T.J., Rao, D.S.P., O'Donnell, C.J., Battese, G.E. (2005): An Introduction to Efficiency and Productivity Analysis. Springer, New York.

Dand, R. (2010): The International Cocoa Trade, 3rd ed. Woodhead Publishing, Sawston.

Debreu, G. (1951): The coefficient of resource utilization. Econometrica 19, 273-292.

Dercon, S. (2003): Poverty Traps and Development: The Equity-Efficiency Debate Revisited. 1st AFD/EUDN Conference on Growth, Inequality, and Poverty, November 13, Paris.

Dinar, A., Karagiannis, G., Tzouvelekas, V. (2007): Evaluating the impact of agricultural extension on farms' performance in Crete: a nonneutral stochastic frontier approach. Agricultural Economics 36, 135-146.

Effendi, Hanani, N., Setiawan, B., Muhaimin, A.W. (2013): Characteristics of farmers and technical efficiency in cocoa Farming at Sigi Regency - Indonesia with approach 
stochastic frontier production function. Journal of Economics and Sustainable Development 4, 154-160.

FAO (2010): Global Forest Resources Assessment. FAO, Rome.

Fare, R., Grosskopf, S., Noh, D., Weber, W. (2005): Characteristics of a polluting technology: theory and practice. Journal of Econometrics 126, 469-492.

Feder, G., Murgai, R., Quizon, J.B. (2004): Sending farmers back to school: the impact of farmer field schools in Indonesia. Review of Agricultural Economics 26, 45-62.

Frimpong, K.O., Asase, A., Yelibora, M. (2007): Cocoa Farming and Biodiversity in Ghana. An Annual Project Report for the Earthwatch Institute, Accra.

Gockoswki, J., Sonwa, D. (2011): Cocoa intensification scenarios and their predicted impact on $\mathrm{CO} 2$ emissions, biodiversity conservation, and rural livelihoods in the guinea rain forest of West Africa. Environmental Management 48, 307-321.

Greene, W. H. (2008): The econometric approach to efficiency analysis. In: Fried, H. O., Lovell, C. A. K., Schmidt, S. S. (Eds), The Measurement of Productive Efficiency and Productivity Growth. Oxford University Press, New York, pp. 92-250.

Huppes, G.,Ishikawa, M. (2005): Eco-efficiency and its terminology. Journal of Industrial Ecology 9, 43-46.

ICCO (2014): The Cocoa Market Situation. International Cocoa Organization, London.

ICCO (2016): Quarterly Bulletin of Cocoa Statistics. International Cocoa Organization, London.

Ingram, V., Waarts, Y., Ge, L., van Vugt, S., Wegner, L., Puister-Jansen, L., Ruf, F., Tanoh, R. (2014): The IDH Cocoa Productivity and Quality Programme (CPQP) in Côte d'Ivoire; Impact assessment framework and baseline. Wageningen, LEI Wageningen UR (University \& Research centre), LEI Report 2014-016.

KKPOD (2013): National Movement of Cocoa Production and Quality improvement (GERNAS KAKAO). KKPOD, Jakarta.

Kumbhakar, S.C., Lovell, C.A.K. (2000): Stochastic Frontier Analysis. Cambridge University Press, Cambridge.

Maytak, L. (2014): Report on Farm Level Sustainability of Cocoa in Côte d'Ivoire: A Synthesis of Five Studies. International Finance Corporation, New York.

Ministry of Agriculture (2015): Directorate General of Estate Crops. Ministry of Agriculture, Indonesia, Jakarta. 
Nkamleu, G.B., Nyemeck, J., Gockowski, J. (2010): Technology Gap and Efficiency in Cocoa Production in West and Central Africa: Implication for Cocoa Sector Development. Working Papers Series No. 104, African Development Bank, Tunis.

Ofori-Bah, A., Asafu-Adjaye, J. (2011): Scope economies and technical efficiency of cocoa agroforestry systems in Ghana. Ecological Economics 70, 1508-1518.

Onumah, J.A., Al-Hassan, R.M., Onumah, E.E. (2013a): Productivity and technical efficiency of cocoa production in Eastern Ghana. Journal of Economics and Sustainable Development 4, 106-117.

Onumah, J.A., Onumah, E.E., Al-Hassan, R.M., Brümmer, B. (2013b): Meta-frontier analysis of organic and conventional cocoa production in Ghana. Agricultural Economics Czech 59, 271-280.

Picazo-Tadeo, A. J., Castillo-Giménez, J., Beltrán-Esteve, M. (2014): An intertemporal approach to measuring environmental performance with directional distance functions: Greenhouse gas emissions in the European Union. Ecological Economics 100, 173182.

Pretzsch, H. (2005): Diversity and productivity in forests: evidence from long-term experimental plots. In: Scherer-Lorenzen, M., Korner, C., Schulze, E. (Eds.), Forest Diversity and Function: Temperate and Boreal Systems. Springer, Berlin, pp. 41-64.

Rao, E.J.O., Brümmer, B., Qaim, M. (2012): Farmer participation in supermarket channels, production technology, and efficiency: the case of vegetables in Kenya. American Journal of Agricultural Economics 94, 891-912.

REDD (2012): Opportunity Costs of Major Land Uses in Central Sulawesi. UN Reducing Emissions from Deforestation and Forest Degradation, Geneva.

Reinhard, S., Lovell, C. A. K., Thijssen, G. (2002): Analysis of environmental efficiency variation. American Journal of Agricultural Economics 84, 1054-1065.

Ruf, F., Schroth, G. (2004): Chocolate forests and monocultures: a historical review of cocoa growing and its conflicting role in tropical deforestation and forest conservation. In: Schroth, G., Fonseca, G., Harvey, C., Gascon, C., Vasconcelos, H., Izac, A.-M. (Eds.), Agroforestry and Biodiversity Conservation in Tropical Landscapes. Island Press, Washington D.C., pp. 107-134.

Ruf, F., Zadi, H. (1998): Cocoa: from deforestation to reforestation. Proceedings of the First International Workshop on Sustainable Cocoa Growing. March 30-April 2, Panama City. 
Scherer-Lorenzen, M., Korner, C., Schulze, E. (2005a): The functional significance of forest diversity: the synthesis. In: Scherer-Lorenzen, M., Korner, C., Schulze, E. (Eds.), Forest Diversity and Functions: Temperate and Boreal Systems. Springer, Berlin, pp. 377-389.

Scherer-Lorenzen, M., Korner, C., Schulze, E. (2005b): The functional significance of forest diversity: the starting point. In: Scherer-Lorenzen, M., Korner, C., Schulze, E. (Eds.), Forest Diversity and Functions: Temperate and Boreal Systems. Springer, Berlin, pp. $3-12$.

Schroth, G., da Fonseca, G., Harvey, C., Gaston, C., Vasconcelos, H., Izac, A. (2004): Agroforestry and Biodiversity Conservation in Tropical Landscapes. Island Press, Washington D.C.

Schroth, G., Harvey, C.A. (2007): Biodiversity conservation in cocoa production landscapes: an overview. Biodiversity and Conservation 16, 2237-2244.

Sickles, R.C., Good, D.H., Getachew, L. (2002): Specification of distance functions using semi- and nonparametric methods with application to the dynamic performance of eastern and western European air carriers. Journal of Productivity Analysis 17, 133155.

Squicciarini, M. P., Swinnen, J. (2016): The Economics of Chocolate. Oxford University Press, Oxford.

Teal, F., Zeitlin, A.,Maamah, H. (2006): Ghana Cocoa Farmers Survey 2004. Report to Ghana Cocoa Board. Centre for the Study of African Economies, University of Oxford, Oxford.

Yaisawarng, S., Klein, J.D. (1994): The effects of sulfur-dioxide controls on productivity change in the United-States electric-power industry. Review of Economics and Statistics 76, 447460.

Waarts, Y., Ingram, V., Linderhof, V., Puister-Jansen, L., van Rijn, F., Aryeetey, R. (2015): Impact of UTZ certification on cocoa producers in Ghana, 2011 to 2014. LEI Wageningen UR, Wageningen.

WBCSD (1992): Changing Course. World Business Council for Sustainable Development, Washington D.C.

Welford, R. (1995): Environmental Strategy and Sustainable Development: The Corporate Challenge for the Twenty-First Century. Routledge, New York. 
Wollni, M., Brümmer, B. (2012): Productive efficiency of specialty and conventional coffee farmers in Costa Rica: Accounting for technological heterogeneity and self-selection. Food Policy 37, 67-76.

Zeller, M., Diagne, A., Mataya, C. (1997): Market access by smallholder farmers in Malawi: Implications for technology adoption, agricultural productivity, and crop income. Agricultural Economics 19, 219-229.

Zeller, M., Schwarze, S., van Rheenen, T. (2002): Statistical sampling frame and methods used for the selection of villages and households in the scope of the research program on stability of rainforest margins in Indonesia (STORMA). STORMA Discussion Paper Series No. 1, University of Göttingen, Göttingen. 


\subsection{Appendix}

Figure 4.A1: Histograms of the differences between the self-reported and measured cocoa farm variables.

a) Cocoa tree age

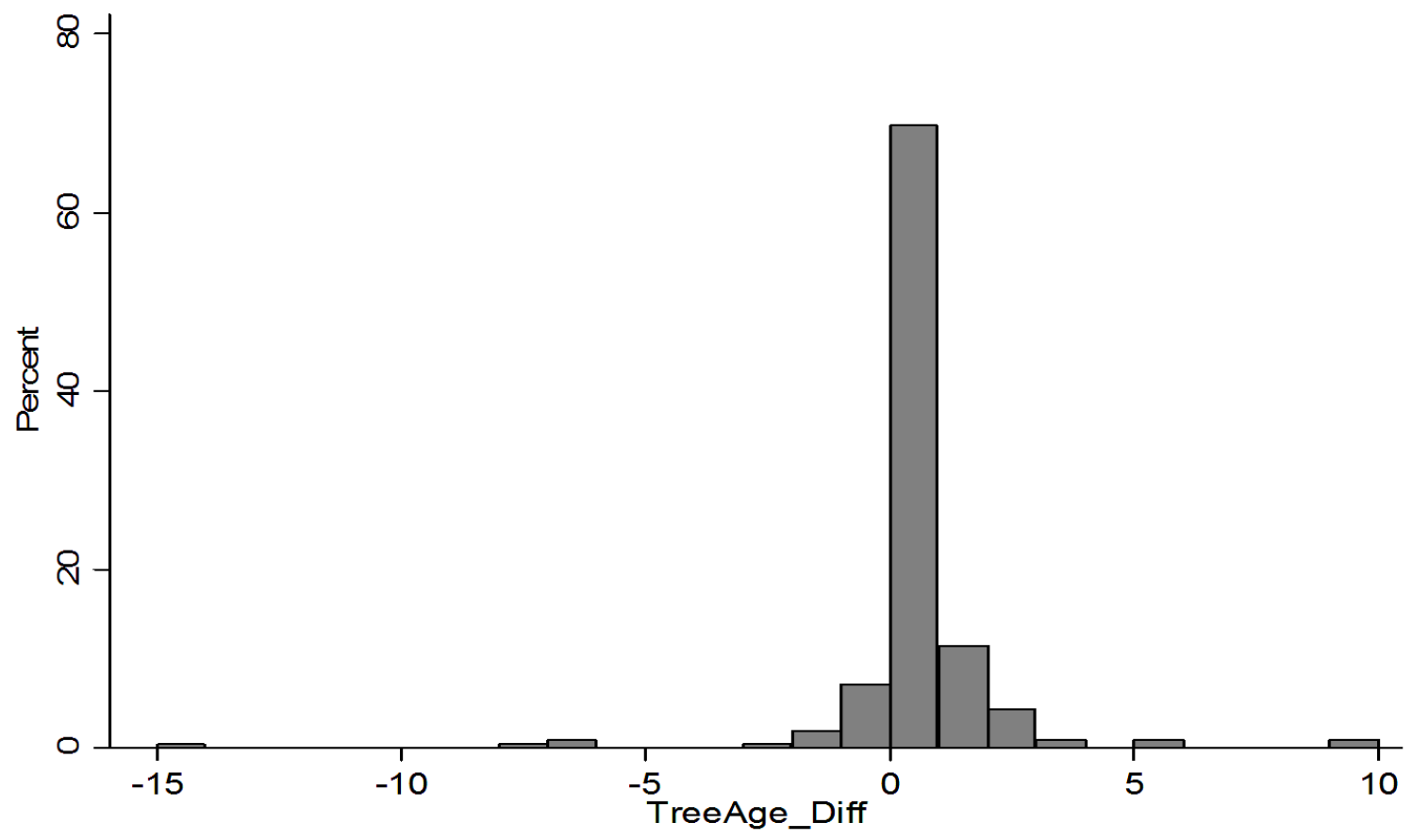

b) Total cocoa farm size

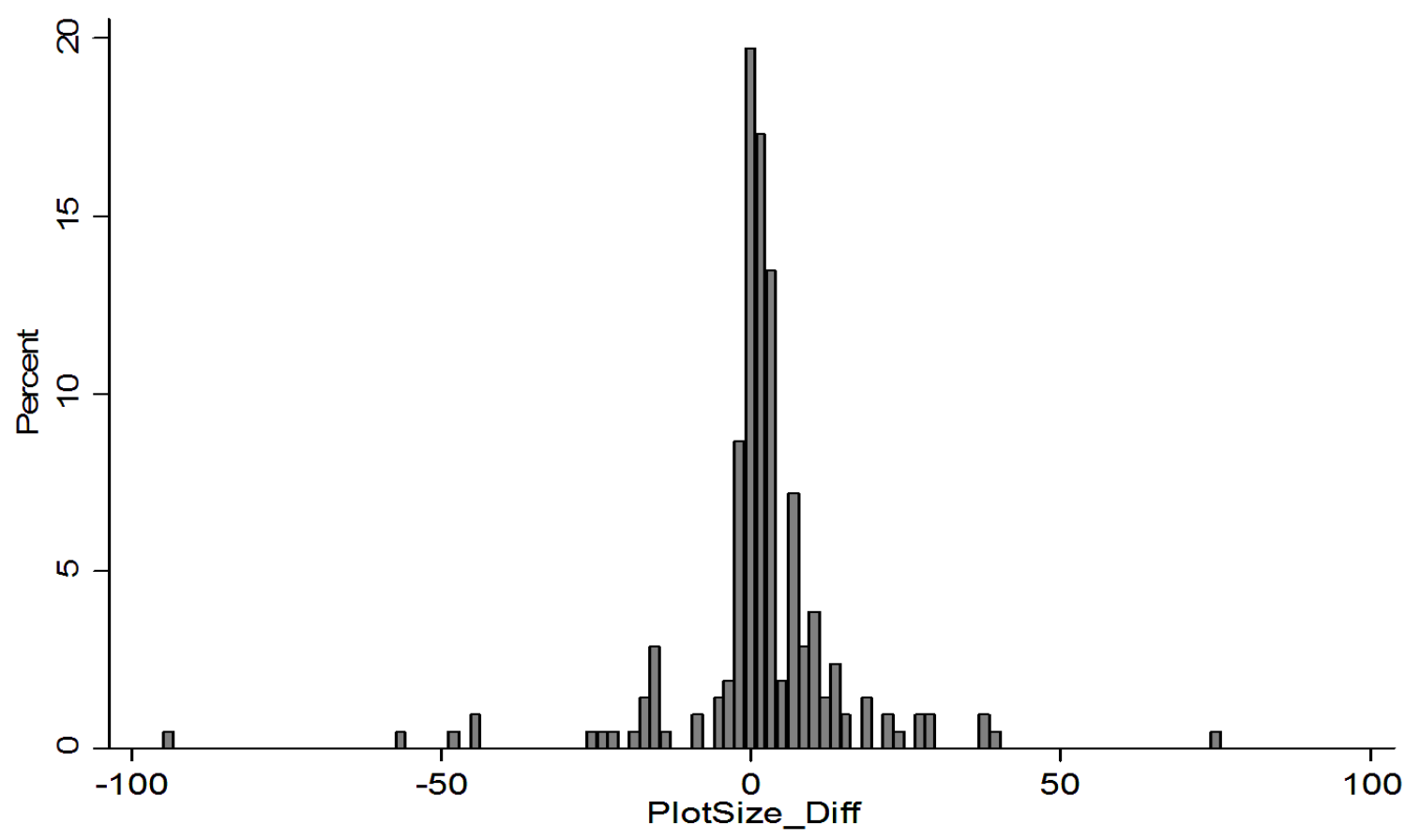


Figure 4.A2: Distribution of cocoa farm efficiencies in the models.

a) technical efficiency estimated using measured explanatory variables

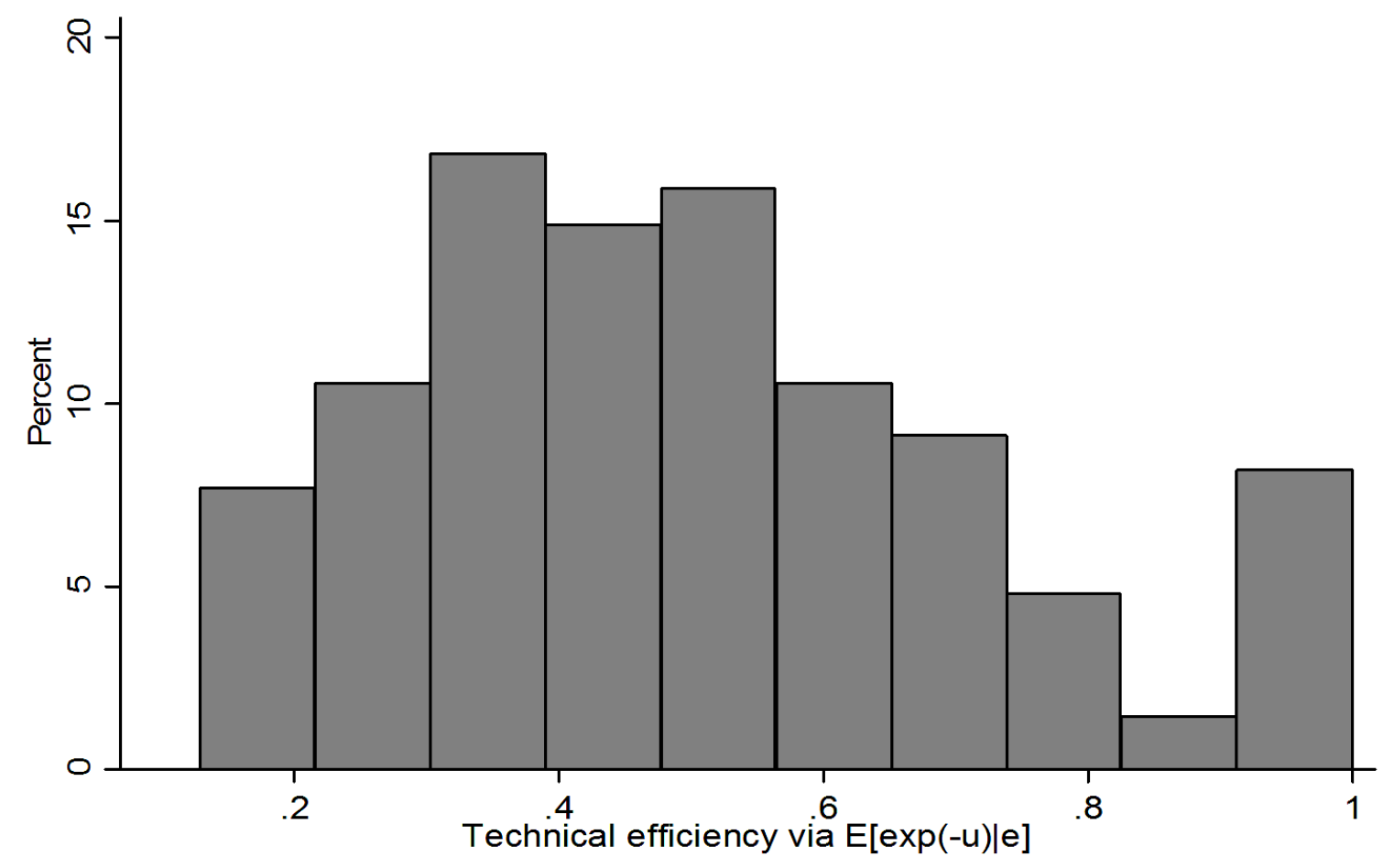

b) technical efficiency using self-reported explanatory variables

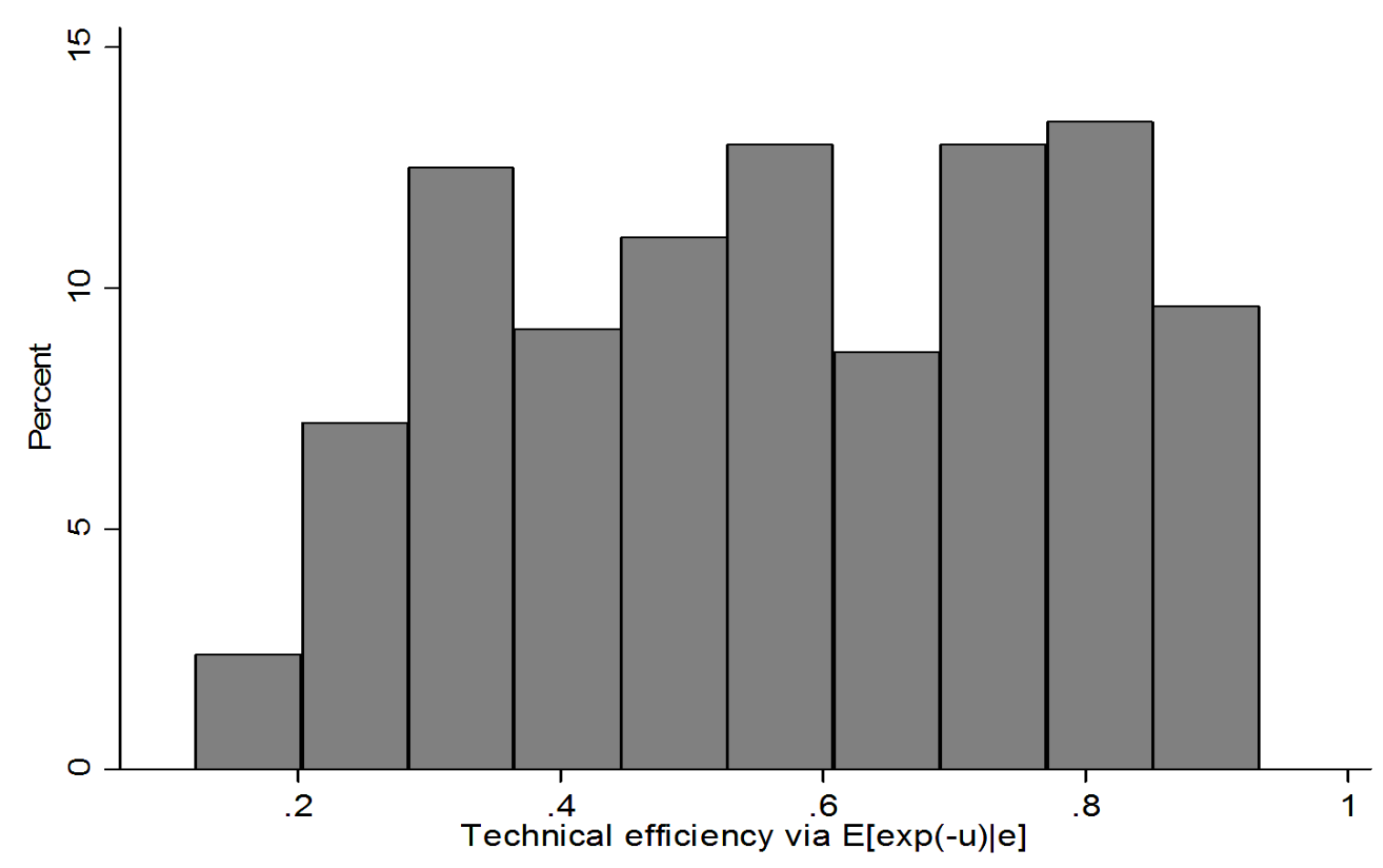


Figure 4.A3: Histogram of the differences between the cocoa farm efficiencies (self-reported - measured variables method).

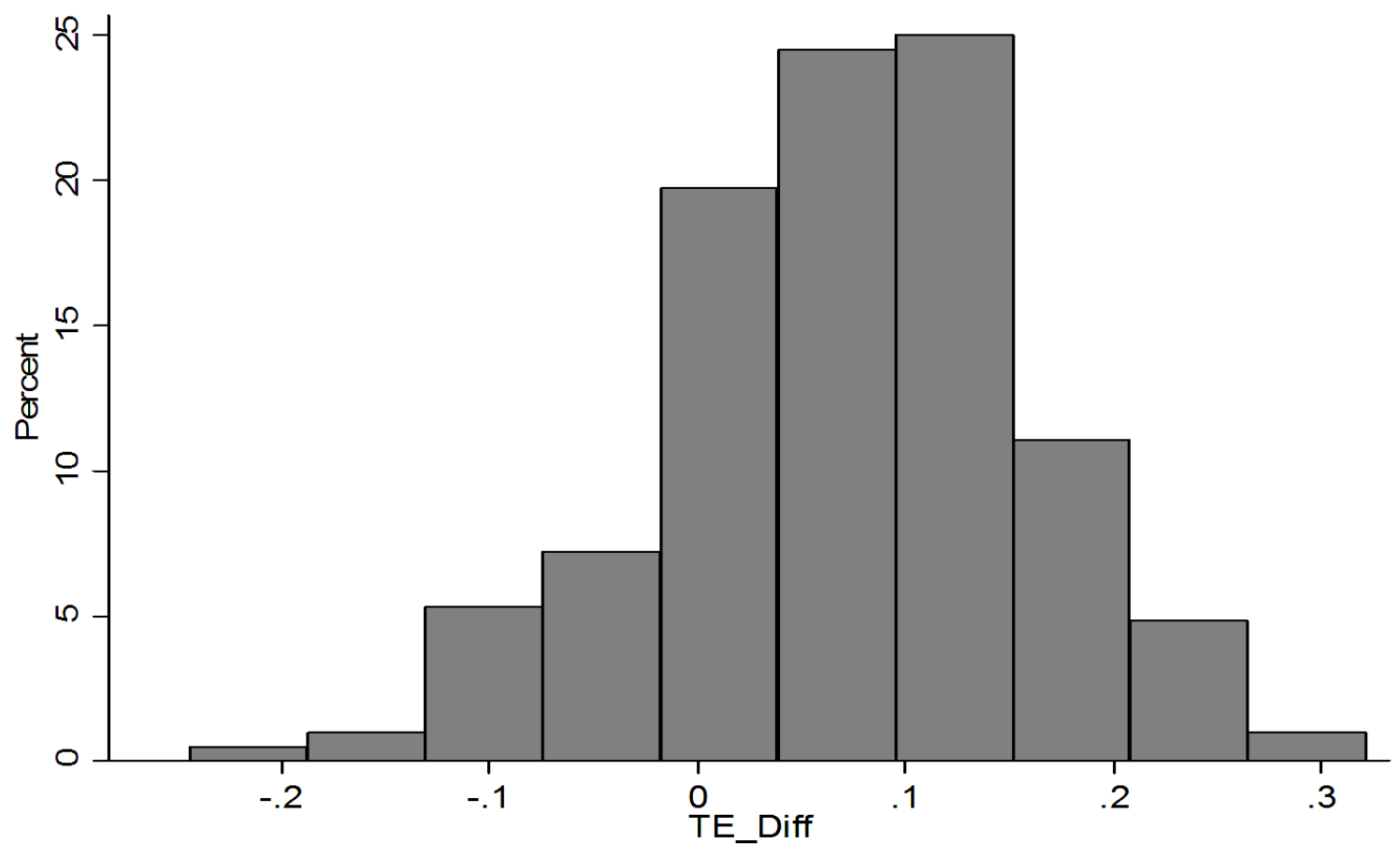

Figure A4: Histogram of the differences between the shadow prices of native rainforest plants in US cents (selfreported - measured variables method).

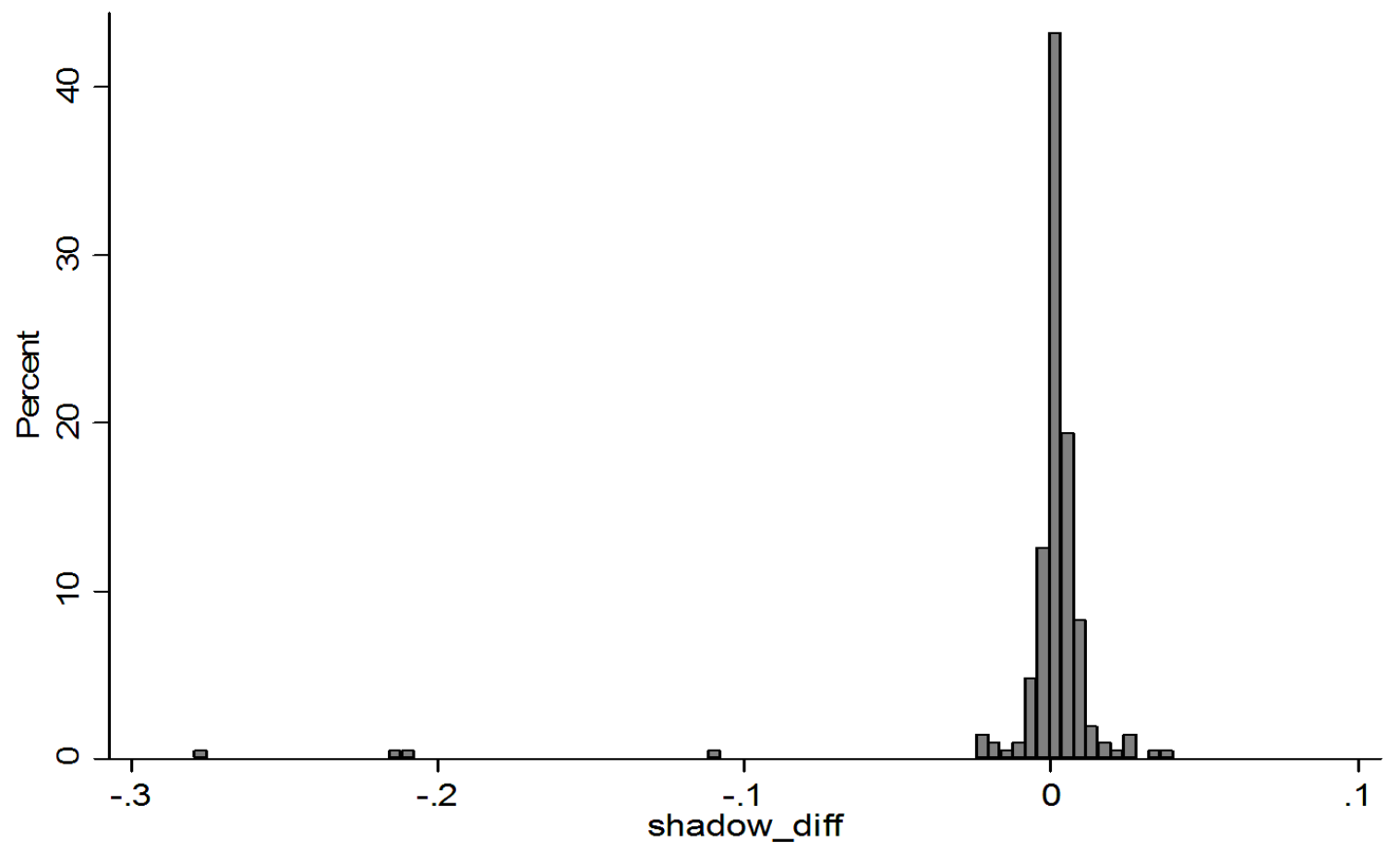


Table 4.A1: Comparison of the self-reported and measured values of the cocoa farm dummy variables.

\begin{tabular}{lrrrrr}
\hline Variables & Observations & Same & & $1 \rightarrow 0$ & \multicolumn{2}{c}{$0 \rightarrow 1$} \\
\hline Intercrop_M vs. Intercrop_S & 208 & 199 & 3 & 6 \\
Shade_M vs. Shade_S & 208 & 189 & 8 & 11 \\
\hline
\end{tabular}




\section{Conclusion}

\subsection{Main findings and policy implications}

The high economic and population growth in Africa and Asia, the increase of global trade, and globalization have largely boosted the global cocoa demand. However, cocoa growing countries can barely meet this expanding demand. These enduring processes triggered a high volatility in world cocoa prices in this new century. This price volatility makes the millions of cocoa farmers in the developing world highly vulnerable to poverty.

Our first essay in Chapter 2 helps to inform development policies of the elements involved in the global cocoa bean market to understand the roots of the recent price volatility. A large volatility in the value of an agricultural commodity is linked to the inelasticity of its supply or demand. Therefore, we test the hypothesis that the price elasticities of the global cocoa supply and demand are low. We describe the global cocoa market with three cointegration dynamic structural sub-models (supply, demand, and price). Our estimates are based on annual global observations covering the years 1963 through 2013. We find that the world cocoa supply is extremely price-inelastic: the corresponding short- and long-run estimates are 0.07 and 0.57 . The price elasticity of the world cocoa demand also falls into the extremely inelastic range: the short- and long-run estimates are -0.06 and -0.34 . Based on these empirical results, we consider the prospects for cocoa price stabilization. The cocoa price volatility was treated with various unsuccessful methods in the past. A possible solution for reducing the price volatility would be the encouragement of crop diversification. This increases the price elasticity of cocoa supply by adjusting the effort and money allocation between the crops, thus decreasing price volatility.

Our second essay in Chapter 3 investigates to what extent and how cocoa cultivation can be made more productive to increase supply and farmer incomes. We concentrate on Indonesia which gives 10 percent of the world production. Nearly 1.5 million Indonesian households depend on cocoa farming and the majority of them are poor. We estimate, based on a large household panel data set and stochastic frontier analysis, the technical efficiency of cocoa production and decompose productivity growth. According to our results, the productivity of Indonesian cocoa farming increased by 75 percent between 2001 and 2013. Technical efficiency growth and the increased chemicals use supported by government subsidies were responsible for the majority of this gain. Furthermore, the calculations show large distortions in the input allocations. Hence, policies that encourage the adjustment of the 
cocoa farms' input use would be highly beneficial. Moreover, the technical change component points to a weather-induced volatility in cocoa production. Thus, policy makers should also promote investment in agricultural research and transfer of drought-resistant cocoa varieties to farmers. Additionally, the average efficiency of cocoa farmers is estimated to be around 50 percent. We find that farmers' educational attainment and their experience in cocoa farming are significant factors that can increase the efficiency levels. Our research also shows the insignificant effect of existing agricultural extension services, farmer associations, and rural credit programs on the technical efficiency of cocoa farming. Hence, public policy should focus on adjusting the public extension programs, fostering the mutual benefits in the farmer groups, and developing viable credit institutions.

In our third essay in Chapter 4, we look at the trade-off between smallholder cocoa intensification and the ecosystem in Indonesia and investigate the determinants of environmental efficiency in the production. We apply a distance output function that includes cocoa production and the abundance of native rainforest plants as outputs. Our data set, based on a household and environment survey conducted in 2015, allows us to analyze 208 cocoa producers with both measured and self-reported data. We find that the intensification of cocoa farms results in higher ecosystem degradation. Additionally, the estimations show substantial average inefficiencies (50 percent), similar to our second essay. Increasing efficiency could lead to a win-win-win situation: more production coming from less hectares, with more native plants co-existing with cocoa on the remaining hectares. On average, the efficiency scores point to a possible production expansion of $367 \mathrm{~kg}$ of cocoa per farm and year, to a possible increase of 43680 rainforest plants per farm, or to a possible acreage reduction of 0.52 hectares per farm. In contrast to our second essay, we find that agricultural extension services have a substantial role in increasing efficiency. Finally, similar to our second paper, our results show that credit access does not have a significant effect on efficiency. Feasible agricultural credit services are viewed by numerous economists as a crucial prerequisite for improving efficiency, a critical part of encouraging development. We recommend linking credit to extension services as part of this effort.

\subsection{Limitations of the study and ideas for future research}

Our analysis has several limitations, which are mostly due to the shortcomings of our cocoa data sets. First, we take into account only one environmental variable in the farm efficiency estimations: the abundance of native rainforest plants. Thus, future research should add more environmental output variables to the cocoa production frontier by extending the data 
collection. For example, we could include biomass such as above-ground and below-ground carbon stocks (Gockoswki and Sonwa, 2011) and soil quality such as moisture and nutrients (Smaling and Dixon, 2006) in the farm efficiency models.

Second, we do not consider undesirable outputs such as pollution in the environmental efficiency calculations. To overcome this limitation, we could you use the nutrient balance approach (Hoang and Nguyen, 2013) by extending the cocoa data set. This perspective examines negative environmental effects that arise from the emissions of inputs such as nitrogen fertilizers. However, this approach necessitates a different efficiency measurement framework: the use of a directional distance function (Fare et al., 2005).

Finally, our environmental efficiency study with cross-sectional data cannot assess changes in environmental variables caused by farm management choices. It is also unable to investigate the role of farm investments, although cocoa is a perennial crop. Future research with panel data would allow us to examine dynamic technical efficiency (Stefanou, 2009). For example, we could incorporate costs for cocoa uprooting and replanting into our efficiency models. For this purpose, a framework with dynamic directional distance function (Serra et al., 2011) could be selected.

\subsection{References}

Fare, R., Grosskopf, S., Noh, D., Weber, W. (2005): Characteristics of a polluting technology: theory and practice. Journal of Econometrics 126, 469-492.

Gockoswki, J., Sonwa, D. (2011): Cocoa intensification scenarios and their predicted impact on $\mathrm{CO} 2$ emissions, biodiversity conservation, and rural livelihoods in the guinea rain forest of West Africa. Environmental Management 48, 307-321.

Hoang, V.N., Nguyen, T.T. (2013): Analysis of environmental efficiency variations: A nutrient balance approach. Ecological Economics 86, 37-46.

Serra, T., Lansink, A.O., Stefanou, S. E. (2011): Measurement of dynamic efficiency: a directional distance function parametric approach. American Journal of Agricultural Economics 93, 756-767.

Smaling, E.M.A., Dixon, J. (2006): Adding a soil fertility dimension to the global farming systems approach, with cases from Africa. Agriculture, Ecosystems and Environment $116,15-26$.

Stefanou, S.E. (2009): A dynamic characterization of efficiency. Agricultural Economics Review 10, 18-33. 
Appendix: Survey questionnaire 


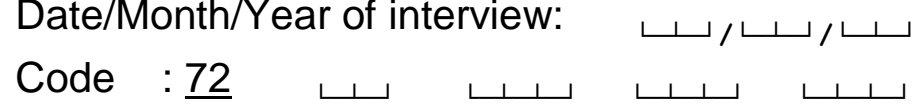

$$
\begin{aligned}
& \text { Prov Regency District Village HHID }
\end{aligned}
$$

\section{O N F I DEN T I A L}

HOUSEHOLD AND COCOA QUESTIONNAIRE 2015 - GlobalFood - A02

Section: LK, HH - PS, EI, FI, CR

\begin{tabular}{|c|c|c|c|}
\hline \multicolumn{2}{|c|}{$\begin{array}{l}\text { A.1 Name of respondent/HHMID/Signature } \\
\text { A.2/A.3 District / Village name }\end{array}$} & \multicolumn{2}{|c|}{ / / ــــ } \\
\hline \multicolumn{2}{|c|}{ Interview } & First visit: $\downarrow / \sqcup \sqcup /$ & Second visit: \\
\hline A.4 & Time the interview started & $\sqcup \sqcup: \sqcup$ & 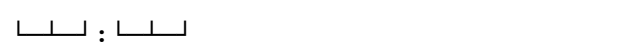 \\
\hline A.5 & Time the interview ended & 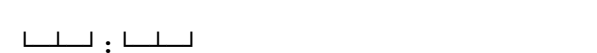 & $\sqcup: \sqcup \sqcup$ \\
\hline
\end{tabular}

\begin{tabular}{|c|c|c|c|c|}
\hline A.6 Interview result & A.9 & rcher & A.10 Data entry 1 & A.11 Data entry 2 \\
\hline $\begin{array}{l}\text { 1. Completed } \\
\text { 2. Half completed, excuse: ... } \\
\text { 3. Refuse } \\
\text { 4. Move } \\
\text { 5. Deceased } \\
\text { 6. Not interviewed, excuse: ... }\end{array}$ & $\begin{array}{l}\text { a. Observed } \\
\text { b. Verified } \\
\text { c. Examined }\end{array}$ & 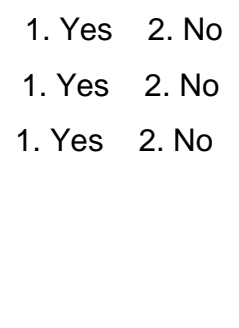 & $\begin{array}{l}\text { 1. Completed entries } \\
\text { 2. No entries, excuse: . }\end{array}$ & $\begin{array}{l}\text { 1. Completed entries } \\
\text { 2. No entries, excuse: ... }\end{array}$ \\
\hline
\end{tabular}


HH. ID.: ــــ

\section{LK. CONTROL SHEET}

Note: Complete the control sheet prior to the interview.

\begin{tabular}{|c|c|c|}
\hline LK.1 & Province & ..................CODE:ــ \\
\hline LK.2 & Regency/City & ....CODE:ــ \\
\hline LK.3 & District & 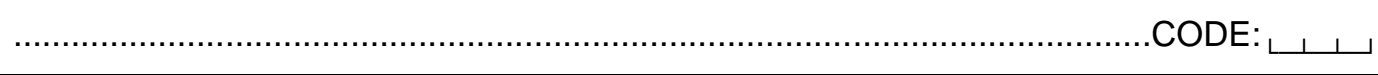 \\
\hline LK.4 & Village & ــ \\
\hline LK.6 & GPS location: & \\
\hline LK.7 & Full address (including sub-village/ neighborhood/kampong, house number) & \\
\hline LK.8 & RT. RW/Hamlet. & RW/Hamlet ${ }^{*} \sqcup ـ$ \\
\hline LK.9 & Is the RW of your residence the same with the village office (kelurahan office)? & $\begin{array}{l}\text { 1. Yes } \\
\text { 2. No } \rightarrow \text { LK.11 }\end{array}$ \\
\hline LK.10 & What is the distance between your house and the village office (kelurahan office)? & $\sqcup \neg \perp \perp \neg \mathrm{m}$ \\
\hline LK.11 & Phone number & 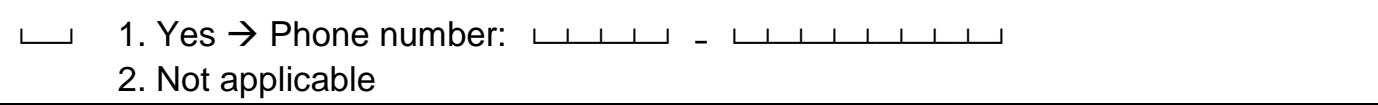 \\
\hline LK.12 & $\begin{array}{l}\text { Other information concerning the location of this household: identify area nearby } \\
\text { the research position that is on the same street as the school, mosque, church, or } \\
\text { any other important buildings. }\end{array}$ & \\
\hline
\end{tabular}

*please choose one 
HH. ID.: : ـــ

HH. HOUSEHOLD COMPOSITION

\begin{tabular}{|c|c|c|c|c|c|c|c|}
\hline $\mathrm{HH} .1$ & $\mathrm{HH} .2$ & $\mathrm{HH} .4$ & $\mathrm{HH} .10$ & $\mathrm{HH} .11$ & $\mathrm{HH} .13$ & $\mathrm{HH} .15$ & HH.NEW \\
\hline HHMID & Full name & Gender & $\begin{array}{l}\text { Age } \\
\text { (years) }\end{array}$ & Marital status & Highest education & Main occupation & $\begin{array}{c}\text { Number of } \\
\text { household members } \\
\text { over the age of } 14\end{array}$ \\
\hline Code 1 & & $\begin{array}{l}\text { 1.Male } \\
\text { 2.Female }\end{array}$ & & Code 6 & Code 8 & Code 10 & \\
\hline$\sqcup$ & & $\sqcup$ & $\sqcup$ & $\sqcup$ & $\sqcup$ & $\sqcup$ & $\sqcup$ \\
\hline
\end{tabular}

\begin{tabular}{|c|c|c|c|}
\hline Code 1 & Code 6 & Code 8 & Code 10 \\
\hline 1. Household head & $\begin{array}{l}\text { 1. Unmarried } \\
\text { 2. Married } \\
\text { 3. Widow/er } \\
\text { 4.Divorce/separated }\end{array}$ & $\begin{array}{l}\text { 0. No school } \\
\text { 1. Primary school } \\
\text { 2. Junior high school } \\
\text { 3. Senior high school } \\
\text { 4. General/vocational school } \\
\text { 5. Diploma I/II } \\
\text { 6. Diploma III } \\
\text { 7. Dimploma IV/Sarjana S1 } \\
\text { 8. S2/S3 }\end{array}$ & $\begin{array}{l}\text { 1. Self-employed in agriculture } \\
\text { 2. Self-employed in non-farm enterprise } \\
\text { 3. Government employee } \\
\text { 4. Casual worker in agriculture } \\
\text { 5. Casual worker in non-agriculture } \\
\text { 6. Salaried worker in agriculture } \\
\text { 7. Salaried worker in non-agriculture } \\
\text { 8. Domestic worker (household wife) } \\
\text { 9. Student } \\
\text { 10. Unemployed, working for job } \\
\text { 11. Unwilling to work or retired } \\
\text { 12. Unable to work (handicapped) }\end{array}$ \\
\hline
\end{tabular}




\section{HH. ID.: $\longleftarrow$ ـ \\ PS. COCOA PLOT SPECIFIC DATA}

PS.2 Cocoa output data

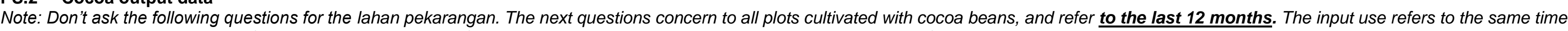
period as the output. The output for each plot has to be transferred into $\mathrm{kg}$. Please write your calculations on the bottom of this sheet.

\begin{tabular}{|c|c|c|c|}
\hline PS.2a & PS.2f & PS.2i & PS.2k \\
\hline Code of plot & Area planted in ares & Quantity harvested in $\mathrm{kg}$ & $\begin{array}{l}\text { Did the crop fail? } \\
\text { 1.yes } \\
\text { 2.no }\end{array}$ \\
\hline$\sqcup$ & بـ & & $\sqcup$ \\
\hline$\sqcup$ & ب & & $\sqcup$ \\
\hline$\sqcup$ & سبـ & & $\sqcup$ \\
\hline$\sqcup$ & سـ & & $\sqcup$ \\
\hline$\sqcup$ & بــ & & $\sqcup$ \\
\hline$\sqcup$ & سـب & & $\sqcup$ \\
\hline$\sqcup$ & بـــ & & $\longleftarrow$ \\
\hline
\end{tabular}


HH. ID.: ـــ ــ

PS.2 Cocoa input data

Note: Please fill in the code of the plot. Remember that input use refers to the last 12 months.

\begin{tabular}{|c|c|c|c|c|c|c|c|c|c|c|c|c|}
\hline \multirow{4}{*}{\begin{tabular}{|c|} 
PS.2p \\
$\begin{array}{c}\text { Code of } \\
\text { plot }\end{array}$ \\
\end{tabular}} & \multirow{4}{*}{$\begin{array}{c}\text { PS.2q } \\
\text { Planting } \\
\text { distance } \\
\mathrm{m} \times \mathrm{m}\end{array}$} & \multicolumn{6}{|c|}{ PS.2r } & \multirow{4}{*}{$\begin{array}{c}\text { PS.2s } \\
\text { Expenses for } \\
\text { pesticides in Rp. }\end{array}$} & \multirow{4}{*}{$\begin{array}{c}\text { PS.2t } \\
\text { Transportation } \\
\text { costs in Rp. }\end{array}$} & \multirow{4}{*}{$\begin{array}{c}\text { PS.2u } \\
\text { Crop processing } \\
\text { costs in Rp. }\end{array}$} & \multicolumn{2}{|c|}{ PS.2v } \\
\hline & & \multicolumn{6}{|c|}{ Fertilizer use } & & & & Tot & osts \\
\hline & & Type & $\begin{array}{l}\text { Quantity in } \\
\mathrm{kg} / \mathrm{l}\end{array}$ & $\begin{array}{c}\text { Price } \\
\text { per kg/l in Rp. }\end{array}$ & Type & $\begin{array}{l}\text { Quantity in } \\
\mathrm{kg} / \mathrm{l}\end{array}$ & $\begin{array}{c}\text { Price } \\
\text { per } \mathrm{kg} / \mathrm{l} \text { in } \mathrm{Rp} .\end{array}$ & & & & $\begin{array}{l}\text { Paid } \\
\text { in Rp. }\end{array}$ & $\begin{array}{l}\text { Family } \\
\text { in hr. }\end{array}$ \\
\hline & & Code 1 & & & Code 1 & & & & & & & \\
\hline$\sqcup$ & $\sqcup x \perp$ & $\sqcup$ & & & $\sqcup$ & & & & & & & \\
\hline$\sqcup$ & $\sqcup \mathrm{X} \perp$ & $\sqcup$ & & & $\sqcup$ & & & & & & & \\
\hline$\sqcup$ & $\sqcup \mathrm{X} \perp$ & $\sqcup$ & & & $\sqcup$ & & & & & & & \\
\hline$\sqcup$ & $\sqcup \mathrm{X} \perp$ & $\sqcup$ & & & $\sqcup$ & & & & & & & \\
\hline$\sqcup$ & $\sqcup \times \perp$ & $\sqcup$ & & & $\sqcup$ & & & & & & & \\
\hline$\sqcup$ & $\sqcup x \perp$ & $\sqcup$ & & & $\sqcup$ & & & & & & & \\
\hline$\sqcup$ & $\sqcup \times \perp$ & $\longleftarrow$ & & & $\sqcup$ & & & & & & & \\
\hline
\end{tabular}

Code 1

1.urea $(\mathrm{kg})$

2.triple super phosphate (TSP) $(\mathrm{kg})$

3.ZA (kg)

4. $\mathrm{KCL}(\mathrm{kg})$
5.NPK $(\mathrm{kg})$

6. pupuk daun $(\mathrm{kg})$

7.pupuk kandang (organic) $(\mathrm{kg})$

8.PONSKA $(\mathrm{kg})$

9.other, specify (give unit in $\mathrm{kg} / \mathrm{l})$... 
PS.3 Additional cocoa questions

Note: Please fill in the code of the plot. Remember that input use refers to the last 12 months.

\begin{tabular}{|c|c|c|c|c|c|}
\hline PS.3a & PS.3b & PS.3c & PS.3e & PS.3j & PS.3k \\
\hline Code of plot & Age of trees in years & $\begin{array}{l}\text { Variety } \\
\text { Code } 1\end{array}$ & $\begin{array}{l}\text { Did you prune your cocoa? } \\
\text { 1.yes } \\
\text { 2.no }\end{array}$ & $\begin{array}{l}\text { How high is the percentage of shade tree cover? } \\
\qquad \text { Code } 5\end{array}$ & $\begin{array}{l}\text { Are there other crops planted in between the } \\
\text { cocoa? } \\
\text { 1.yes } \\
\text { 2.no }\end{array}$ \\
\hline$\sqcup$ & ــ & $\sqcup$ & $\sqcup$ & $\sqcup$ & $\sqcup$ \\
\hline$\sqcup$ & $\sqcup$ & $\sqcup$ & $\sqcup$ & $\sqcup$ & $\sqcup$ \\
\hline$\sqcup$ & 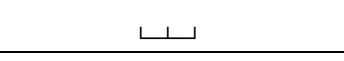 & $\sqcup$ & $\sqcup$ & $\sqcup$ & $\sqcup$ \\
\hline$\sqcup$ & بـ & $\sqcup$ & $\sqcup$ & $\sqcup$ & $\sqcup$ \\
\hline$\sqcup$ & $\sqcup$ & $\sqcup$ & $\sqcup$ & $\sqcup$ & $\sqcup$ \\
\hline$\sqcup$ & 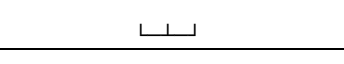 & $\sqcup$ & $\sqcup$ & $\sqcup$ & $\sqcup$ \\
\hline$\sqcup$ & ــ & $\sqcup$ & $\longleftarrow$ & $\sqcup$ & $\longleftarrow$ \\
\hline
\end{tabular}

\begin{tabular}{|c|c|}
\hline $\begin{array}{ll}\text { Code } 1 \\
\end{array}$ & Code 5 \\
\hline $\begin{array}{l}\text { 1.local (green) } \\
\text { 2.hibrida (violet) } \\
\text { 3.hibrida (green) } \\
\text { 4.Sulawesi } 1 \text { (S1) } \\
\text { 5.other, specify: ........... }\end{array}$ & $\begin{array}{l}\text { 1.less than } 35 \% \\
\text { 2.between } 35 \% \text { and } 60 \% \\
\text { 3.between } 60 \text { and } 80 \% \\
\text { 4.higher than } 80 \%\end{array}$ \\
\hline
\end{tabular}




\section{El. ENVIRONMENTAL INDICATORS}

\begin{tabular}{|l|l}
\hline El.10 & Have you met an extension officer in the last 12 months?
\end{tabular}

\llcorner

1.yes

FI. FARMERS' INSTITUTIONS

\begin{tabular}{|c|c|c|c|}
\hline $\mathrm{Fl} .2$ & Did you participate in farmer associations/groups in the last 12 months? & $\sqcup$ & $\begin{array}{l}\text { 1.yes } \\
\text { 2.no }\end{array}$ \\
\hline $\mathrm{Fl} .4$ & Did you participate in the government program GERNAS pro Kakao in the last 3 years? & $\sqcup$ & $\begin{array}{l}\text { 1.yes } \\
\text { 2.no }\end{array}$ \\
\hline
\end{tabular}

CR. CREDITS

\begin{tabular}{|l|l}
\hline CR.2 & Have you obtained a credit in the last 3 years?
\end{tabular}

$\sqcup \quad 1$.yes

2.no 